\title{
Organización de los servicios sociales municipales en las comunidades autónomas: cinco estudios de caso $^{1}$
}

\section{SIIS Centro de Documentación y Estudios}

<estudios@siis.net>

\section{Lucía Martínez Virto}

Departamento de Trabajo Social, Universidad Pública de Navarra

\section{Miguel Ángel Manzano}

Servei d'Acció Social, Gerència de Serveis de Benestar Social, Àrea d'Atenció a les Persones, Diputació de Barcelona

\section{Carlos Santos}

Servizo de Coordinación de Servizos Sociais Comunitarios,

Dirección Xeral de Familia e Inclusión, Consellería de Política Social, Xunta de Galicia

\section{Carmen de la Sierra}

Servizo de Coordinación de Servizos Sociais Comunitarios, Dirección Xeral de Familia e Inclusión, Consellería de Política Social, Xunta de Galicia

\section{Arantxa Hernández Echegaray}

Departamento de Servicios Sociales, Ayuntamiento de Palencia

\section{María José Aguilar}

Departamento de Trabajo Social y Servicios Sociales,

Universidad de Castilla-La Mancha

Artikulu honetan deskribatzen dira bost autonomiaerkidegoetako udaletako gizarte-zerbitzuen antolakuntza - Nafarroako Foru Erkidegoa, Katalunia, Galizia, Gaztela eta Leon, eta Gaztela-Mantxa- eta etorkizunean izango dituzten erronkak. Bertako xedea da testuinguruan jartzea Euskal Autonomia Erkidegoan dauden tankerako zerbitzuen egoera, eta nabarmentzen dira ezaugarri bereizgarrienak, eta, gehienbat, nahi dira identifikatu autonomia-erkidego horietako sistemak aintzat hartuz Euskal Autonomia Erkidegoko gizarte-zerbitzuen antolakuntza hobetzeko lagungarri gerta daitezkeen osagaiak.

\section{GAKO-HITZAK:}

Oinarrizko gizarte-zerbitzuak, udaletxeak, Nafarroa, Katalunia, Galizia, Gaztela eta Leon, Gaztela-Mantxa.
En este artículo se describe la organización de los servicios sociales municipales de cinco comunidades autónomas españolas - la Comunidad Foral de Navarra, Catalunya, Galicia, Castilla y León, y Castilla-La Mancha- y los retos que tienen planteados. Se pretende así contextualizar la situación de tales servicios en la Comunidad Autónoma de Euskadi, señalando sus características más distintivas, y sobre todo, identificar en esos sistemas autonómicos elementos que puedan contribuir a mejorar la organización de los servicios sociales de atención primaria en la Comunidad Autónoma de Euskadi.

\section{PALABRAS CLAVE:}

Servicios sociales de base, ayuntamientos, Navarra, Cataluña, Galicia, Castilla y León, Castilla-La Mancha. 


\section{Introducción}

En este artículo se describe la organización de los servicios sociales municipales de cinco comunidades autónomas españolas: la Comunidad Foral de Navarra, Catalunya (con especial atención al caso de la provincia de Barcelona), Galicia, Castilla y León, y Castilla-La Mancha. Con ello se pretende contextualizar la situación de tales servicios en la Comunidad Autónoma de Euskadi, señalando sus características más distintivas, y sobre todo, identificar en esos sistemas autonómicos elementos que puedan contribuir a mejorar la organización de los servicios sociales de atención primaria en la Comunidad Autónoma de Euskadi.

La descripción de estos cinco sistemas está basada en la información remitida por cinco expertos y expertas de esas comunidades autónomas, cada uno de los cuales ha elaborado un informe monográfico sobre la organización y la situación de los servicios sociales municipales en su respectiva comunidad. Las personas que han elaborado estos informes son: Lucía Martínez Virto (Navarra), Miguel Ángel Manzano (Cataluña), Carlos Santos y Carmen de la Sierra (Galicia), Arantxa Hernández Echegaray (Castilla y León) y María José Aguilar (Castilla-La Mancha).

La descripción de cada uno de los sistemas se agrupa en torno a seis grandes cuestiones:

- Marco normativo y estructura competencial.

- Estructura y funciones de los servicios sociales municipales.

- Dotaciones mínimas y ratios de personal.

- Ordenación territorial y fórmulas de colaboración interadministrativa.

- Herramientas de coordinación, inspección y gestión de la información.

- Financiación.

Como conclusión y a partir de la información remitida por esas personas, el último punto de este artículo resume los principales retos que tienen planteados los servicios sociales municipales de esas cinco comunidades autónomas y extrae, desde la óptica de la Comunidad Autónoma de Euskadi, los elementos más significativos, es decir, las características más distintivas del modelo de servicios sociales municipales establecido en la Comunidad Autónoma de Euskadi y los elementos de los cinco modelos analizados que podrían incorporarse, para su mejora, al sistema actualmente existente en la Comunidad Autónoma de Euskadi.

A la hora de interpretar la información que se recoge en las páginas siguientes, es necesario tener en cuenta los siguientes aspectos:

- Si bien se ha intentado seguir el mismo esquema en todos los casos, la información obtenida no es siempre la misma para las cinco comunidades autónomas. En función del perfil de las personas consultadas, de su conocimiento respecto al sistema local de servicios sociales y de la propia configuración del sistema analizado, el nivel de detalle no es siempre el mismo, ni tampoco son siempre los mismos los elementos abordados. Se observará también que mientras que en algunos casos el análisis tiene un carácter más valorativo o interpretativo, en otros se limita a describir la situación en lo que se refiere a los elementos que se han considerado esenciales.

- Muchas de las cuestiones abordadas en este artículo se solapan, superponen y repiten en más de un apartado. Con todo, se ha realizado un esfuerzo por ofrecer una descripción lo más ordenada y sistemática posible de cada sistema a partir de la estructura común ya señalada. Del mismo modo, no siempre es sencillo separar la información específicamente relativa a los servicios sociales municipales de la relativa al conjunto de los servicios sociales de cada Comunidad.

- En general, el sistema establecido en cada comunidad autónoma se describe a partir de la legislación vigente en cada una de ellas. Sin embargo, es obvia la distancia que existe - particularmente en el ámbito de los servicios sociales - entre lo que se establece en la normativa y el funcionamiento real de las políticas públicas, lo que en ocasiones hace que la mera descripción del marco normativo resulte insuficiente y dificulta la descripción del funcionamiento real de cada sistema. También hay que recordar la propia complejidad que supone describir unos sistemas que no siempre se han diseñado siguiendo un patrón preestablecido, sino más bien mediante la superposición de estructuras y elementos nuevos a los que existían con anterioridad. Por todo ello, se ha intentado a lo largo de todo el artículo, además de describir el marco normativo vigente, recoger con la mayor fidelidad posible el funcionamiento real de los servicios sociales municipales en las cinco comunidades autónomas analizadas y las estructuras que los articulan.

\section{Marco normativo y estructura competencial}

\subsection{Comunidad Foral de Navarra}

Como el resto de las leyes de servicios sociales de tercera generación aprobadas durante la pasada década en el Estado español, la Ley Foral 15/2006 de Servicios Sociales, tras las anteriores leyes de 1983 y 1990, se aprueba en Navarra con la finalidad de superar el marco asistencialista previo y con dos objetivos fundamentales: el reconocimiento de derecho subjetivo a los servicios sociales y la adecuación del sistema de servicios sociales a las necesidades de la ciudadanía navarra. Para ello, la Ley Foral 15/2006 ofrece una nueva definición 
y configuración de los servicios sociales, reforma su ordenación, estructura y financiación y, en ese contexto, reconoce por primera vez una cartera de servicios en la que se incluyen todas las prestaciones a las que la ciudadanía navarra tendrá derecho. A ese respecto, la Ley navarra diferencia las que se consideran prestaciones garantizadas - “un derecho subjetivo que será exigible ante las Administraciones que deban realizarlas y, en última instancia, ante los Tribunales"-, de las no garantizadas, que se prestarán en función de la disponibilidad presupuestaria y que, por tanto, quedan sujetas a la discrecionalidad técnica y política de las administraciones competentes.

En lo que se refiere a la estructura competencial de los servicios sociales, la Ley Foral 15/2006 se desarrolla, al igual que en el resto de comunidades autónomas, bajo una lógica de funciones y competencias autonómicas y locales, atribuyendo al Gobierno Foral los servicios sociales especializados y a las administraciones locales los servicios sociales básicos. En ese marco, la Comunidad Foral de Navarra, a través actualmente de la Vicepresidencia de Derechos Sociales, es responsable de: a) ejecutar y gestionar la Cartera de Servicios Sociales de Ámbito General; b) impulsar la coordinación del sistema de servicios sociales, c) elaborar los planes estratégicos, sectoriales, básicos y especializados y coordinar su ejecución; d) elaborar los planes de calidad, garantizarla y homologarla en los programas que prestan el servicio, tiene la capacidad de sancionar el incumplimiento de las normas desarrolladas en este ámbito; y e) mantener y gestionar los servicios sociales especializados de titularidad propia, así como los centros de servicios sociales que se establezcan en el Plan Estratégico. Por otro lado, más allá de lo organizativo, también tiene asignadas competencias para fomentar la participación ciudadana, el asociacionismo, el voluntariado y otras fórmulas de ayuda mutua, además de impulsar y desarrollar programas de formación dirigidos a los profesionales de servicios sociales, fomentar la investigación y el estudio en materia de servicios sociales y cooperar con las entidades locales de Navarra para la aplicación de las políticas de servicios sociales.

Las competencias municipales son las siguientes:

- Estudiar y detectar las necesidades sociales que se produzcan dentro de su ámbito territorial.

- Participar en la planificación general de los servicios sociales realizada por la Administración de la Comunidad Foral de Navarra.

- Aprobar planes estratégicos y sectoriales de ámbito local y programas básicos o comunitarios y especializados de ámbito local.

- Crear, mantener y gestionar los servicios sociales de base de su ámbito territorial.

- Crear, mantener y gestionar los servicios sociales especializados que considere necesarios dentro de su ámbito territorial.
- Aprobar la Cartera de Servicios Sociales de ámbito local cuando pretenda completar en su ámbito territorial la cartera de servicios de ámbito general.

Así pues, como ocurre en buena parte de las comunidades autónomas analizadas, la administración autonómica - además de sus competencias de coordinación, regulación y planificación- asume la prestación de los servicios sociales especializados, mientras que las administraciones municipales asumen, básicamente, la prestación de los servicios sociales de base de su ámbito territorial, así como la creación y gestión de servicios sociales especializados en aquellos casos en que los consideren necesarios dentro de su ámbito territorial y dispongan de los medios económicos para poder financiar la prestación de esos servicios. Este último punto limita, en la práctica, la capacidad de desarrollar servicios de atención especializada de titularidad municipal únicamente a las ciudades de medio o gran tamaño, ya que son las únicas que disponen de recursos suficientes. En el caso de Navarra, sólo Pamplona cuenta con recursos especializados desarrollados por la administración municipal.

\subsection{Catalunya}

El sistema de servicios sociales de Catalunya está regido por la Ley 12/2007, de 11 de octubre, de Servicios Sociales. Esta ley sustituye a la aprobada en 1985 y se redacta en el marco de la implementación de la Ley 39/2006, de 14 de diciembre, de Promoción de la Autonomía Personal y Atención a las Personas en Situación de Dependencia, y del paradigma del cuarto pilar del bienestar y la incorporación de los derechos subjetivos y la universalidad. Como en el caso de la Comunidad Autónoma de Euskadi, la Ley 12/2007 establece la creación de una cartera de servicios sociales con el objetivo de definir las prestaciones que ha de ofrecer la red pública de servicios sociales y que incluye todas las prestaciones de servicio, económicas y tecnológicas. Desde ese punto de vista, la Cartera ha de definir cada tipo de prestación, la población a la que va destinada, el establecimiento o el equipo profesional que debe gestionarla, los perfiles y ratios de los profesionales del equipo y los estándares de calidad. Una de las novedades más importantes que introduce la Ley 12/2007 es la incorporación de las prestaciones garantizadas, que son de derecho subjetivo una vez acreditada la situación de necesidad social por parte del ciudadano.

Tal y como ocurre en las demás comunidades autónomas analizadas, la Ley 12/2007 consolida la división existente del sistema en dos niveles: el de atención primaria, que pasa a denominarse básico, y el especializado. Según la Ley 12/2007, la competencia en la prestación del primer nivel de atención, los servicios sociales básicos, corresponde 
a los municipios, que están obligados a crearlos y gestionarlos de acuerdo con la Cartera de Servicios Sociales y el Plan Estratégico correspondiente. Como se señala más adelante, los consejos comarcales suplen a los municipios de menos de $\mathbf{2 0 . 0 0 0}$ habitantes en la titularidad de las competencias propias de los servicios sociales básicos que éstos no estén en condiciones de asumir directamente o mancomunadamente.

Los servicios sociales básicos son concebidos en la Ley 12/2007 como el punto de acceso al sistema, e incluyen los Equipos Básicos de Profesionales, el Servicio de Ayuda a Domicilio y Teleasistencia, y el Servicio de Intervención Socioeducativa No Residencial para Infancia y Adolescencia². Posteriormente veremos, sin embargo, que la Cartera de Servicios Sociales incorpora nuevas competencias al nivel básico, delegadas por el segundo nivel de atención. Las funciones que desde un principio se atribuyen en la Ley 12/2007 a los servicios sociales básicos son las siguientes:

- Detectar las situaciones de necesidad personal, familiar y comunitaria.

- Ofrecer información, orientación y asesoramiento a las personas con relación a los derechos y recursos sociales y a las actuaciones sociales a que pueden tener acceso.

- Valorar y realizar los diagnósticos social, socioeducativo y sociolaboral de las situaciones de necesidad social.

- Proponer y establecer el programa individual de atención a la dependencia y de promoción de la autonomía.

- Revisar el programa individual de atención a la dependencia y de promoción de la autonomía personal cuando corresponda.

- Realizar las actuaciones preventivas, el tratamiento social o socioeducativo y las intervenciones necesarias en situaciones de necesidad social y efectuar su evaluación.

- Intervenir en los núcleos familiares o convivenciales en situación de riesgo social.

- Impulsar proyectos comunitarios y programas transversales.

${ }^{2}$ Los servicios sociales básicos se definen en el sistema catalán como la "puerta de entrada al sistema público de servicios sociales, accesibles a toda la población. Los equipos profesionales que los prestan y gestionan están formados por personas diplomadas en Trabajo Social y en Educación Social. Este colectivo de profesionales informan, orientan, hacen diagnósticos y valoraciones, prescriben prestaciones, detectan situaciones de riesgo para actuar de forma preventiva y realizan proyectos comunitarios para la integración social de personas y colectivos en riesgo". Los servicios sociales especializados, por el contrario, "dan respuesta a situaciones o necesidades que requieren una especialización técnica o la disposición de recursos determinados. Proporcionan apoyo técnico y prestan colaboración a los servicios sociales básicos en las materias de su competencia".
- Prestar servicios de ayuda a domicilio, teleasistencia y apoyo a la unidad familiar o de convivencia.

- Prestar servicios de intervención socioeducativa no residencial para niños y adolescentes.

- Orientar el acceso a los servicios sociales especializados.

- Promover medidas de inserción social, laboral y educativa.

- Gestionar prestaciones de urgencia social.

- Aplicar protocolos de prevención y atención ante maltratos a personas de los colectivos más vulnerables.

- Gestionar la tramitación de las prestaciones económicas de ámbito municipal y coordinarse con los servicios sociales especializados, con los equipos profesionales de los demás sistemas de bienestar social, con las entidades del mundo asociativo y con las que actúan en el ámbito de los servicios sociales.

- Informar, a petición de jueces y fiscales, sobre la situación personal y familiar de personas afectadas por causas judiciales.

Así, la función de la primaria sería la de facilitar el acceso al sistema de servicios sociales, elaborar un diagnóstico de las necesidades de la ciudadanía y proponer un plan de actuación, prescribiendo los recursos necesarios para que la situación que imposibilita el normal desarrollo del bienestar se reduzca o elimine. El objetivo de articular el sistema mediante dos niveles -básico y especializadoestaba basado en la necesidad de disponer de estructuras especializadas para dar respuesta a las necesidades más complejas. Una de las consecuencias de esta estructuración ha sido la difusión del estereotipo de que los servicios sociales básicos eran tecnológicamente sencillos y de fácil gestión y organización. Por tanto, en la distribución competencial era fácil atribuirlos a los municipios, que desde la recuperación democrática ya habían venido prestando este servicio (Aguilar Hendrickson, 2014).

En ese marco, el reto de desarrollar un dispositivo de atención a la ciudadanía, con garantía de equidad en el acceso y capacidad de proporcionar una respuesta profesional eficaz, ha marcado el esfuerzo de los servicios sociales municipales catalanes desde su creación. Uno de los motivos de esa complejidad es la diversidad de funciones y encargos que se atribuyen a los servicios sociales municipales, y que incluye facilitar el acceso al sistema, realizar una primera valoración, intervenir socialmente en situaciones de alto riesgo (infancia en riesgo de exclusión, violencia de género, etc.), diseñar, proveer y gestionar servicios como la ayuda a domicilio y la teleasistencia, o evaluar el impacto de la intervención en la reducción del riesgo30 ${ }^{3}$. Así pues,

3 Es preciso recordar que una parte de estos encargos deriva de leyes, tanto de ámbito estatal como autonómico, que otorgan com- 
a la hora de analizar la estructura competencial de los servicios sociales catalanes debe destacarse la mezcla de funciones y tareas que se atribuyen a los servicios sociales básicos, que no ayudan a delimitar claramente el objeto de su actuación (Vilà, 2009) y los convierten en una especie de cajón de sastre.

Además de la atribución a todos los municipios de la prestación de los servicios previamente señalados, la Ley 12/2007 prevé que los municipios y comarcas de más de 50.000 habitantes asuman competencias delegadas del nivel especializado. Históricamente, algunos ayuntamientos ya habían creado servicios y prestaciones de este tipo y, en ocasiones, habían creado dispositivos de atención muy potentes. La Ley regulariza esta situación, y permite delegar servicios y prestaciones de proximidad en la medida en que se considera que tienen más sentido gestionados desde el ámbito local, al menos en el caso de los municipios de mayor tamaño. Las prestaciones que se delegan en todos los entes locales mayores de 50.000 habitantes son:

\section{- Equipos de Atención a la Infancia y a la} Adolescencia (EAIA).

- Servicio de transporte adaptado.

- Servicios de información y atención a las mujeres.

El resto de servicios y prestaciones de la Cartera pueden ser delegados a los municipios en función de su titularidad previa, es decir, en función de si previamente habían sido promovidos por la administración local:
- Residencia para personas con discapacidad.

- Centros de día ocupacionales para personas con discapacidad.

- Servicio prelaboral.

- Residencia para personas mayores.

- Centro de día para personas mayores.

- Sistema de respuesta urgente para mujeres que se encuentren en situación de violencia y para sus hijos e hijas.

- Programas y acciones de acogida y de integración de personas extranjeras inmigradas.

- Servicio de atención precoz.

- Programas de atención social a personas afectadas por el VIH/sida.

- Programas de atención social a personas con drogodependencias.

- Servicio de integración familiar.

- Programas de apoyo a familias en situación de vulnerabilidad.

La anomalía que supone la prestación de servicios especializados por parte del nivel local no ha sido suficientemente abordada en el marco de los servicios sociales catalanes. De hecho, el Departamento de Bienestar Social de la Generalitat de Catalunya no dispone aún de un mapa de las prestaciones de servicios sociales especializados de titularidad de un ente local. Tampoco se ha realizado una evaluación que permita determinar su eficiencia en el ámbito municipal o confirmar los impactos positivos teóricamente atribuidos a su mayor proximidad a la ciudadanía. Sí existen, por el contrario, evidencias de que los equipamientos de servicios sociales, sobre todo en el ámbito de las residencias para personas mayores o con discapacidad, necesitan de suficiente dimensión para llegar al punto de equilibrio económico y pueden suponer cargas económicas importantes para las finanzas municipales. La explicación la encontraríamos en un modelo de concertación de plazas que trata igual a los servicios proveídos por organizaciones lucrativas, no lucrativas y públicas, en una atomización y centrifugación del sistema en referencia a la atención social a nivel municipal y en la financiación general de los servicios.

En definitiva, el modelo actualmente establecido en Cataluña es resultado de la superposición de realidades existentes, sin una opción clara por una planificación y gestión centralizada (en el ánimo de la Ley 12/2007) o por la descentralización de competencias y responsabilidades consensuada y con posibilidad de financiación propia por parte la administración competente.

Para terminar de explicar la arquitectura institucional de los servicios sociales de Catalunya y, más concretamente, de Barcelona, es necesario hacer referencia al papel que juega en este ámbito la Diputación de Barcelona. petencias y funciones a los servicios sociales básicos. En ese senti-
do, la Ley de Promoción de la Autonomía Personal y Atención a las personas en situación de dependencia (conocida popularmente comc los Derechos y las Oportunidades en la Infancia y la Adolescencia, en nar modificaciones en las organizaciones municipales o comarcales. eran marginales fragmentadas - iniciativas públicas para paliar las situaciones de pobreza en los ámbitos de la alimentación o el acceso a la energía han reintroducido la necesidad de que sean los servicios sociales básico solicitantes, reforzando en algunos casos el carácter discrecional en la gestión de este tipo de ayudas. Finalmente, no podemos olvidar diciembre, de Racionalización y Sostenibilidad de la Administración Local, tenían cierta autonomía -que seguirán teniendo, dada la anulación por parte del Tribunal Constitucional el pasado 3 de mar zo (Sentencia 41/2016) de la disposición transitoria segunda, que establecía la fecha límite para que las entidades locales dejaran de prestar buena parte de sus servicios sociales y fueran asumidos por las comunidades autónomas- para la creación de prestaciones y servicios: ayudas económicas, vivienda social, mediación comunitaria y planes de desarrollo comunitario son algunos de los ejemplos de políticas sociales de ámbito municipal encargadas a los servicios sociales básicos. Todas ellas se suman a los encargos descritos anteriormente y contribuyen a agravar la complejidad ya señalada. 
En Catalunya, las diputaciones provinciales no tienen asignada una competencia o función específica en el marco de los servicios sociales. La redacción de la Ley $12 / 2007$ coincide con el periodo de reforma del Estatuto de Autonomía de Catalunya, que aspiraba a su desaparición y a la sustitución de la provincia por otra ordenación territorial propia, las veguerías. Esta medida siempre tuvo el obstáculo de su encaje en el ordenamiento constitucional, ya que necesita de la aprobación en el ámbito estatal del cambio en los límites territoriales. La sentencia del Tribunal Constitucional sobre la reforma del Estatuto deja en vía muerta la posibilidad de la desaparición de las diputaciones provinciales en Catalunya. Para soslayar esta situación, la Ley 12/2007 hace una referencia genérica a los entes locales supramunicipales, y otorga competencias en el ámbito del apoyo técnico, económico y jurídico a las administraciones gestoras de las áreas básicas de servicios sociales, a las que posteriormente se hace referencia. Esta función coincide (con diverso grado de desarrollo) con las que ya venían desarrollando las cuatro diputaciones provinciales catalanas, pero omite una función esencial, como es la prestación mancomunada de servicios de competencia municipal. Por otra parte, otorga a estos entes funciones de planificación, gestión de servicios especializados o promoción del asociacionismo, que, con algunas excepciones, no están siendo prestados por parte de las diputaciones.

En ese marco, como se explica más adelante en el apartado relativo a la financiación, el apoyo económico a los municipios y consejos comarcales es, por regla general, la prestación común de las cuatro diputaciones hacia las administraciones locales en el ámbito de los servicios sociales. La Diputación de Girona gestiona, además, el servicio local de teleasistencia y el servicio local de orientación familiar. Es, sin embargo, la Diputación de Barcelona la que históricamente ha jugado un papel singular por su rol y actuación en el apoyo a los servicios sociales de la provincia. El Catálogo de Servicios de la Diputación se basa en tres ejes:

- Financiación ordinaria de los servicios sociales básicos (10.463.421 € en 2014).

- Prestación de servicios a la ciudadanía: servicio local de teleasistencia, Servicio de Orientación Jurídica, Servicio de Intermediación Hipotecaria y Servicio de Atención a la Drogodependencia. En este ámbito, destacan además las residencias de estancia limitada para personas mayores y personas con discapacidad.

- Asesoramiento técnico: programa de gestión de servicios sociales (HESTIA), planificación y gestión, atención social en los ámbitos de adolescencia e infancia, autonomía funcional e inclusión social, actuaciones de supervisión y formación de equipos y evaluación de servicios (círculos de comparación intermunicipal en servicios sociales).
La singularidad de la Diputación de Barcelona en el campo de los servicios sociales obedece tanto al volumen de recursos destinados (casi 25 millones de euros, sin contar el capítulo I y 430 profesionales) como, sobre todo, a la orientación a los municipios desde la óptica de la innovación y la economía de escala.

\subsection{Galicia}

El marco normativo básico en materia de servicios sociales en la comunidad autónoma gallega se articula fundamentalmente a través de dos normas: la Ley $13 / 2008$, de 3 de diciembre, de Servicios Sociales de Galicia y el Decreto 99/2012, de 16 de marzo, por el que se regulan los servicios sociales comunitarios y su financiación. Tras las dos leyes anteriores ${ }^{4}$, la Ley 13/2008 entra dentro de las que se han considerado en el Estado español como leyes de servicios sociales de tercera generación. Esta norma pretende establecer el marco legal para un sistema único de servicios sociales, que integre y armonice las actuaciones e iniciativas que, en el ámbito social, se han ido agregando y superponiendo en los últimos años a la estructura definida por las anteriores leyes de servicios sociales, como los sistemas de inclusión social y atención a la dependencia, protección a la familia y la infancia (menores), igualdad y conciliación, etc. Para ello, establece cambios en cuanto a la estructura de los servicios sociales, así como respecto de las prestaciones que, en parte, vienen condicionados por regulación de la Ley $39 / 2006$, de 14 de diciembre, de Promoción de la Autonomía Personal y Atención a las Personas en Situación de Dependencia.

Como en los casos ya analizados de Cataluña y Navarra, la Ley 13/2008 estructura el sistema gallego de servicios sociales en forma de red, comprendiendo dos niveles de atención: los servicios sociales comunitarios, "de carácter predominantemente local”, que a su vez se subdividen en dos modalidades - básicos y específicos-; y los servicios sociales especializados, de competencia autonómica.

En lo que se refiere a la determinación del derecho a los servicios sociales, la Ley 13/2008 incorpora también -al igual que las analizadas hasta ahora- el concepto de derecho subjetivo en el

${ }^{4}$ La primera ley de servicios sociales, la Ley 3/1987, de 27 de mayo, definía el derecho al bienestar social como "medio para favorecer el pleno y libre desarrollo, participación e integración del ser humano en la sociedad" y como una de las metas de los poderes públicos en "una comunidad autónoma orientada hacia la justicia social”. La segunda, la Ley 4/1993, de 14 de abril, de Servicios Sociales, trató de regular exhaustivamente los aspectos básicos de los servicios sociales en Galicia, estableciendo los contenidos que constituían la oferta del sistema a la sociedad gallega, para lo cual estructuraba los servicios sociales en dos niveles de atención y nueve áreas de actuación. Como la mayoría de leyes de segunda generación de otras comunidades autónomas, la Ley 4/1993 estructuraba los servicios sociales en dos niveles (atención primaria y atención especializada) y definía de forma acotada las áreas que serían objeto de intervención del sistema. 
ámbito de los servicios sociales. Como en el caso navarro, sin embargo, diferencia las intervenciones, programas, servicios y prestaciones considerados como esenciales de las normalizadoras, dando a las primeras carácter de derecho exigible o subjetivo, y a las segundas, un carácter discrecional o potestativo. Así, las prestaciones esenciales "se configuran como derecho exigible y estarán garantizadas para aquellas personas que cumplan las condiciones establecidas de acuerdo con la valoración técnica de su situación", mientras que las normalizadoras "estarán incluidas en la oferta habitual, en función de las disponibilidades presupuestarias y se accederá [a ellas] en régimen de concurrencia". La Ley señala además que, reglamentariamente, se desarrollará y actualizará el Catálogo a instancias del departamento competente en materia de servicios sociales, si bien la Administración gallega, por el momento, ha optado por desarrollar carteras de servicios por sectores de actuación, actualmente en proceso de elaboración y aprobación (Cartera de Servicios de Atención a las Personas en Situación de Dependencia, Cartera de Servicios de Familia, Infancia y Adolescencia, Cartera de Servicios de Inclusión...).

La Ley define las intervenciones o servicios de carácter técnico-profesional como los actos profesionales realizados para: a) la información, orientación, asesoramiento y acompañamiento a las personas, familias o grupos; b) la valoración y diagnóstico social de las demandas de la ciudadanía; c) la intervención social, biopsicosocial, sociológica o socioeducativa que favorezca la adquisición o recuperación de funciones y habilidades personales y sociales de cara a la mejora de la autonomía, de la convivencia social y familiar y de la inclusión social, dando a todos ellos el carácter de esenciales. Estos servicios y actuaciones de naturaleza material o tecnológica, que pueden ser tanto de carácter esencial ${ }^{5}$ como normalizador, son:

- La protección social de las personas, con capacidad de obrar limitada, que se encuentren en situación de conflicto o desamparo.

- La atención residencial, que comporta alojamiento, continuado o temporal, sustitutivo del hogar.

- La atención diurna, que ofrece cuidados personales y actividades de promoción y prevención que no requieran el ingreso en un centro residencial.

- La ayuda en el hogar, consistente en ofrecer un conjunto de atenciones a personas o familias en su propio domicilio.

${ }^{5}$ La Ley establece que estos servicios y prestaciones tendrán carácter esencial, previa la correspondiente valoración técnica, siempre y cuando se trate de personas con déficit de autonomía personal incluidas en el Sistema para la Autonomía y Atención a la Dependencia (SAAD). De esta forma, mientras que las intervenciones o servicios de carácter técnico-profesional están en todo caso garantizadas como derecho subjetivo, las prestaciones de naturaleza material o tecnológica -incluyendo, por ejemplo, la atención diurna o residencialsólo lo están si se dirigen a las personas cubiertas por el SAAD.
- La teleasistencia social y otros servicios de carácter tecnológico, que procuren la permanencia de las personas usuarias en su medio habitual.

Las prestaciones, que tienen en cualquier caso consideración de normalizadoras, son las siguientes:

- El apoyo a la movilidad personal, en los términos previstos en la normativa.

- La manutención, ya sea en locales de atención colectiva o en el propio domicilio.

- Las ayudas técnicas e instrumentales, que permitan mantener la autonomía.

- El servicio de asistente personal.

- Cualquier otro servicio o actuación no prevista en la Ley que se consideren necesarios para garantizar una adecuada atención social.

Asimismo, la norma recoge y define como parte del Catálogo de Servicios las prestaciones económicas del sistema gallego de servicios sociales como las aportaciones en dinero, de carácter periódico o de pago único, que tienen como finalidad, entre otras, apoyar el cuidado de menores, paliar situaciones transitorias de necesidad, garantizar mínimos de subsistencia y reforzar procesos de integración familiar e inclusión social, así como garantizar el cuidado de personas con limitaciones en su autonomía personal.

Por último, la Ley define como parte del Catálogo los programas de intervención comunitaria, al respecto de los cuales expresa que se elaborarán a partir del diagnóstico social de una comunidad determinada, favoreciendo la cooperación con los otros servicios de bienestar social existentes en su ámbito de actuación y con la implicación de la ciudadanía, a fin de incidir en la superación de las situaciones detectadas, mediante la elaboración y desarrollo de actuaciones con una perspectiva preventiva y de inclusión social.

En lo que se refiere a la estructuración funcional y competencial, como ya se ha señalado, el sistema gallego de servicios sociales se estructura en forma de red conforme a dos niveles de actuación: un primer nivel constituido por los servicios sociales comunitarios, que comprenden dos modalidades -comunitarios básicos y comunitarios específicos-, de responsabilidad municipal en ambos casos; y un segundo nivel, el de los servicios sociales especializados, de responsabilidad autonómica. Así, de acuerdo con los artículos 59 y siguientes de la Ley 13/2008 les corresponde a los ayuntamientos en todo caso la prestación de los servicios sociales comunitarios básicos y, como regla general, también de los servicios sociales comunitarios específicos, mientras que se reservan a la comunidad autónoma las competencias de planificación, evaluación y control del sistema, además de la competencia para la prestación de los servicios sociales especializados. 
La prestación de los servicios comunitarios considerados básicos es obligatoria, mientras que en el caso de los considerados específicos, su prestación es potestativa. El artículo 61 de la Ley 13/2008 deja muy claro cuáles son los servicios mínimos que deben garantizar los ayuntamientos, al establecer que la prestación de los servicios sociales comunitarios básicos es un servicio mínimo obligatorio que deben asegurar todos los ayuntamientos de Galicia ${ }^{6}$. No obstante, cada municipio, en ejercicio de su autonomía local, podrá optar entre prestar estos servicios por su cuenta, o bien establecer acuerdos de agrupación con otros ayuntamientos para compartir y mejorar la eficiencia de la actuación del personal técnico o de los programas desarrollados en su nivel de atención. No ocurre lo mismo con los servicios sociales comunitarios específicos, cuya prestación por parte de los ayuntamientos se configura como potestativa ("los ayuntamientos podrán crear y gestionar [...] centros o programas de servicios sociales comunitarios específicos"). Al tratarse de una prestación no obligatoria, la propia Ley contempla tanto la posibilidad de su titularidad municipal como la de su gestión mediante fórmulas de colaboración interadministrativa de adhesión voluntaria o, incluso, su prestación por la propia comunidad autónoma.

La Ley 13/2008 también especifica las competencias de las diputaciones provinciales en materia de servicios sociales, limitando sus atribuciones a proporcionar "asistencia económica, técnica y jurídica a los ayuntamientos en la ejecución de sus competencias en materia de servicios sociales, especialmente en la prestación de servicios sociales comunitarios básicos por aquellos ayuntamientos con menos de veinte mil habitantes". Por su parte, el Decreto 99/2012, de 16 de marzo, en su artículo 31, concreta un poco más esta previsión legal al establecer que las diputaciones provinciales apoyarán prioritariamente la financiación del SAD básico a los ayuntamientos de menos de 20.000 habitantes, así como la financiación a estas mismas entidades para la contratación de personal técnico de los equipos municipales de servicios sociales comunitarios con perfiles profesionales diferentes y complementarios al del/de la trabajador/a social de referencia?.
${ }^{6}$ Aun así, atendiendo a lo que establezcan los instrumentos de planificación del sistema, la comunidad autónoma podrá asumir la creación y gestión de servicios sociales comunitarios específicos o, incluso, excepcionalmente, apoyar la creación y gestión de servicios especializados por ayuntamientos, siempre que en ambos casos se responda a la planificación estratégica aprobada por la Xunta de Galicia.

7 En todo caso, el propio Decreto 99/2012, de 16 de marzo, atribuye a la comunidad autónoma, como titular de la competencia de planificación general del sistema, la coordinación de las actuaciones de apoyo financiero de las diputaciones provinciales a los ayuntamientos, disponiendo que "los programas de cooperación económica con las entidades locales que elaboren las diputaciones provinciales en esta materia, cualquiera que sea su denominación, serán puestos, antes de su aprobación, en conocimiento del órgano superior de la Xunta de Galicia competente en materia de servicios sociales y de la Comisión Gallega de Cooperación Local”.
Finalmente, como ocurre en las demás comunidades autónomas analizadas, la prestación de los servicios sociales especializados se configura como una competencia reservada con carácter general a la administración autonómica. Así se prevé en el artículo 59 de la Ley 13/2008, de 3 de diciembre, que detalla las competencias que le corresponden a la administración de la comunidad autónoma:

- El establecimiento del marco normativo en materia de servicios sociales.

- La planificación y programación general de los servicios sociales mediante la elaboración del Plan Estratégico y de los planes y programas sectoriales.

- El Registro Único de Entidades Prestadoras de Servicios Sociales.

- La autorización y acreditación de centros, servicios y programas sociales.

- La formación e investigación en el campo de los servicios sociales.

- El asesoramiento y asistencia técnica a las entidades e instituciones que participen en la prestación de los servicios sociales.

- El diseño, creación, gestión, coordinación, mantenimiento y actualización de un sistema de información estadística de los servicios sociales.

- La supervisión y evaluación de la calidad en la prestación de los servicios sociales.

- La creación, mantenimiento y gestión de los servicios sociales especializados, así como de los centros y programas de los servicios sociales comunitarios específicos que, de acuerdo con el Plan Estratégico de Servicios Sociales, asuma la Xunta de Galicia.

- La valoración técnica para el reconocimiento del derecho a los servicios y prestaciones esenciales de carácter material o económico.

- La concesión de las prestaciones o ayudas económicas destinadas a personas físicas.

- La gestión de subvenciones o ayudas públicas que conceda a centros y entidades prestadoras de servicios sociales.

- El ejercicio de las potestades inspectora y sancionadora.

- Otras que le sean atribuidas por la normativa vigente $u$ otras que, siendo necesarias para el desarrollo y ejecución de la política de servicios sociales, no estén expresamente atribuidas a otra administración pública.

\subsection{Castilla y León}

El sistema de servicios sociales de la Comunidad Autónoma de Castilla y León está regulado por la Ley 16/2010, de Servicios Sociales, que deroga la anterior normativa, que se remonta a 1988 (Ley $18 / 1988$ de 28 de diciembre). Como ley de 
tercera generación, garantiza "el derecho de acceso, en condiciones de igualdad, a un sistema de servicios sociales de carácter universal y hacer efectivo el derecho subjetivo a las prestaciones esenciales del sistema de servicios sociales de responsabilidad pública” (art. 1a). El art. 2 configura como derecho subjetivo garantizado y exigible judicialmente el acceso a las prestaciones que se definen como esenciales, frente a las no esenciales que, como en Navarra o Galicia, tienen carácter discrecional. Según el art. 19 de la Ley, las prestaciones esenciales son las siguientes:

- Las de información, orientación y asesoramiento.

- Las de valoración, planificación de caso y seguimiento.

- La renta garantizada de ciudadanía (RGC), regulada por la Ley $1 / 2015$, de 4 de marzo, de modificación del Decreto Legislativo 1/2014, de 27 de febrero, por el que se aprueba el texto refundido de las normas legales vigentes en materia de condiciones de acceso y disfrute de la prestación esencial de renta garantizada de ciudadanía.

- Las ayudas destinadas a la atención de necesidades básicas de subsistencia en situaciones de urgencia social (Decreto $12 / 2013$, de 21 de marzo, por el que se regula la prestación económica destinada a la atención de necesidades básicas de subsistencia en situaciones de urgencia social).

- Las medidas específicas para la protección de menores de edad en situación de riesgo y desamparo.

- La atención temprana dirigida a niños con discapacidad o con riesgo de padecerla (como mínimo, la prevención, detección precoz, el diagnóstico y la atención de casos).

- La teleasistencia (en el caso de las personas mayores de 80 años, en todo caso) y la ayuda a domicilio, el servicio de estancia diurna y nocturna, y las estancias residenciales permanentes reconocidas por el Sistema para la Autonomía y Atención a la Dependencia (SAAD).

- La prestación económica para ciudadanos en el entorno familiar y apoyo a cuidadores no profesionales.

- La prestación económica de asistencia personal.

- Los servicios de prevención de las situaciones de dependencia y los servicios de promoción de la autonomía personal.

- La prestación económica vinculada cuando no sea posible el acceso a un servicio público o concertado.

- Las de protección jurídica y ejercicio de la tutela de las personas mayores de edad incapacitadas legalmente y que se encuentren en situación de desamparo.

- La atención en el centro de día que garantice, con continuidad a la del sistema educativo, el proceso de integración social y laboral de las personas con discapacidad una vez culminados los ciclos educativos a los que puedan acceder.

Las prestaciones del sistema de servicios sociales de titularidad y de responsabilidad pública quedan tipificadas en el Catálogo de Servicios Sociales de Castilla y León, regulado mediante el Decreto $58 / 2014$, de 11 de diciembre. Éste se estructura en dos apartados que conforman los anexos de la norma. El primero contiene el conjunto de las prestaciones del sistema, en su denominación y necesidad de cobertura. El segundo está configurado por las fichas descriptivas de cada prestación social, en su calificación de esencial o no esencial. Se clasifican cuatro niveles de atención social:

- Nivel 1. Acceso al sistema de servicios sociales de responsabilidad pública. Hace referencia a la información y evaluación de las situaciones de necesidad social.

- Nivel 2. Atención inmediata o de proximidad. Atención de proximidad a las personas en situación de riesgo o de exclusión social.

- Nivel 3. Atención alternativa al mantenimiento en el entorno y hogar familiar.

- Nivel 4. Otras prestaciones.

En lo que se refiere a la estructura competencial, la atención social sigue estando estructurada en dos niveles, el básico y el especializado. El primero comprende la prestación de servicios de carácter polivalente, preventivo, promocional y asistencial de la población general; tales servicios se prestan mediante la red de centros de acción social (CAS) y constituyen la puerta de entrada al sistema de servicios sociales. El segundo nivel abarca la atención especializada, que se articula por sectores de población (menores, personas mayores y con discapacidad, minorías étnicas, etc.).

Por el contrario, como en las demás comunidades autónomas analizadas, la atención especializada corresponde a la administración autonómica; en el caso del nivel básico de servicios sociales, la gestión puede corresponder bien a los ayuntamientos, bien a las diputaciones, dependiendo del tamaño de los municipios. Así, en los municipios mayores de $\mathbf{2 0 . 0 0 0}$ habitantes la gestión de los servicios sociales básicos es asumida por los ayuntamientos, mientras que en los que no llegan a esa población la gestión corresponde a las diputaciones. Concretamente, la gestión de los servicios sociales básicos es asumida por todas las capitales de provincia y por otros seis municipios (Miranda de Ebro y Aranda de Duero en Burgos; Laguna de Duero y Medina del Campo, en Valladolid; y San Andrés de Rabanedo y Ponferrada en León). Así pues, sólo quince municipios de la región asumen directamente la gestión de los servicios sociales básicos, correspondiendo la gestión de esos servicios en el resto de los municipios a las diputaciones. 


\subsection{Castilla-La Mancha}

El marco normativo vigente en la Comunidad de Castilla-La Mancha es la Ley $14 / 2010$, de 16 de diciembre, de Servicios Sociales de CastillaLa Mancha, que establece en su literalidad el acceso a los servicios sociales como derecho de ciudadanía. En la práctica, sin embargo, ese derecho no es exigible ni justiciable, al no haberse desarrollado ninguno de los reglamentos ni desarrollos normativos que la propia Ley señalaba que habían de ser elaborados y aprobados en los dos años siguientes a su entrada en vigor.

Los desarrollos normativos que la Ley 14/2010 establecía que antes de 2013 debían estar aprobados son: a) el Plan Estratégico de Servicios Sociales; b) el Mapa de Servicios Sociales; c) el Catálogo de Prestaciones del Sistema Público de Servicios Sociales; d) la Carta de Derechos y Deberes; e) la urgencia social; f) la renta básica; y g) el Registro de Entidades y Centros de Servicios Sociales. Ninguno de ellos se ha elaborado, ni se está elaborando en la actualidad. El desarrollo reglamentario completo de la Ley debería haberse completado en su totalidad en un periodo máximo de cuatro años desde su entrada en vigor, periodo en el cual no se ha hecho ni aprobado reglamento alguno.

En todo caso, es importante destacar que en el título III de la Ley se definen las prestaciones mínimas que configuran el sistema público de servicios sociales, reconociendo aquellas que están garantizadas ${ }^{8}$ de las no garantizadas, y que se dividen en dos niveles: atención primaria y atención especializada. En el primer nivel se incluyen las siguientes prestaciones:

- Información y orientación.

- Estudio, valoración y acompañamiento.

- Atención a la familia o unidad de convivencia.

- Ayuda a domicilio.

- Teleasistencia domiciliaria.

- Alojamiento temporal para situaciones de urgencia social.

- Prevención y atención integral ante situaciones de exclusión social.

- Fomento de la participación en el ámbito comunitario.

${ }^{8}$ Que estén consideradas como prestaciones garantizadas por la Ley no significa que en la práctica exista tal garantía, ya que su disfrute está sujeto a disponibilidad de recursos, en ciertos servicios se exige el copago, y en numerosas prestaciones técnicas, hay cuantiosos expedientes sin valorar, como es en el caso de la dependencia. Además, en muchos casos en los que se ha realizado la valoración (como en los valorados con grado 1), no se ha elaborado el plan individual de atención (PIA), por lo que no reciben atención alguna -son las personas que se encuentran en el denominado 'limbo de la dependencia'-. Igualmente, otras prestaciones, como las estancias diurnas y nocturnas, están sujetas a disponibilidad de plazas y dotación presupuestaria, lo que hace que en la práctica muchas personas con derecho a ellas no accedan a la prestación.
Las prestaciones correspondientes al nivel especializado son las siguientes:

- Valoración de situaciones de dependencia.

- Valoración del grado de discapacidad.

- Valoración y atención temprana.

- Valoración y atención en situaciones de desprotección de menores.

- Atención en estancias diurnas.

- Atención en estancias nocturnas.

- Atención residencial.

- Acogimiento familiar.

- Información, valoración y seguimiento de adopciones.

- Prestación destinada a familias numerosas (reconocimiento de la condición).

Además de las prestaciones señaladas, la norma establece una serie de prestaciones especializadas de acceso condicionado (entre otros elementos, a la disponibilidad presupuestaria), así como prestaciones económicas, que igualmente pueden ser garantizadas o condicionadas.

En lo que se refiere a la articulación competencial del sistema, los servicios sociales son competencia exclusiva de la administración autonómica (tal como recoge el Estatuto de Autonomía), excepto en el caso de ayuntamientos de más de 20.000 habitantes, para los cuales la Ley de Bases de Régimen Local establece una serie de obligaciones comunes a todos los municipios del país superiores a este tamaño. En la práctica, en Castilla-La Mancha, todos los municipios de más de 5.000 habitantes, y todos los que teniendo una población inferior se encuentran agrupados en una misma zona de servicios sociales, disponen de al menos un trabajador social de referencia y de algunas de las prestaciones básicas garantizadas.

La diferencia entre los municipios más grandes (capitales de provincia y municipios de más de 20.000 habitantes) y el resto es que, en el caso de ayuntamientos con mayor capacidad de gestión, los servicios sociales se organizan a través del Plan Concertado, mientras que en el resto es la Junta de Comunidades (JCCM) quien se hace cargo de la contratación y gestión del personal, mediante convenio con los ayuntamientos implicados.

En todo caso, es a los servicios de atención primaria los que corresponde competencialmente prestar a los ayuntamientos, y sólo en los casos de ayuntamientos grandes (como en el de Albacete, por ejemplo, que es el único con más de 100.000 habitantes), también ciertos servicios especializados son de titularidad

9 Castilla-La Mancha cuenta con quince municipios de más de 20.000 habitantes, en los que se concentra el $40 \%$ de la población de la Comunidad. 
y gestión municipal. Se trata, en cualquier caso, de apenas 20 municipios de un total de 916 que podrían disponer de servicios sociales especializados de titularidad y gestión municipal. La mayor parte de los servicios sociales especializados de CastillaLa Mancha son de titularidad y/o gestión autonómica, con acceso y derivación desde el nivel primario, pero siempre bajo decisión o acuerdo de los servicios provinciales autonómicos, que son los que otorgan la prestación especializada.

\section{Contenido, funciones y estructura de los servicios sociales municipales}

\subsection{Comunidad Foral de Navarra}

Uno de los cambios más significativos de la Ley Foral 15/2006 fue, sin duda, la nueva estructuración de los servicios sociales de atención primaria, fruto de un intenso trabajo previo de reflexión y debate sobre el papel de la atención primaria de servicios sociales. La reordenación de la atención primaria por la que se opta a partir de ese debate pretende romper la tradicional separación entre una primera atención basada en la acogida y la posterior derivación a los servicios sociales especializados, y apuesta por un modelo de atención primaria más especializado, similar en algunos aspectos al que se establece después en la Comunidad Autónoma de Euskadi ${ }^{10}$.

La Ley Foral 15/2006 recoge en lo esencial las propuestas realizadas en la fase de debate y define un modelo de atención basado en un nivel primario y en un segundo nivel de servicios sociales especializados. Esta estructura de programas se asentaría en una organización territorial compuesta por servicios sociales de base, centros de servicios sociales y servicios sociales especializados.

Pese a su escaso desarrollo posterior, resulta

${ }^{10}$ Véase el Documento base para un plan de atención comunitaria de servicios sociales (Gobierno de Navarra, 2000). El documento se asentaba en la filosofía de integrar el sistema de servicios sociales en la comunidad y tenía como objetivo fundamental tratar de superar las dificultades que entrañaba el modelo de atención primaria generalista previamente existente: una red fragmentada, falta de especialización de los profesionales, un modelo de atención dependiente de la demanda, un desigual desarrollo comunitario y poca participación de las entidades sociales. Tras varios meses de debate, se acuerda una propuesta de modelo de atención primaria más especializado, que incluya acciones de detección de necesidades y prevención, integrado en el ámbito comunitario, más cercano a la ciudadanía y más coordinado entre los profesionales de diferentes programas. Para ello se diseña un modelo de atención primaria integrado por cuatro programas específicos: Programa de Acogida y Orientación Social, Programa de Atención Comunitaria a las Personas con Dificultades de Autovalimiento, Programa de Incorporación Social en la Atención Comunitaria y Programa de Atención a la Infancia y Familia. Del mismo modo, se propone una reordenación de la red que permitiera una mejor implantación de los cuatro programas, así como un refuerzo de la acción de los servicios sociales de base. Esta estructura propuesta se organizaría en tres niveles: la zona básica (nivel básico de atención directa), el área (integrada por un centro de servicios sociales que agruparía diferentes zonas de servicios sociales, apoyaría en la atención directa, participaría en el desarrollo de acciones conjuntas y gestionaría aquellos recursos compartidos entre las zonas básicas) y la Comunidad Foral (dirección, programación y apoyo técnico a los servicios de zona y área). particularmente interesante, como se indica más adelante, la creación de un ente intermedio entre los servicios sociales de base y los servicios especializados, los centros de servicios sociales, de carácter comarcal, y diseñados para apoyar a los primeros tanto en lo que se refiere a la coordinación como al seguimiento de determinados casos.

En este esquema, los servicios sociales de base se configuran como unidad básica del sistema público de servicios sociales, puerta de acceso y nivel más próximo a la ciudadanía. Son titularidad de las entidades locales, aunque contarán, como se explica más adelante, con la participación en la financiación de Gobierno de Navarra y su organización territorial se determinará a partir de una zonificación específica, articulada mediante áreas y zonas básicas de servicios sociales. Según el artículo 30 de la Ley, las funciones de estos servicios serán las de:

a. Detectar, analizar y diagnosticar las situaciones de necesidad en su ámbito territorial, informando a los servicios competentes y proponiendo respuestas.

b. Atender a las personas que presenten demandas ante los servicios sociales, con el fin de ofrecerles una primera respuesta.

c. Facilitar a la ciudadanía el acceso a las prestaciones del sistema de servicios sociales y al resto de sistemas de protección social.

d. Valorar y realizar el diagnóstico social y/o socioeducativo de las situaciones de necesidad social a demanda del usuario, de su entorno familiar o social, o de otros servicios de la red de atención pública de necesidad social.

e. Ofrecer apoyo y acompañamiento social continuado a las personas que estén en situaciones de necesidad social.

f. Realizar actuaciones preventivas y de promoción social.

g. Ejecutar los programas y las prestaciones incluidas en éstos.

h. Gestionar prestaciones de emergencia social.

i. Realizar actuaciones de sensibilización social.

j. Promocionar el voluntariado y la ayuda mutua.

k. Gestionar las prestaciones que les sean atribuidas en la Cartera de Servicios Sociales de Ámbito General.

Para el desarrollo de estas funciones, en este nivel de atención primaria se identifican cuatro programas de obligatorio desarrollo para toda Navarra:

a. El Programa de Acogida y Orientación Social, dirigido a toda la población, que ofrecerá intervención social a las personas que presenten demandas ante los servicios sociales.

b. El Programa de Promoción de la Autonomía Personal y Atención a las Personas en Situación de Dependencia, que tendrá como objetivo 
posibilitar a las personas en situación de dependencia la permanencia en su medio habitual el máximo tiempo posible, e incluye la prestación de ayuda a domicilio.

c. El Programa de Incorporación Social en Atención Primaria, cuya finalidad es favorecer la inclusión social de personas en riesgo o en situación de exclusión social en cualquiera de sus ámbitos.

d. El Programa de Atención a la Infancia y Familia en Atención Primaria, que tendrá como objetivo asegurar a los menores de edad un entorno que permita su desarrollo personal, mediante mecanismos de protección, apoyo personal, familiar y social.

Vinculado a estos cuatro programas, la Ley también establece la necesidad de dotar de prestaciones técnicas, económicas y materiales a estos programas, por lo que dos años más tarde se aprobó el Decreto Foral 69/2008, que definía la Cartera de Servicios Sociales de Ámbito General en Navarra. Esta Cartera, que establece la intensidad mínima de protección en el ámbito general, dispuso también la posibilidad de que las entidades locales, en su ámbito territorial, puedan desarrollar otras prestaciones complementarias aprobadas y definidas en sus propias carteras de servicios sociales.

En cualquier caso, la Ley Foral 15/2006 ya definió, en su artículo 31, ya algunas prestaciones mínimas que, obligatoriamente, debían garantizarse:

- En el Programa de Acogida y Orientación Social: la tramitación del acceso a las prestaciones técnicas y económicas del sistema de servicios sociales y a las prestaciones de los otros sistemas de protección social.

- En el Programa de Promoción de Autonomía Personal y Atención a las Personas en Situación de Dependencia: la atención domiciliaria municipal.

- En el Programa de Incorporación Social en Atención Primaria: el acompañamiento social en los procesos de incorporación local mediante acuerdos de incorporación social, como instrumento de compromiso entre las partes.

- En el Programa de Atención a la Infancia y a la Familia en Atención Primaria: las competencias de prevención y atención a situaciones de desprotección leve y moderada atribuidas a las entidades locales por la legislación foral en materia de infancia y juventud.

Además de ello, los cuatro programas incluirían:

- Prestaciones técnicas de acogida, orientación, asesoramiento, valoración y diagnóstico social y/o socioeducativo.

- La renta de inclusión social.

- Prestaciones de emergencia social.

- Prestaciones mínimas de atención a la dependencia.
- Prestaciones técnicas de atención a la infancia en situación de desprotección y conflicto social (detección, recepción, investigación, valoración, diagnóstico, plan de intervención).

- Recursos de alojamiento temporal a personas sin hogar, mujeres víctimas de violencia de género o menores en situación de desprotección.

- Acceso a plazas residenciales de carácter temporal o permanente a personas en situación de dependencia, conflicto familiar o falta de soporte familiar.

La estructura de los servicios sociales de base se complementa, como antes se ha dicho, con los centros de servicios sociales, que se configuran como estructura de apoyo a los servicios sociales de base. Aunque se contempla la posibilidad de que los entes locales promuevan algunos de estos centros, la Ley atribuye a la administración foral la obligación de desarrollar, al menos, uno por cada área de servicios sociales (véase el punto siguiente). Sus funciones (art. 21) son las de:

- Servir de apoyo a los servicios sociales de base para complementar sus funciones y para coordinar a éstos con los servicios sociales especializados, constituyéndose por tanto como un nivel intermedio ente el nivel especializado y la atención primaria.

- Colaborar y asesorar a los servicios sociales de base, contribuyendo a la redistribución de los recursos.

- Establecer criterios homogéneos a nivel de área para garantizar la igualdad en todas las zonas.

- Colaborar con los servicios sociales de base en el seguimiento e intervención de casos.

- Fomentar programas de actuación transversal de cara a un aprovechamiento de los recursos.

Por último, a los servicios sociales especializados se les atribuye la responsabilidad de ejecutar las prestaciones e intervenciones de carácter sectorial diseñadas para la atención de necesidades 0 colectivos que requieran una atención específica, bien mediante centros específicos, bien mediante equipos de intervención directa, que actúan también como apoyo a los servicios sociales de base. Se crean en ese sentido los Equipos de Incorporación Sociolaboral (EISOL), los Equipos de Atención a la Infancia y Adolescencia (EAIA), los Equipos de Atención Integral a Víctimas de Violencia de Género (EAIV) o los Equipo de Incorporación Social en la Vivienda (EISOVI). Si bien la responsabilidad respecto al desarrollo de estos centros corresponde a la administración autonómica, se prevé la posibilidad de que sean los propios entes locales los que los desarrollen.

Es importante señalar en todo caso que, a pesar del compromiso de la administración foral en garantizar esta estructura, lo cierto es que en la práctica no todos los niveles has sido desarrollados conforme a las funciones marcadas en la Ley. La diferencia entre 
las previsiones legales y la realidad es especialmente clara en lo que se refiere a los centros de servicios sociales que, en la práctica, se han configurado únicamente como un espacio físico en el que se ubican los equipos especializados garantizados en la Cartera y que apoyan a la atención primaria de servicios sociales en cada área. Actualmente, sólo existen dos centros de servicios sociales en Navarra, aunque otras áreas cuentan también con la atención de algunos de los equipos especializados ${ }^{11}$. En un principio, estos centros estaban previstos como servicios de titularidad y gestión pública; sin embargo, desde su configuración los servicios fueron gestionados por entidades privadas y la dirección de éstos se mantuvo en manos del Gobierno de Navarra. Finalmente, también la dirección de los centros pasó a ser gestionado por la empresa adjudicataria del concurso. La contratación de estos servicios por parte de Gobierno de Navarra ha permitido el desarrollo de los equipos especializados en las áreas; sin embargo, sus funciones se alejan a las establecidas en la Ley, y la gestión indirecta lleva al riesgo de que los distintos equipos funcionen con lógicas de intervención diferentes.

\subsection{Catalunya}

El Decreto 142/2010, de 11 de octubre, por el que se aprueba la Cartera de Servicios Sociales 2010-2011 es prorrogado bianualmente hasta la fecha y amplía las prestaciones de los servicios sociales básicos inicialmente recogidas en la Ley 12/2007. El listado de prestaciones del nivel básico de atención es:

- Servicio básico de atención social: consiste en las acciones de información, orientación, intervención social y acceso a prestaciones realizadas por los Equipos Básicos Profesionales (veremos su composición más adelante).

- Servicios de atención domiciliaria: incluye la ayuda a domicilio y servicios de las tecnologías de apoyo y cuidado (teleasistencia).

- Servicios residenciales de estancia limitada: para situaciones de emergencia y para personas adultas en situación de exclusión social.

- Servicio de comedor social.

- Servicio de asesoramiento técnico de atención social: jurídico, psicológico, etc. ${ }^{12}$.

${ }^{11}$ Existen actualmente en Navarra dos centros de servicios sociales - el de Estella y el de Tudela- que ofrecen tres de los cuatro equipos especializados recogidos en la Cartera de servicios Sociales: el Equipo de Incorporación Sociolaboral (EISOL), el Equipo de Atención a la Infancia y Adolescencia (EAIA) y el Equipo de Atención Integral a Víctimas de Violencia de Género (EAIV). Por otro lado, el área de Tafalla cuenta con el desarrollo de dos de estos equipos: el Equipo de Incorporación Sociolaboral (EISOL) y el Equipo de Atención a la Infancia y Adolescencia (EAIA). Para las áreas de servicios sociales de la Comarca de Pamplona, Noreste y Noroeste, se ofrece solamente el Equipo de Incorporación Sociolaboral (EISOL). Por último, el Equipo de Incorporación Social en la Vivienda (EISOVI) sólo se encuentra desarrollado en Pamplona y comarca.

${ }^{12}$ Este servicio, incluido en la Cartera y considerado como prestación garantizada, no se dirige sólo a las personas usuarias, sino
- Servicio de intervención socioeducativa no residencial para infancia y adolescencia: centros abiertos.

- Prestaciones económicas de urgencia social.

En la actualidad, la Cartera de Servicios tiene un $100 \%$ de implantación en lo que se refiere al servicio básico de atención social, los servicios de atención domiciliaria y las prestaciones económicas de urgencia social. Más desigual es la implantación del servicio de comedor social o los servicios residenciales de estancia limitada, generalizados en los municipios de mayor tamaño, pero que tienden a sustituirse en los de menor tamaño por prestaciones económicas u otras soluciones. Son servicios que necesitan de establecimientos y equipos profesionales de alto coste económico y que no pueden ser abordados por la capacidad presupuestaria de los ayuntamientos de menor dimensión.

Un caso singular es el Servicio de Intervención Socioeducativa No Residencial para Niños y Adolescentes, una prestación que tiene unas ratios de cobertura que se definen a partir de la población residente, sin tener en cuenta los diferentes niveles de riesgo en la infancia según territorios, ni las dificultades de gestión en comarcas con poca población o con alta dispersión geográfica. Por ello, este servicio ha iniciado una evolución de equipamientos con funcionamiento diario después del horario lectivo a servicios de intervención en el medio habitual con un mayor componente profesional.

En la línea del desarrollo de otros aspectos de la Ley $12 / 2007$, cabe decir que la Cartera de Servicios se ha quedado en un planteamiento que suponía un paso adelante con una implementación deficiente. Los derechos subjetivos de los ciudadanos en las prestaciones garantizadas no han sido totalmente efectivos en numerosas prestaciones y el acceso a éstas o su intensidad ha sido limitado, sobre todo por falta de disponibilidad presupuestaria. La propia Cartera, cabe añadir, se ha convertido en un complicado e interminable catálogo detallista y burocratizado.

\subsection{Galicia}

Como ya se ha indicado, el sistema gallego de servicios sociales se estructura en forma de red, conforme a dos niveles de actuación: un primer nivel de competencia municipal, constituido por los servicios sociales comunitarios, que comprenden dos modalidades -comunitarios básicos y comunitarios específicos-;

también a los propios profesionales de los servicios. El objeto del servicio es el de proporcionar apoyo y asesoramiento técnico a los equipos multiprofesionales de los servicios básicos de atención social, en el ejercicio de sus funciones, $y$ atender a las personas $y / o$ familias derivadas por los profesionales de los servicios básicos de atención social cuando sea necesario. 
y un segundo nivel, el de los servicios sociales especializados, de competencia autonómica. También se ha señalado que, para las administraciones locales, mientras que la prestación de los servicios comunitarios básicos es obligatoria, la de los servicios comunitarios específicos es potestativa.

En lo que se refiere a la articulación y las funciones de los servicios sociales locales, los servicios sociales comunitarios tienen carácter predominantemente local, están referenciados a un territorio y población determinados y constituyen el acceso normalizado y el primer nivel de intervención del sistema gallego de servicios sociales. Su titularidad se atribuye en consecuencia, como ya se ha dicho, a los ayuntamientos, si bien, en ejercicio de su autonomía local, éstos pueden decidir gestionarlos a través de agrupaciones de municipios o mancomunidades.

Dentro de los servicios sociales comunitarios, los considerados básicos tienen un carácter inequívocamente local, abierto y polivalente, y constituyen la vía normal de acceso al sistema de servicios sociales, garantizando su universalidad y su cercanía a las personas usuarias y a los ámbitos familiar y social. Se prestan desde los centros de servicios sociales municipales, por medio de equipos interdisciplinares y con la estructura organizativa que establezca la administración titular del servicio. Las funciones de los servicios sociales comunitarios básicos son:

- El estudio y diagnóstico social de la comunidad, que implica la detección y análisis de necesidades y demandas.

- La elaboración de un plan de intervención comunitario acorde con las necesidades detectadas.

- La identificación de grupos de población vulnerables y la detección precoz de situaciones de riesgo.

- La atención de las situaciones individuales, la información con relación a las demandas presentadas, el diagnóstico y valoración técnica previa y la consecuente intervención en el caso, y la derivación, cuando proceda, hacia el recurso idóneo.

- La participación en la gestión de las prestaciones económicas y el seguimiento de los correspondientes proyectos personalizados de intervención.

- La gestión del Servicio de Ayuda en el Hogar, así como la participación en la gestión de las prestaciones destinadas a garantizar la autonomía personal y la atención a la dependencia.

- La información, orientación y asesoramiento a toda la población, facilitando su acceso a los recursos sociales.

- El fomento de la participación activa de la ciudadanía mediante estrategias socioeducativas que impulsen la solidaridad y la cooperación social organizada.

En particular, los servicios sociales comunitarios básicos desarrollarán las funciones enumeradas, de manera estructurada, por medio de los programas y servicios siguientes:

a. Programa de valoración, orientación e información en materia social a las personas, grupos o a la comunidad en general, que se desarrollará en todas las entidades locales titulares de servicios sociales comunitarios de Galicia.

b. Servicio de ayuda a domicilio (SAD), que tiene por objeto prestar un conjunto de atenciones a las personas o familias en su domicilio, desde una perspectiva integral y normalizadora, para facilitar su desarrollo personal y la permanencia en su entorno habitual, especialmente en aquellas situaciones en que tengan limitada su autonomía o en otras situaciones de riesgo social para las que resulte un recurso idóneo.

c. Servicio de educación y apoyo familiar, que integra el conjunto de proyectos y servicios de apoyo educativo y psicosocial dirigidos a las familias, con el objetivo de detectar, prevenir y superar las situaciones de dificultad, especialmente las eventuales situaciones de maltrato infantil o cualquier otra desprotección, así como promover procesos de cambio que favorezcan un adecuado ejercicio de las responsabilidades familiares, la mejora de la autonomía, de la integración y de la participación social de las familias y unidades de convivencia.

d. Programa básico de inserción social que procure valorar, dar respuesta o derivar al recurso idóneo a las personas en situaciones o riesgo de exclusión social, aplicando tanto proyectos de intervención social personalizados o de grupo como prestaciones económicas específicas.

e. Programa de fomento de la cooperación y solidaridad social, que facilite la participación comunitaria en tareas colectivas, impulse el asociacionismo solidario y, en especial, la organización y coordinación del voluntariado social.

Una de las singularidades del modelo gallego - con relación al menos al de Navarra y Cataluña, pero no al establecido en la Comunidad Autónoma de Euskadi- es la existencia de los llamados servicios sociales comunitarios específicos. Su papel es desarrollar programas y centros orientados a grupos de población con problemáticas identificadas y singulares, procurando su normalización y reincorporación social o como espacio de tránsito a un servicio especializado. Para ello, los servicios sociales comunitarios específicos tienen asignadas las siguientes funciones:

a. El desarrollo de programas y actividades para prevenir la exclusión de grupos vulnerables. 
b. La atención directa a colectivos con déficits de autonomía o en riesgo de exclusión que se desarrolle a través de programas en medio abierto, en centros de carácter no residencial o de carácter residencial temporal.

c. La gestión de equipamientos comunitarios para sectores de población con necesidades específicas.

En lo que se refiere a su organización, los servicios sociales comunitarios específicos, atendiendo a criterios de equidad territorial y de rentabilidad social, podrán tener un carácter supramunicipal, de acuerdo con la planificación y ordenación del sistema gallego de servicios sociales, y su prestación incluso podrá llegar a ser asumida por la comunidad autónoma cuando, por su naturaleza, ámbito supramunicipal u otras circunstancias debidamente justificadas así se prevea en la planificación del sistema.

\subsection{Castilla y León}

El Catálogo de Servicios Sociales, regulado mediante el Decreto 58/2014, de 11 de diciembre, atribuye la titularidad de los diversos servicios bien a la administración local, bien en la autonómica, o bien a ambas. Las prestaciones esenciales que se atribuyen a la administración social en exclusiva son las siguientes:

- Servicio de información especializada sobre inclusión social.

- Servicio de apoyo familiar para la protección a la infancia.

- Teleasistencia.

- Ayuda a domicilio.

- Prestación económica para necesidades básicas de subsistencia en situaciones de urgencia social.

Además, el Catálogo atribuye a la atención primaria un amplio grupo de prestaciones no esenciales ${ }^{13} y$ establece que determinadas prestaciones esenciales pueden ser tanto de titularidad municipal como autonómica. Entre ellas, cabe destacar las siguientes:

${ }^{13}$ Servicio de promoción de hábitos y estilos de vida saludables; servicio de adquisición de competencias para la vida autónoma; servicio de promoción de la relación con el entorno; servicio de acción social comunitaria y promoción de la solidaridad; servicio de actuaciones preventivas para familias con hijos o hijas menores en situación de riesgo; servicio de apoyo preventivo a la infancia y a la adolescencia en situación de riesgo; servicio de apoyo a mujeres embarazadas o madres en situación de especial vulnerabilidad; servicio de apoyo familiar para la promoción de la autonomía personal en situaciones de dependencia, y/o discapacidad; servicio de formación de cuidadores y cuidadoras no profesionales de personas con dependencia; servicio de apoyo familiar para la inclusión social; servicio de apoyo técnico a personas en situación de dependencia y/o de discapacidad; servicio de apoyo técnico para la inclusión social; servicio de alojamiento para personas sin hogar; prestación extraordinaria frente a situaciones de deuda hipotecaria.
- Servicio de información sobre derechos y recursos del sistema de servicios sociales.

- Servicio de valoración, orientación, planificación de caso y seguimiento.

- Servicio de prevención de la situación de dependencia.

- Servicio de apoyo para la elaboración del proyecto de vida.

- Servicio de apoyo técnico a la infancia para su protección.

- Servicio de atención en centros de día para personas con discapacidad.

- Servicio de atención en centros de día para personas mayores en situación de dependencia.

- Servicio de atención en centros de emergencia, casas de acogida y viviendas para víctimas de violencia.

- Servicio de atención residencial o en vivienda para personas con discapacidad.

- Servicio de atención residencial con cuidados sociales y sanitarios para personas en situación de convalecencia.

- Servicio de atención residencial para personas mayores en situación de dependencia.

En cuanto a su organización funcional, como se señala posteriormente, el sistema se estructura en dos niveles:

- El primero corresponde a los Equipos de Acción Social Básica, que desarrollarán su actividad mediante los centros de acción social (CEAS, equiparables a los servicios sociales de base de la Comunidad Autónoma de Euskadi) y sobre la base territorial de las llamadas zonas de acción social ${ }^{14}$.

- El segundo nivel está compuesto por los Equipos Multidisciplinares Específicos y están establecidos en cada área de acción social ${ }^{15}$.

- La titularidad y la gestión de ambos equipos corresponderán a las entidades locales competentes en servicios sociales.

\subsection{Castilla-La Mancha}

Como se señala al analizar la ordenación territorial de los servicios sociales de atención primaria de Castilla-La Mancha, existen dos tipos de zonas de servicios sociales: las zonas PRAS (Plan Regional de Acción Social), que están formadas por municipios menores de 5.000 habitantes, y las zonas Plan

${ }^{14}$ Como se explica posteriormente, la zona de acción social (ZAS) es la unidad de referencia para la detección de necesidades, asignación y planificación de recursos y servicios sociales. Se establece un módulo de 20.000 habitantes para el medio urbano y 10.000 para el rural.

${ }^{15}$ Como se explica posteriormente, las áreas son agrupaciones de ZAS y corresponde a cada entidad local su delimitación. Cada área deberá integrar un mínimo de tres y un máximo de cinco ZAS. 
Concertado, que además de ser municipios con mayor número de habitantes disponen de ayuntamientos con mayor capacidad de gestión. En las zonas Plan Concertado, el ayuntamiento aporta más recursos que en las zonas PRAS, lo que implica la disponibilidad de más profesionales y mayor capacidad de intervención técnica. Las funciones y contendidos del servicio también varían en función del tipo de zona:

- Zonas PRAS. La totalidad de municipios menores de 5.00o habitantes están en este tipo de zonas, así como una buena parte de los municipios inferiores a 20.000. En cada zona PRAS, hay al menos un profesional de trabajo social contratado por la Junta de Castilla Mancha (en alguna puede haber dos), y en algunas existen también educadores (no en la mayoría) y un auxiliar administrativo. Los trabajadores y trabajadoras sociales son personal funcionario de la Junta, mientras que los educadores educadoras y el personal administrativo son personal de la Junta no funcionario, financiado mediante convenio entre ésta y el ayuntamiento o la mancomunidad. Hasta 2012 hubo zonas PRAS en las que algunos ayuntamientos reforzaban los servicios sociales municipales mediante la contratación de educadores y educadoras o algún trabajador o trabajadora social adicional, con presupuesto municipal. Sin embargo, debido a los recortes presupuestarios sufridos por los ayuntamientos, esas figuras profesionales contratadas de forma directa prácticamente han desaparecido en estas zonas.

- Zonas Plan Concertado. Son las de municipios de más de $\mathbf{2 0 . 0 0 0}$ habitantes y algunos con población inferior. Dado el mayor tamaño y la mayor capacidad de gestión y compromiso municipal con los servicios sociales en este tipo de zonas, la dotación de personal es mayor aquí que en las zonas PRAS. Así, por ejemplo, en todas las zonas Plan Concertado hay educadores (cosa que no ocurre con las zonas PRAS) y, en general, cuentan con más personal profesional especializado (psicólogos, por ejemplo, en algunos casos) y de gestión.

El servicio de ayuda a domicilio es objeto de un convenio separado entre el Gobierno autonómico y cada ayuntamiento, por lo que el personal de este servicio tiene una consideración y vinculación diferente con la administración local. Existe una salvedad en el modo de gestión del SAD en la provincia de Albacete, dada la existencia de un Consorcio Provincial de Servicios Sociales, en virtud del cual es la diputación provincial quien supervisa y contrata en esta provincia a todos los auxiliares del SAD para las zonas rurales, lo que hace que en esta provincia la gestión del SAD sea de mayor calidad y esté más controlada que en el resto de las provincias, donde depende de cada municipio.

Esta organización territorial y el sistema de dotación de personal hacen que, en la actualidad, sólo se pueda hablar de cuatro servicios o prestaciones mínimas realmente garantizados en todo el territorio autonómico:
- Información y orientación.

- Estudio, valoración y acompañamiento.

- Ayuda a domicilio.

- Teleasistencia.

- Atención a la familia o unidad de convivencia, antes denominado 'educación familiar' (esta prestación técnica solamente está garantizada en las zonas donde existen educadores, que no son la mayoría).

Cabe señalar además que, hasta 2012, las prestaciones de atención primaria relacionadas con la atención integral a situaciones de exclusión social y de fomento de la participación comunitaria eran implementadas mediante subvenciones que la propia Junta de Castilla-La Mancha otorgaba a los ayuntamientos, previa presentación del proyecto de acción correspondiente. Los municipios, generalmente subcontrataban a asociaciones, entidades del tercer sector o empresas, la realización de dichos proyectos, una vez concedida al municipio la subvención regional para llevarlos a cabo. Este tipo de actuaciones y prestaciones 'garantizadas' prácticamente han desaparecido, al eliminarse o reducirse muy drásticamente estas partidas presupuestarias en la última legislatura.

\section{Dotaciones mínimas y ratios de personal}

\subsection{Comunidad Foral de Navarra}

En Navarra, las ratios de personal de los servicios sociales de base están parcialmente vinculadas a la financiación de esos servicios que, como más adelante se indica, están cofinanciados por los ayuntamientos y el Gobierno de la Comunidad Foral.

En ese sentido, el tramo fijo de financiación que aporta el Gobierno de la Comunidad se determina a partir de los Equipos Mínimos Interprofesionales de Atención Primaria necesarios para el desarrollo de los cuatro programas obligatorios en cada territorio. Como puede comprobarse en el Cuadro 1, se determina que, por ejemplo, un municipio de entre 5.000 y 7.000 habitantes debe disponer como mínimo de 1,5 trabajadores/as sociales, 1 administrativo/a; 2,5 trabajadores/as familiares y 1 educador/a social (por programas: 1,5 trabajadores/as sociales y 1 administrativo/a para el programa de acogida; 0,5 trabajadores/as sociales y 2,5 trabajadores/as familiares para el de autovalimiento; 0,5 educadores/as sociales para el programa de infancia y 0,5 educadores/as sociales para el de incorporación.)

\subsection{Catalunya}

Para la mayor parte de los servicios, la Cartera de Servicios Sociales indica que "se dispondrá de profesionales suficientes en número y perfil para la prestación del servicio". En algunos casos, 


\begin{tabular}{|c|c|c|c|c|c|}
\hline Población & Acogida & $\begin{array}{l}\text { Autonomía personal y } \\
\text { atención a la dependencia }\end{array}$ & Infancia & Incorporación & Total \\
\hline$<5.000$ habs. & $\begin{array}{l}0,75 \text { ts. } \\
1 \text { adm. } \\
0,5 \text { asc. }\end{array}$ & $\begin{array}{l}0,25 \text { ts. } \\
2 \text { tf. }\end{array}$ & 0,25 es. & 0,25 es. & $\begin{array}{c}1 \text { ts. } \\
1 \text { adm. } \\
0,5 \text { es. } \\
0,5 \text { asc. } \\
2 \text { tf. }\end{array}$ \\
\hline 5.000-7.500 habs. & $\begin{array}{c}1 \mathrm{ts} . \\
1 \mathrm{adm} .\end{array}$ & $\begin{array}{l}0,5 \text { ts. } \\
2,5 \text { tf. }\end{array}$ & 0,5 es. & 0,5 es. & $\begin{array}{c}1,5 \text { ts. } \\
1 \mathrm{adm} . \\
2,5 \mathrm{tf} . \\
1 \mathrm{es} .\end{array}$ \\
\hline 7.500-10.00o habs. & $\begin{array}{c}1 \mathrm{ts} . \\
1 \mathrm{adm} .\end{array}$ & $\begin{array}{l}0,5 \text { ts. } \\
3 \text { tf. }\end{array}$ & $\begin{array}{l}0,25 \text { ts. } \\
0,50 \text { es. }\end{array}$ & 0,25 ts. 0,5 es. & $\begin{array}{c}2 \mathrm{ts} . \\
1 \mathrm{adm} . \\
3 \mathrm{tf} . \\
1 \mathrm{es} .\end{array}$ \\
\hline 10.000-15.000 habs. & $\begin{array}{l}1,25 \text { ts. } \\
1 \mathrm{adm} .\end{array}$ & $\begin{array}{l}0,75 \text { ts. } \\
3,5 \text { tf. }\end{array}$ & $\begin{array}{l}0,25 \text { ts. } \\
0,75 \text { es. }\end{array}$ & 0,25 ts. 0,75 es. & $\begin{array}{l}2,5 \text { ts. } \\
1 \mathrm{adm} . \\
3,5 \text { tf. } \\
1,5 \text { es. }\end{array}$ \\
\hline 15.000-20.000 habs. & $\begin{array}{l}1,50 \text { ts. } \\
1,5 \text { adm. }\end{array}$ & $\begin{array}{l}1 \mathrm{ts} . \\
4 \mathrm{tf} .\end{array}$ & $\begin{array}{l}0,50 \text { ts. } \\
1 \text { es. }\end{array}$ & $\begin{array}{l}0,50 \text { ts. } \\
1 \text { es. }\end{array}$ & $\begin{array}{c}3,5 \text { ts. } \\
1,5 \text { adm. } 4 \text { tf. } \\
2 \text { es. }\end{array}$ \\
\hline 20.000-30.000 habs. & $\begin{array}{c}1,5 \text { ts. } \\
1,5 \text { adm. }\end{array}$ & $\begin{array}{l}1 \mathrm{ts} \text {. } \\
4,5 \mathrm{tf}\end{array}$ & $\begin{array}{l}0,75 \text { ts. } \\
1,25 \text { es. }\end{array}$ & $\begin{array}{l}0,75 \text { ts. } \\
1,25 \text { es. }\end{array}$ & $\begin{array}{c}4 \text { ts. } \\
1,5 \text { adm. } \\
4,5 \text { tf. } \\
2,5 \text { es. }\end{array}$ \\
\hline$>30.000$ habs. & $\begin{array}{c}2 \text { ts. } \\
1,5 \mathrm{adm} .\end{array}$ & $\begin{array}{l}1 \mathrm{ts} . \\
5 \mathrm{tf} .\end{array}$ & $\begin{array}{l}0,5 \text { ts. } \\
1 \text { es. }\end{array}$ & $\begin{array}{l}0,5 \text { ts. } \\
1 \text { es. }\end{array}$ & $\begin{array}{c}\text { ( } 4 \text { ts. } \\
1,5 \text { adm. } \\
2 \text { es. } \\
5 \text { tf.) } \\
\text { / ZB }\end{array}$ \\
\hline
\end{tabular}

ts.: trabajador/a social. adm.: administrativo/a. asc.: animador/a sociocultural. tf.: trabajador/a familiar. es.: educador/a social. ZB: zona básica.

Fuente: Elaboración propia.

sin embargo, establece también las ratios y la cualificación del personal que debe prestar esos servicios:

En lo se refiere al Servicio Básico de Atención Social, definido como el "conjunto organizado y coordinado de acciones profesionales, integrado por equipos técnicos, con el objetivo de mejorar el bienestar social y favorecer la integración de las personas", se establece una ratio de tres trabajadores o trabajadoras sociales y dos educadores o educadoras sociales por cada 15.000 habitantes.

Las ratios de personal que establece el Decreto de Cartera para el servicio de centro abierto ${ }^{16}$ son las siguientes: 1 director/a-coordinador/a, ratio no inferior a 0,2: 2 educadores/as sociales 0 1 educador/a social y 1 integrador/a social por cada 20 personas usuarias. Se puede disponer de monitores/as de tiempo libre para actividades específicamente lúdicas y de apoyo.

${ }^{16}$ Este servicio se define como un servicio diurno preventivo, fuera del horario escolar, que da apoyo, estimula y potencia la estructuración y el desarrollo de la personalidad, la socialización, la adquisición de aprendizajes básicos y el ocio, y compensa las deficiencias socioeducativas de las personas atendidas mediante el trabajo individualizado, el grupal, la familia, el trabajo en red y con la comunidad. Su objetivo es proporcionar atención a todos los menores en situación de riesgo, favoreciendo su desarrollo personal e integración social y la adquisición de aprendizajes, previniendo y evitando el deterioro de las situaciones de riesgo, y compensando déficits socioeducativos".
Los datos del Mapa de Servicios Sociales de la Generalitat de Catalunya ponen de manifiesto que, en 2014, las ratios de personal están por término medio, para el conjunto del territorio, ligeramente por debajo de lo establecido en la Ley, con 2,88 trabajadores o trabajadoras sociales y 1,78 educadores o educadoras sociales por cada 15.000 habitantes ${ }^{17}$.

\subsection{Galicia}

El Decreto 99/2012, de 16 de marzo, además de definir o regular los aspectos básicos de contenido y funcionamiento de los servicios sociales comunitarios, establece los criterios para dotarlos de personal y sienta las bases para una adecuada coordinación operativa entre los servicios sociales comunitarios y el resto del sistema gallego de servicios sociales. Con el fin de hacer efectiva la garantía del acceso universal y gratuito al sistema, así como la prestación de servicios de carácter

${ }^{17}$ Es importante señalar, a este respecto, que el Mapa recoge el número de trabajadores y trabajadoras sociales y educadores y educadoras sociales de todas y cada una de las zonas básicas municipales y comarcales, indicando en qué medida se cumplen en cada una de ellas las ratios mínimas establecidas en la normativa. La publicación de estos datos tiene un impacto importante en lo que se refiere a la transparencia del sistema y la rendición de cuentas por parte de las administraciones locales a la ciudadanía. 
profesional en todo el territorio, este decreto establece la obligatoriedad de que en todos los servicios sociales comunitarios se desarrolle el programa de valoración, orientación e información en materia de bienestar social a las personas, a los grupos y a la comunidad y de que se les asigne, a las personas usuarias, un profesional de referencia: una trabajadora o trabajador social.

Para delimitar la dotación de personal necesaria para la prestación de estos servicios, dicho decreto define primeramente distintos tipos de equipos técnicos o ‘unidades de actuación' de servicios sociales comunitarios básicos. Así, en función del área social y del ayuntamiento en que se actúa, se definen los siguientes tipos de equipo profesional:

a. Unidades de trabajo social (UTS).

b. Unidades de trabajo y educación social (UTES).

c. Unidades interdisciplinares de intervención social (UNIS).

Con carácter general, los criterios de dotación mínima que se aplicarán son los siguientes:

- En las unidades de trabajo social (UTS), se asegurará la presencia de un trabajador o trabajadora social.

- En las unidades de trabajo y educación social (UTES), se integrarán personas tituladas en Trabajo Social y Educación Social.

- En las unidades interdisciplinares de intervención social (UNIS), deberá asegurarse, además, la presencia de al menos una persona titulada superior o en posesión de grado universitario en Psicología, Sociología o materia relacionada con los programas desarrollados por los servicios sociales comunitarios.

En tanto no se aprueben y publiquen el Mapa de Servicios Sociales y el Plan Estratégico, se establece como referencia para la dotación de recursos humanos de los servicios sociales comunitarios básicos la planificación establecida en los anexos I y II del Decreto 99/2012, partiendo de la clasificación de los ayuntamientos en diferentes tipos de áreas sociales y de la definición de diferentes equipos técnicos o unidades de actuación para cada tipo de ayuntamiento y de área (Cuadro 2). De acuerdo con esos anexos, la dotación de las unidades de actuación de servicios sociales comunitarios básicos no es la misma en los diversos tipos de área (véase el apartado relativo a la ordenación territorial para una explicación más detallada sobre los diferentes tipos de áreas existentes). Si en las áreas urbanas, con carácter general, se aplicará una ratio de una persona técnica por cada 8.000 habitantes, en las semiurbanas y metropolitanas la dotación mínima varía en función del modelo de unidad y de los tramos de población.

Para los ayuntamientos de las áreas rurales y de las áreas de alta dispersión, se establecen también dotaciones mínimas, que incluyen en general las mismas figuras profesionales (Cuadros 3 y 4 ).

El decreto en cuestión, a la hora de establecer los criterios para la financiación del SAD, también establece una serie de ratios de cobertura, que se definen en función del tamaño del municipio y

\begin{tabular}{|l|l|c|c|c|c|}
\hline \multicolumn{6}{|l|}{ Cuadro 2. Galicia. Dotación profesional de las áreas semiurbanas y metropolitanas } \\
\hline Población & Modelo unidad & Trabajadores sociales & Educadores & $\begin{array}{c}\text { Psicólogos/sociólogos o titulados } \\
\text { superiores idóneos }\end{array}$ & $\begin{array}{c}\text { Auxiliares } \\
\text { administrativos }\end{array}$ \\
\hline <10.000 habs. & UTS & $1-2$ & $* *$ & $*$ & $0-0,5$ \\
\hline $10.000-15.000$ habs. & UTES & 2 & 1 & $*$ & 1 \\
\hline $15.000-25.000$ habs. & UNIS urbana & $2-3$ & $1-2$ & 1 & $1-2$ \\
\hline $20.000-40.000$ habs. & $\begin{array}{l}\text { UNIS urbana } \\
\text { reforzada }\end{array}$ & $3-5$ & $2-3$ & 1 & $2-3$ \\
\hline
\end{tabular}

UTS: unidad de trabajo social. UTES: unidad de trabajo y educación social. UNIS: unidad interdisciplinaria de intervención social. * Se determinará en función de la población del conjunto del área.

** Se procurará la gestión conjunta con ayuntamientos limítrofes.

Fuente: Elaboración propia.

\begin{tabular}{|c|c|c|c|c|c|}
\hline Población & Modelo unidad & Trabajadores sociales & Educadores & $\begin{array}{l}\text { Psicólogos/sociólogos o titulados } \\
\text { superiores idóneos }\end{array}$ & $\begin{array}{c}\text { Auxiliares } \\
\text { administrativos }\end{array}$ \\
\hline$<5.000$ habs. & UTS & $1-2$ & ** & * & $0-0,5$ \\
\hline 5.000-12.00o habs. & UTES & $1-2$ & 1 & * & 1 \\
\hline 12.000-20.000 habs. & UNIS rural & $2-3$ & $1-2$ & 1 & $1-2$ \\
\hline
\end{tabular}

UTS: unidad de trabajo social. UTES: unidad de trabajo y educación social. UNIS: unidad interdisciplinaria de intervención social.

* Se determinará en función de la población del conjunto del área.

** Contarán con el apoyo de los educadores vinculados al área.

Fuente: Elaboración propia. 
Cuadro 4. Galicia. Dotación profesional de las áreas rurales de alta dispersión

\begin{tabular}{|c|c|c|c|c|c|}
\hline Población & $\begin{array}{l}\text { Modelo } \\
\text { unidad }\end{array}$ & Trabajadores sociales & Educadores & $\begin{array}{l}\text { Psicólogos/sociólogos o titulados } \\
\text { superiores idóneos }\end{array}$ & $\begin{array}{l}\text { Auxiliares } \\
\text { administrativos }\end{array}$ \\
\hline$<2.000$ habs. & \multicolumn{5}{|c|}{$\begin{array}{l}\text { Se asegurará la presencia regular de un trabajador social. Se potenciarán formas flexibles de cooperación entre } \\
\text { ayuntamientos para compartir profesionales y programas. }\end{array}$} \\
\hline $\begin{array}{l}2.000-5.000 \\
\text { habs. }\end{array}$ & UTS & $1 / 2$ & $\star \star \star$ & * & $0-0,5$ \\
\hline
\end{tabular}

UTS: unidad de trabajo social.

* Se determinará en función de la población del conjunto del área.

** Contarán con el apoyo de los educadores vinculados al área.

Fuente: Elaboración propia.

oscilan entre una unidad de convivencia atendida por cada 75 habitantes, en las áreas rurales de alta dispersión, y una unidad de convivencia atendida por cada 500 habitantes, en las áreas de más de 30.000 habitantes.

\subsection{Castilla y León}

La Ley 16/2010 de Servicios Sociales prevé que reglamentariamente se desarrolle la composición del personal de los equipos de los centros de acción social (CEAS), desarrollo que no ha sido acometido por el momento ${ }^{18}$. Por su parte, el Catálogo de Servicios Sociales no contempla una intensidad mínima para las prestaciones que estos centros ofrecen, salvo en el caso del SAD, en el que no se establecen ratios de personal, sino determinadas intensidades horarias mínimas, tanto para las personas en situación de dependencia, en cuyo caso se trata de una prestación esencial, siguiendo los criterios que establece la normativa del SAAD, como en los demás casos, en los que se trata de una prestación optativa.

\subsection{Castilla-La Mancha}

Dado que la Ley 14/2010 no se ha desarrollado y, más concretamente, no se ha elaborado ni el Plan, ni el Mapa, ni el Catálogo de Servicios Sociales, no existen dotaciones o ratios mínimas para los servicios de atención primaria, más allá de las intensidades mínimas que se puedan establecer, por ejemplo, con relación al SAD, en el marco del Sistema Nacional de Atención a la Dependencia (SAAD).

\section{Ordenación territorial y fórmulas de colaboración interadministrativa}

\subsection{Comunidad Foral de Navarra}

Uno de los aspectos fundamentales que implica la Ley 15/2006 es el reconocimiento de la necesidad de

${ }_{18}$ El Decreto 13/1990, establecía que el personal mínimo del CEAS fuera un trabajador social y un animador comunitario. trabajar por la cohesión territorial de la Comunidad Foral de Navarra. Para ello se requería una estructura cercana a la ciudadanía y que garantizara el acceso universal al sistema. Con el fin de lograr estos objetivos y a partir de los tres niveles básicos de la estructura anteriormente presentados (servicios sociales de base, centros de servicios sociales y servicios sociales especializados), la Ley establece una ordenación territorial específica para los servicios sociales, muy basada en cualquier caso en la estructura anterior formada por zonas y mancomunidades de municipios.

Esta nueva organización se desarrolló al amparo del Decreto Foral 33/2010, de 17 de mayo, por el que se establece la zonificación de servicios sociales de la Comunidad Foral de Navarra ${ }^{19}$. A partir de esta norma, la estructura territorial de Navarra para el ámbito de servicios sociales queda compuesta por 44 zonas básicas de servicios sociales (formadas por diferentes mancomunidades de municipios), agrupadas a su vez en seis áreas de servicios sociales.

${ }^{19}$ Aunque, tal y como se ha mencionado anteriormente, los servicios sociales en Navarra tienen una organización territorial propia, el Decreto Foral 33/2010, de 17 de mayo, antepuso la necesidad de que ésta coincidiera, al menos en su nivel de atención primaria, con las zonas ya delimitadas del sistema de salud o educativo. El Sistema de Salud de Navarra se organiza en torno a zonas básicas, que a su vez se agrupan en tres áreas de salud encabezadas por un complejo hospitalario: Pamplona, Estella y Tudela. El sistema educativo, por otro lado, está organizado en dieciocho distritos educativos que incluyen zonas de educación secundaria y centros de enseñanza primaria. Ambas organizaciones territoriales son previas a la de servicios sociales. La coincidencia de zonas básicas fue posible con las zonas básicas de salud, de tal forma que la organización permitiera, al menos, garantizar una buena coordinación entre servicios sociales y sanitarios en el nivel de atención primaria. Este objetivo se alcanzó sobre todo en las zonas rurales, donde sí se ha producido esa convergencia entre las zonas básicas de servicios sociales y las de atención sanitaria. Sin embargo, no parece que haya ocurrido lo mismo en el ámbito urbano de Pamplona. Las diferencias en lo urbano y rural se deben, fundamentalmente, a que la organización territorial sanitaria en el ámbito de Pamplona se ha definido a partir de criterios de población, mientras que la de servicios sociales ha estado más vinculada a criterios de barrio e identidad. Por el contrario, el éxito de esta común zonificación en lo rural se debe a que han convergido tanto los lazos culturales, identitarios y sociales, como los políticos (vinculados a distritos electorales) y de salud. Esta convergencia ha hecho posible un desarrollo común territorial para el ámbito sanitario y social en las zonas rurales, facilitando la interlocución y coordinación entre sistemas. En el caso educativo, las diferencias no sólo se producen en el ámbito urbano, sino que es común a todo el territorio navarro. Esta circunstancia da lugar a una dificultad importante, especialmente latente en algunas zonas rurales. 
En este esquema, las áreas agrupan a entre cinco y doce zonas básicas, mientras que cada zona básica incluye una media de 22 municipios. El tamaño poblacional de las áreas oscila entre los 20.193 del área noreste y los 357.957 del área de Pamplona, que representan el $55 \%$ de la población de la Comunidad Foral. El tamaño medio de las zonas básicas de servicios sociales es de unos 15.000 habitantes, si bien lógicamente su tamaño real depende del número y tamaño de los municipios que lo integran. Así, mientras que la zona básica de Alsasua incluye los municipios de Alsasua, Olazti y Ziordia, la de Doneztebe incluye trece municipios (Bertizarana, Donamaria, Doneztebe/Santesteban, Elgorriaga, Eratsun, Ezkurra, Ituren, Labaien, Oitz, Saldias, Sunbilla, Urrotz y Zubieta). Cinco zonas básicas - todas del área de Pamplona y comarca: las de Aranguren, Barañain, Burlada, Pamplona y Egüéscoinciden con un solo municipio, y en ningún caso los municipios se dividen en más de una zona básica.

Además de esta organización, la norma también establece la posibilidad de designar 'distritos de servicios sociales', una agrupación de zonas de servicios sociales con el fin de compartir servicios de ámbito superior a la zona. Actualmente se han designado distritos para dos de las áreas, la de Estella y la del área noroeste. Sin embargo, esta designación territorial no se materializa en la práctica en ningún servicio ni función compartida, según se ha podido comprobar a partir de los encuentros mantenidos con profesionales de estas zonas. Por tanto, es una mera nominación territorial.

Cabe señalar por otra parte que, al margen de esta ordenación territorial, Navarra carece de una herramienta, como el Mapa de Servicios Sociales de la Comunidad Autónoma de Euskadi, que establezca dotaciones o coberturas mínimas, a nivel del conjunto del territorio o de sus unidades territoriales, para los diversos servicios garantizados de la Cartera.

\subsection{Catalunya}

Como se ha señalado previamente, la competencia en la prestación del primer nivel de atención - los servicios sociales básicos- es de los municipios, que están obligados a crearlos y gestionarlos de acuerdo con la Cartera de Servicios Sociales y el Plan Estratégico correspondiente. Los consejos comarcales suplen los municipios de menos de $\mathbf{2 0 . 0 0 0}$ habitantes en la titularidad de las competencias propias de los servicios sociales básicos que estos no estén en condiciones de asumir directamente o mancomunadamente.
La división administrativa y unidad primaria de atención social es el área básica de servicios sociales (en adelante, ABSS), que se organiza en torno a una población mínima de 20.000 habitantes. El titular del área puede ser el municipio o la comarca (Cuadro 5).

\begin{tabular}{|c|c|c|c|}
\hline \multicolumn{4}{|c|}{$\begin{array}{l}\text { Cuadro } 5 . \text { Catalunya. Organización territorial de las áreas } \\
\text { básicas de servicios sociales }\end{array}$} \\
\hline \multirow{2}{*}{ Población } & \multicolumn{3}{|c|}{ Área básica de servicios sociales } \\
\hline & Titular & Descentralizac & territorial \\
\hline \multirow{2}{*}{$\begin{array}{l}<20.000 \\
\text { habs. }\end{array}$} & \multirow{2}{*}{$\begin{array}{c}\text { Comarca o } \\
\text { ente asociativo } \\
\text { municipal }\end{array}$} & $\begin{array}{l}\text { Sin delegación de } \\
\text { competencia }\end{array}$ & $\begin{array}{l}\text { Equipos } \\
\text { Básicos de } \\
\text { Atención }\end{array}$ \\
\hline & & $\begin{array}{l}\text { Con delegación } \\
\text { voluntaria de } \\
\text { competencia }\end{array}$ & Municipio \\
\hline $\begin{array}{l}>20.000 \\
\text { habs. }\end{array}$ & Municipio & $\begin{array}{r}\text { Centros de serv } \\
\text { Servicios y Equip } \\
\text { Atenc }\end{array}$ & $\begin{array}{l}\text { os sociales, } \\
\text { Básicos de }\end{array}$ \\
\hline
\end{tabular}

Fuente: Elaboración propia.

Los municipios de más de 20.000 habitantes pueden crear más de una ABSS en función de su población y necesidades sociales. La realidad es, sin embargo, que ningún municipio tiene más de un área. Para realizar una prestación del servicio de proximidad y facilitar el acceso al sistema de servicios sociales, algunos ayuntamientos se han decantado por la creación de centros, servicios o equipos de atención básica descentralizados territorialmente. Los criterios para su creación no han sido homogéneos y han dado respuesta a las diferentes realidades geográficas (barrios, distritos, entes locales descentralizados, etc.) y/o prioridades políticas. El proceso de implantación no ha tenido una evaluación suficiente en términos de eficiencia, y mucho menos de distribución y prevalencia de necesidades.

En el caso de las comarcas que agrupan municipios menores de $\mathbf{2 0 . 0 0 0}$ habitantes, la situación es más compleja y, a lo largo del tiempo, se han desarrollado diversos modelos de gestión. En síntesis, podemos encontrar tres formas de organización del área básica en función de la combinación de los elementos descritos en el Cuadro 5:

a. El Consejo Comarcal ${ }^{20}$ es el titular, gestiona los servicios y contrata el personal. Dispone de uno o más equipos básicos de atención que atienden los diversos municipios de la comarca. En el apartado siguiente, se describe la forma de financiación del servicio en estos casos.

b. El Consejo Comarcal delega en los municipios la gestión de servicios y la contratación de personal y se reserva las funciones de planificación y control de la financiación y la gestión.

c. Los municipios pueden crear una mancomunidad, o ente local asociativo voluntario que se encarga de la gestión de los servicios sociales.

Es una opción minoritaria pero que permite, en ocasiones, aportar un alto valor añadido en dos tipos de situaciones:

- En el caso de que los municipios tengan una larga tradición en la mancomunación

${ }^{20}$ Los Consejos Comarcales son los órganos de gobierno y gestión de las Comarcas creados en la ley $6 / 1987$, de 4 de abril, de la Organización Comarcal de Catalunya. 
de servicios y dispongan ya de una estructura jurídica y técnica. Es el caso de la Mancomunitat de La Plana, que agrupa a doce municipios de la comarca de Osona, en la provincia de Barcelona.

- Cuando en una misma comarca existan dos ABSS (la de ámbito comarcal y la de la capital de comarca) que necesiten crecer en masa crítica para mejorar su eficacia y eficiencia. La solución adoptada en algún caso ha sido la creación de un consorcio entre las administraciones titulares que asume las competencias en servicios sociales. El mejor ejemplo es el Consorci d'Acció Social de La Garrotxa, en la provincia de Girona, formado por el Ayuntamiento de Olot y el Consejo Comarcal.

Según el Mapa de Servicios Sociales de Catalunya de 2014, la configuración del sistema se concreta en 62 áreas básicas municipales y 41 comarcales (Cuadro 6).

\begin{tabular}{|l|l|l|c|}
\hline \multicolumn{4}{|l|}{$\begin{array}{l}\text { Cuadro 6. Catalunya. Número y población de las áreas } \\
\text { básicas de servicios sociales }\end{array}$} \\
\hline & $\begin{array}{c}\text { No áreas básicas } \\
\text { de servicios } \\
\text { sociales }\end{array}$ & Habitantes & Habitantes/área \\
\hline Municipales & 62 & 5.243 .220 & 84.568 \\
\hline Comarcales & 41 & 2.275 .683 & 55.504 \\
\hline Total & 103 & 7.518 .903 & 72.999 \\
\hline
\end{tabular}

Fuente: Elaboración propia.

La dimensión media del ABSS se sitúa en torno a los 73.000 habitantes, pero es necesario señalar que oscilan entre un mínimo de los 13.553 habitantes de Badia del Vallès (una excepción a la norma que fijan el mínimo en los 20.000 habitantes) y la ciudad de Barcelona, con 1.602.386 habitantes. Entre las ABSS comarcales, también hay una enorme dispersión: la comarca de Alta Ribagorça tiene una población de 3.873 habitantes, mientras que el Vallès Oriental reúne $291.974^{21}$.

En lo que se refiere a las fórmulas de colaboración interadministrativa para la prestación de los servicios sociales de atención primaria, cabe hacer referencia, a título ilustrativo, al caso del Consorcio de Servicios Sociales de Barcelona. La Carta Municipal de Barcelona ${ }^{22}$ crea el Consorcio de Servicios Sociales

${ }^{21}$ Esta realidad nos muestra que la heterogeneidad en cuanto al volumen de población, las diferencies socioeconómicas, la dimensión geográfica, la dispersión y al carácter más o menos rural o urbano han supuesto características insalvables para conseguir un despliegue homogéneo en todo el territorio. Cabe señalar, además, que algunas de las decisiones en materia de organización territorial, adoptadas a lo largo de los años (sobre todo, en el ámbito de las ABSS comarcales) han contribuido a agravar el problema, más que a solucionarlo. Un ejemplo es la delegación, descrita anteriormente, de la gestión de los servicios sociales básicos por parte de las comarcas en los municipios (en ocasiones, a ayuntamientos de dimensiones menores a los 5.000 habitantes y sin acreditar la condición de ser capaces de asumirla directamente).

${ }^{22}$ La Carta Municipal de Barcelona es la norma (reconocida a nivel autonómico y estatal) que regula la especificidad del régimen jurídico de la ciudad. formado por el Ayuntamiento de Barcelona y la Generalitat de Catalunya. Ha de realizar la gestión de los servicios sociales en el ámbito regional de Barcelona, en especial:

- Elaborar la planificación general.

- Proponer al Gobierno de la Generalitat la reglamentación de las entidades, servicios y establecimientos, públicos y privados, que presten servicios sociales en el municipio de Barcelona.

- Programar, prestar y gestionar los servicios especializados.

- Organizar la información a los ciudadanos y proporcionar el apoyo informativo, de evaluación y estadístico a las labores ordenadoras y planificadoras de los servicios sociales.

En los órganos de gobierno del Consorcio de Servicios Sociales, la Generalitat de Cataluña cuenta con las tres quintas partes de representantes o votos, y el Ayuntamiento de Barcelona, con las dos quintas partes restantes.

El Consorcio es una iniciativa pionera para evitar la actuación de diferentes niveles de la Administración en un mismo territorio desde la óptica de la cooperación y codecisión. El objetivo ha sido evitar duplicidades, detectar y atender las necesidades de las personas atendidas y favorecer sus itinerarios, especialmente entre la atención básica y la especializada. En ausencia de una evaluación formal, hay que destacar el desarrollo incompleto de la implantación del Consorcio, especialmente la falta de integración en él de los servicios sociales básicos. De momento sus 40 centros de servicios sociales dependen de un Instituto autónomo y no del Consorcio, lo que reproduce en la ciudad de Barcelona la dualidad de administraciones competentes y hace aparecer los problemas de relación y los costes de transacción.

Como valoración de esta experiencia, desde la óptica de Cataluña, cabe señalar que los consorcios pueden ser una opción para superar los efectos negativos de la actual división de los servicios sociales por niveles y sus problemas de gobernanza y coordinación. Tienen como ventaja que no necesitan de un cambio legislativo relativo al ámbito competencial de cada una de las administraciones, pero incorporan elementos de complejidad en la gestión, como la necesidad de dotarse de estructuras de toma de decisiones eficaces y el riesgo del desarrollo de organigramas ejecutivos superpuestos.

\subsection{Galicia}

Como ya se ha señalado, la planificación general del sistema gallego de servicios sociales le corresponde a la comunidad autónoma. No obstante, la Ley 13/2008, de 3 de diciembre, también deja cierto margen a los ayuntamientos para elaborar 
su propia planificación, si bien siempre orientada a completar, en su ámbito territorial, la planificación estratégica aprobada por la comunidad autónoma, a través de planes y programas de servicios sociales municipales. En ese sentido, la normativa autonómica fija como unidad territorial de referencia para la planificación de los servicios sociales el área social, definida atendiendo a indicadores sociales, económicos y demográficos, con la finalidad de facilitar una distribución equilibrada de los recursos y garantizar la igualdad de oportunidades en el acceso a los servicios sociales para toda la ciudadanía, con independencia de su lugar de residencia.

Aunque la Ley prevé la aprobación del Mapa gallego de Servicios Sociales, en el que se definirán las áreas sociales y se establecerán los criterios de dotación de centros y de servicios en el territorio de Galicia, este mapa aún no ha sido aprobado. No obstante, el Decreto 99/2012, de 16 de marzo, por el que se regulan los servicios sociales comunitarios y su financiación, ha avanzado algo en esta dirección, definiendo las áreas sociales, pero únicamente a los efectos de establecer la dotación de los servicios sociales comunitarios y con un valor provisional, en tanto no se aprueben los instrumentos de planificación del sistema gallego de servicios sociales: el Mapa gallego de Servicios Sociales y el Plan Estratégico de Servicios Sociales, también pendiente de aprobación ${ }^{23}$.

Las áreas sociales de referencia para la planificación de los servicios sociales comunitarios parten de los ayuntamientos como unidad básica de prestación de los servicios ${ }^{24}$, clasificándolos y agrupándolos de acuerdo con demarcaciones caracterizadas por criterios poblacionales, sociales y geográficos. De esta manera, la ordenación territorial de los servicios sociales viene a coincidir, casi en su totalidad, con la ordenación municipal, pues, salvo en los casos de agrupaciones o mancomunidades, que son minoritarias y voluntarias, cada ayuntamiento presta los servicios sociales en su término municipal, careciendo de referencias comunes o de similitudes

${ }^{23}$ Sí se han aprobado otras herramientas de planificación sectoriales, como la Estrategia marco para la prevención y detección precoz de la dependencia en Galicia, que establece una serie de objetivos y recomendaciones para orientar la organización y funcionamiento de los diferentes servicios (sociales, sanitarios y educativos) hacia una mejora de las condiciones de vida de las personas en cuanto a salud y autonomía personal, hacia la prevención de los factores de riesgo y de limitaciones funcionales y a la atención integral, el Plan para la dinamización demográfica de Galicia 2013-2016, que, a partir del objetivo principal, desarrolla los objetivos estratégicos y cuatro áreas de intervención que establecen medidas orientadas a promover la dinamización demográfica, o la Estrategia de inclusión social de Galicia 2014-2020, que constituye un marco integrado de intervenciones orientadas a responder de un modo efectivo y coordinado a las situaciones personales y familiares de vulnerabilidad, pobreza y exclusión social y procurar los apoyos precisos para que las personas afectadas alcancen su inclusión social y laboral, por citar las más importantes.

${ }^{24} \mathrm{~A}$ ese respecto, el Decreto señala que las áreas para la planificación de referencia de servicios sociales comunitarios parten en todo caso de los ayuntamientos como unidad básica de prestación de los servicios, clasificándolos y agrupándoos de acuerdo con demarcaciones caracterizadas por criterios poblacionales, sociales y geográficos que se establecen. con la organización territorial del sistema educativo o sanitario. En total, se establecen en el Decreto 61 áreas diferentes, agrupadas en seis categorías o niveles.

La tipología de las áreas sociales se define siguiendo criterios de tamaño, densidad y dispersión poblacional, configuración orográfica, así como índices de dependencia, envejecimiento y discapacidad (anexo I del Decreto 99/2012, de 16 de marzo), y se establece la siguiente clasificación:

- Áreas urbanas: siete en total. Tienen esta consideración los ayuntamientos de A Coruña, Santiago de Compostela, Ferrol, Lugo, Ourense, Pontevedra y Vigo (las siete ciudades de Galicia).

- Áreas metropolitanas: se caracterizan por su proximidad a determinadas áreas urbanas, existiendo una continuidad territorial con éstas, o por situarse en su zona directa de influencia económica, demográfica y social. Se establecen cuatro áreas de este tipo.

- Áreas semiurbanas: presentan caracteres análogos a las metropolitanas, sin que exista una continuidad física o territorial con las áreas urbanas o por no encontrarse en su área de influencia. Hay nueve en total.

- Áreas rurales: se delimitan por referencia a los ámbitos territoriales que presentan características propias de los núcleos de población establecidos en el medio rural. Son, en total, 35.

- Áreas rurales de alta dispersión: seis áreas, caracterizadas por un importante declive demográfico, alta dispersión poblacional y elevados índices de envejecimiento.

En lo que se refiere a las fórmulas de colaboración interadministrativa para la prestación de los servicios sociales en Galicia, cabe hacer referencia a la Agencia Gallega de Servicios Sociales y al Consorcio Gallego de Igualdad y Bienestar. En efecto, la estructura administrativa de referencia para la coordinación o prestación conjunta de servicios en Galicia es el Consorcio Gallego de Servicios de Igualdad y Bienestar, integrado por la Xunta de Galicia y por 272 de los 314 ayuntamientos gallegos, así como por cuatro mancomunidades. La integración en el Consorcio tiene carácter voluntario para todas las administraciones que lo integran.

Este organismo ha sido fundamental para mejorar el equilibrio territorial en la oferta de servicios sociales públicos desde su creación en 2006 , en especial de los servicios sociales comunitarios específicos, y ha permitido garantizar la prestación de servicios de calidad con niveles suficientes de cobertura y facilitar el acceso a escuelas infantiles y puntos de atención a la infancia, centros de atención a personas mayores y a la dependencia (centros de día, viviendas comunitarias, hogares residenciales y minirresidencias), equipos comarcales de inclusión social, centros de información y asesoramiento a la 
juventud u otros servicios de proximidad, como la comida a domicilio. Todo ello se basa en una fórmula de colaboración interadministrativa y de adhesión voluntaria a través de la cual los ayuntamientos ceden sus equipamientos para que sean gestionados por dicho consorcio, comprometiéndose a aportar el $30 \%$ de la financiación, mientras que el consorcio asume el $70 \%$ restante con cargo a las transferencias de financiación que recibe de la administración autonómica y a los ingresos procedentes del copago de las personas usuarias.

Actualmente, en virtud de la modificación de la Ley $13 / 2008$, de 3 de diciembre, operada a través de la Ley $14 / 2013$, de 26 de diciembre, de racionalización del sector público autonómico, y del Decreto 40/2014, de 20 de marzo, por el que se crea la Agencia Gallega de Servicios Sociales y se aprueban sus estatutos, el Consorcio Gallego de Servicios de Igualdad y Bienestar se encuentra en proceso de ser absorbido por la Agencia Gallega de Servicios Sociales, que pretende dar continuidad a esta fórmula de colaboración con los ayuntamientos para facilitar la prestación de servicios sociales.

\subsection{Castilla y León}

Como se ha señalado previamente, en lo que se refiere al nivel básico de servicios sociales, el sistema de servicios sociales de Castilla y León se organiza territorialmente en dos niveles: las zonas de acción social (en adelante, ZAS) y las áreas de acción social (ASS). La ZAS es la unidad de referencia para la detección de necesidades, asignación y planificación de recursos y servicios sociales. Se establece un módulo de $\mathbf{2 0 . 0 0 0}$ habitantes para el medio urbano y de 10.000 para el rural. Las áreas son agrupaciones de ZAS y corresponde a cada entidad local su delimitación. Cada área deberá integrar un mínimo de tres y un máximo de cinco ZAS. La organización territorial se instrumentará a través del Mapa de Servicios Sociales de Castilla y León, pendiente de desarrollo en el momento actual.

En 2011, la Comunidad quedaba estructurada en 189 zonas de acción social, 119 rurales y 70 urbanas, que integran un total de 197 centros de acción social (CEAS), 124 rurales y 73 urbanos (Cuadro 7).

\begin{tabular}{|c|c|c|}
\hline \multicolumn{3}{|c|}{ Cuadro 7. Castilla y León. Organización de centros de acción social, por provincias } \\
\hline Provincia & Entidad local & Centros de acción social ( $N$ ) \\
\hline \multirow{2}{*}{ Ávila } & Ayuntamiento de la capital & 4 \\
\hline & Diputación & 8 \\
\hline \multirow{4}{*}{ Burgos } & Ayuntamiento de la capital & 9 \\
\hline & Diputación & 18 \\
\hline & Aranda de Duero & 2 \\
\hline & Miranda de Ebro & 2 \\
\hline \multirow{4}{*}{ León } & Ayuntamiento de la capital & 7 \\
\hline & Diputación & 7 \\
\hline & Ponferrada & 3 \\
\hline & San Andrés de Rabanedo & 2 \\
\hline \multirow{2}{*}{ Palencia } & Ayuntamiento de la capital & 4 \\
\hline & Diputación (mancomunidades) & 11 \\
\hline \multirow{2}{*}{ Salamanca } & Ayuntamiento de la capital & 8 \\
\hline & Diputación & 14 \\
\hline \multirow{2}{*}{ Segovia } & Ayuntamiento de la capital & 3 \\
\hline & Diputación & 10 \\
\hline \multirow{2}{*}{ Soria } & Ayuntamiento de la capital & 2 \\
\hline & Diputación & 10 \\
\hline \multirow{4}{*}{ Valladolid } & Ayuntamiento de la capital & 19 \\
\hline & Diputación & 13 \\
\hline & Laguna de Duero & 1 \\
\hline & Medina del Campo & 1 \\
\hline \multirow{2}{*}{ Zamora } & Ayuntamiento de la capital & 4 \\
\hline & Diputación & 10 \\
\hline
\end{tabular}

Fuente: Elaboración propia a partir de datos de la Junta de Castilla y León (〈http://www.serviciossociales.jcyl.es〉). 
En cuanto a la organización funcional, como ya se ha señalado, el sistema se estructura en dos niveles: el primero corresponde a los Equipos de Acción Social Básica, que desarrollarán su actividad en los CEAS (coinciden con el ámbito territorial de las ZAS); y un segundo nivel, a los Equipos Multidisciplinares Específicos (establecidos en cada área de acción social). La titularidad y la gestión de ambos equipos corresponderán a las entidades locales competentes en servicios sociales.

\subsection{Castilla-La Mancha}

Desde el punto de vista de la ordenación territorial del sistema, la Ley de Servicios Sociales reconoce al municipio como unidad territorial básica para la prestación de servicios sociales de atención primaria, permitiendo formas de agrupamiento para su prestación en los casos (muy numerosos) en que, por su escaso número de habitantes, no puedan hacerlo solos. Corresponde al ejecutivo regional establecer dicha ordenación territorial mediante el Mapa de Servicios Sociales. Sin embargo, dado que dicho Mapa no ha sido elaborado hasta la fecha, se sigue aplicando - pese a que ha quedado a todas luces obsoleto- el Decreto 287/2004, de 28 de diciembre, por el que se regula la estructura territorial de las zonas y áreas de servicios sociales y la estructura funcional del sistema público de servicios sociales de Castilla-La Mancha.

Sin embargo, dadas las características espaciales y demográficas de la comunidad autónoma, aunque la unidad territorial básica para la prestación de los servicios sociales de atención primaria sea el municipio, la prestación de servicios sociales se organiza en la mayor parte del territorio mediante la agrupación voluntaria de municipios (cuando existen mancomunidades), y todos ellos (excepto los más grandes) se integran en zonas y áreas de servicios sociales establecidas. Así, todo el territorio está dividido en áreas de servicios sociales, en las cuales se integran dos o más zonas de servicios sociales. Sólo en el caso de municipios de más de 20.000 habitantes con capacidad de gestión propia (que apenas son una veintena en toda la comunidad autónoma, como ya se ha dicho) es el municipio la entidad local responsable de la prestación de servicios sociales.

Como se ha señalado previamente, existen dos tipos de zonas de servicios sociales: las zonas PRAS (Plan Regional de Acción Social), que están formadas por municipios menores de 5.000 habitantes; y las zonas Plan Concertado, que además de ser municipios con mayor número de habitantes disponen de ayuntamientos con mayor capacidad de gestión. En las zonas Plan Concertado, el ayuntamiento aporta más recursos que en las zonas PRAS, lo que implica la disponibilidad de más profesionales y mayor capacidad de intervención técnica. Las zonas PRAS se corresponden con la totalidad de municipios menores de 5.000 habitantes, así como con una buena parte de los municipios inferiores a 20.000 habitantes. Las zonas Plan Concertado corresponden a los municipios de más de 20.000 habitantes y algunos con población inferior.

El sistema descrito funciona de forma relativamente diferente en la provincia de Albacete, donde existe el Consorcio Provincial de Servicios Sociales, formado por la Diputación provincial y 93 ayuntamientos y orientado básicamente a la prestación del SAD y de una serie de prestaciones complementarias (comida a domicilio, ayudas técnicas, acompañamiento y apoyo personal, etc.). Este modelo hace que, en esta provincia, la gestión del SAD sea de mayor calidad y esté más controlada que en el resto de las provincias, donde depende de cada municipio.

\section{Mecanismos de coordinación, inspección y gestión del conocimiento}

\subsection{Comunidad Foral de Navarra}

En lo que se refiere a los mecanismos de coordinación, la Ley 15/2006 establece dos organismos orientados a ese fin: el Consejo Interadministrativo de Servicios Sociales y el Comité de Ética en la Atención Social de Navarra. El primero está orientado a la coordinación interadministrativa, y entre sus funciones destacan las de informar sobre el desarrollo de los planes estratégicos, sectoriales o proponer el traspaso de algunas competencias a las entidades locales, siempre con el consentimiento de ambas partes.

Sin embargo, el desarrollo de estos dos organismos no ha sido suficiente para sentar las bases de una coordinación real en el ámbito de los servicios sociales, por lo que, a través de la Orden Foral 9/2015, se ha regulado la Comisión de Coordinación de Atención Primaria de los Servicios Sociales de Base de la Comunidad Foral de Navarra, formada por seis representantes del Departamento responsable de los servicios sociales (actualmente, la Vicepresidencia de Derechos Sociales) y siete representantes de las áreas de los servicios sociales de base. La representación de cada área será rotatoria cada dos años entre sus propias zonas, a excepción de Pamplona y comarca, que tendrán dos representantes (uno, por Pamplona, y el otro, por la comarca).

Según el artículo 3 de la citada Orden, las funciones de esta comisión, que se reúne con una periodicidad cuatrimestral (a excepción de convocatorias extraordinarias), son las siguientes:

- Constituir un foro de debate permanente sobre las necesidades, inquietudes e iniciativas dirigidas a mejorar la calidad de los servicios sociales de atención primaria.

- Estudio y propuesta de iniciativas, actividades y programas a desarrollar en los servicios sociales de base y su seguimiento y evaluación. 
- Desarrollar estrategias de formación, información y evaluación acerca de la coordinación entre los profesionales del ámbito social de los que se deduzcan, si fuera necesario, propuestas de modificación de los recursos o servicios existentes.

- Aportación de criterios técnicos relacionados con la normativa de servicios sociales, sus herramientas de gestión, etc.

- Estudio y propuesta de iniciativas relativas a las necesidades de medios materiales, personales y de formación en los servicios sociales de atención primaria.

- Análisis y proposición de recomendaciones que potencien la colaboración y cooperación con las diferentes administraciones y entidades privadas en materia de acción social y servicios sociales.

- Detectar necesidades que precisen de una respuesta conjunta dentro del ámbito social, analizarlos en común y adoptar soluciones técnicas coordinadas en su ámbito de actuación profesional, con una metodología de trabajo compartida.

- Intercambiar conocimientos acerca de las actuaciones de los grupos formales e informales de apoyo, a fin de incluirlos, en la medida de lo posible, en los procesos de coordinación, favoreciendo la solución de los problemas concretos.

- Informar sobre los nuevos recursos y servicios que puedan aparecer en las diferentes demarcaciones geográficas.

- Informar sobre el desarrollo de sus actividades de coordinación a los profesionales, así como a las asociaciones y órganos de participación comunitaria de su ámbito, como forma de que puedan efectuar las aportaciones oportunas.

Sin embargo, a pesar de las funciones establecidas en la normativa, las sesiones de la Comisión han tenido hasta el momento un mero carácter informativo, limitándose básicamente a la transmisión de información desde el Gobierno de Navarra a las representantes de cada área y dejando, por tanto, un hueco importante que hasta ahora no se ha abordado: una coordinación 'intra-área' que haga efectiva la mayoría de las funciones de la Comisión (coordinación, comunicación, detención de necesidades, etc.). Para ello, sería pertinente definir normativamente una figura de coordinación de área (con funciones, objetivos, tareas y tiempo de coordinación reconocido) que asuma además la interlocución con el Gobierno de Navarra.

Al margen de lo señalado, no se han desarrollado hasta la fecha otras estructuras de coordinación interdepartamental ni protocolos generales de actuación. Si bien es cierto que en algunas áreas, como la de atención a la infancia, sí quedan recogidos los protocolos de intervención entre los diferentes sistemas implicados (salud, educación,
Policía, etc. ${ }^{25}$, en el resto de ámbitos de actuación faltan criterios de coordinación y compromisos que vayan más allá de la propia voluntad de los profesionales. De todas estas cuestiones se desprende, por tanto, que la coordinación continúa siendo una de las debilidades del sistema de servicios sociales de Navarra.

\subsection{Catalunya}

Desde 2008, la relación entre la Generalitat de Catalunya y los entes locales gestores de áreas básicas de servicios sociales se rige mediante la figura de los contratos-programa, que tienen como base el Acuerdo Marco cuatrienal firmado entre el Departamento de la Generalitat competente en servicios sociales y las entidades asociativas municipales (Federació Catalana de Municipis y Associació de Municipis de Catalunya). Los objetivos de los contratos-programa reflejados en el Acuerdo Marco son:

- Articular los compromisos en las relaciones de coordinación y cooperación entre el Gobierno y los entes locales.

- Mejorar la calidad de los servicios públicos dirigidos a los ciudadanos y ciudadanas.

- Mejorar la eficiencia en el uso de los recursos públicos.

- Propiciar un cambio de cultura en las relaciones con los entes locales, promoviendo la corresponsabilidad y la coparticipación en las políticas sociales.

Para los entes locales, como se señala más adelante, la figura de los contratos-programa está estrechamente ligada a la financiación de los servicios sociales básicos que la Ley 12/2007 les atribuye. En ese sentido, los objetivos de los municipios con relación a esta figura son tres:

- En primer lugar, asegurar el nivel de financiación de los servicios sociales básicos, que, como se señala más adelante, no puede, de acuerdo con la Ley 12/2007, ser inferior, en ningún caso, al $66 \%$ del coste de los equipos básicos, de los programas y proyectos y de los servicios de ayuda a domicilio y de teleasistencia que establece la Cartera de Servicios.

- Un segundo objetivo de los entes locales ha sido asegurarse la financiación cuatrienal que también recoge la Ley. Hasta el momento de la firma de los contratos-programa, la aportación económica

${ }^{25}$ El desarrollo de estas acciones coordinadas ha sido posible, por un lado, por la creación de redes locales de protección o de buen trato a la infancia, que han conseguido integrar a profesionales de diferentes sistemas de protección social (algunos ejemplos con resultados muy positivos son municipios como Burlada, Estella o San Adrián). Por otro lado, también a nivel autonómico se prevén algunos protocolos de actuación en el Manual de intervención en situaciones de desprotección infantil en la Comunidad Foral de Navarra (2006). 
se negociaba años y estaba sujeta a una inseguridad que hacía muy difícil la planificación y el compromiso a largo término de los entes locales. En el Acuerdo Marco, se consigue que el Gobierno de la Generalitat de Catalunya apruebe un compromiso de gasto plurianual que asegura la financiación para cuatro años.

- Finalmente, los entes locales han conseguido asegurarse el reconocimiento y la financiación de los servicios especializados propios mediante su inclusión en el contrato-programa y la consideración de que son prestados por delegación de la Generalitat. A este efecto, el contrato se estructura hasta en un máximo de 25 apartados (fichas), que recogen las obligaciones de financiación de diferentes prestaciones y funciones de los servicios sociales municipales.

Un reto pendiente del contrato-programa es convertirse en un instrumento de planificación y control de los servicios prestados por los municipios. Aunque en todas las fichas se incluyen objetivos que cumplir e indicadores para poder evaluarlos, en la realidad su formulación no es la mejor para la función que se les ha encomendado, limitándose en general al enunciado de objetivos y metas de proceso, y no recogiéndose indicadores de impacto con relación al resultado que se quiere lograr.

Además de la figura del contrato-programa, el Decreto 202/2009, de 22 de diciembre, de Órganos de Participación y Coordinación del Sistema Catalán de Servicios Sociales desarrolla los órganos de coordinación y participación ya incluidos en la Ley 12/2007. Entre ellos, cabe destacar el Consejo General de Servicios Sociales, el Consejo de Coordinación de Bienestar Social y el Comité de Evaluación de Necesidades de Servicios Sociales. Este decreto regula también los Consejos Municipales de Servicios Sociales, así como los Consejos Supramunicipales, para las comarcas o las asociaciones de municipios que integran una misma zona básica de servicios sociales.

Además, cabe hacer referencia al Modelo de servicios sociales básicos de Catalunya (2015) publicado por la Generalitat. El objetivo de ese documento es el de construir un marco de ordenación común y comprensible que facilite y oriente las prioridades del sistema catalán de servicios sociales, mediante el establecimiento de unos mínimos que permitan a las administraciones locales comparar y analizar su situación con relación a unos estándares amplios y flexibles, pero al mismo tiempo, concretos. Aunque se plantea como un modelo abierto, sujeto a revisión, el texto plantea que, una vez aprobado, debería constituir la base de un posterior proceso de regulación. Los contenidos de esa normativa serían básicamente los que aborda el modelo: criterios de prestación y acceso a los servicios, organización de los equipos de trabajo, requerimientos de los equipamientos y requisitos del sistema de información.
Por otra parte, antes ya se ha hecho referencia al papel que juega la Diputación de Barcelona en lo que se refiere al asesoramiento técnico de las administraciones municipales en el ámbito de los servicios sociales. Cabe destacar, en ese sentido, las actuaciones de supervisión y formación de equipos y de evaluación de servicios que se realizan mediante los Círculos de Comparación Intermunicipal de Servicios Sociales. Impulsados por la Diputación de Barcelona, los Círculos de Comparación Intermunicipal de Servicios Sociales son grupos estables de municipios que trabajan por la mejora de los servicios sociales a partir de la comparación de indicadores que reflejan su actuación y del intercambio y contraste de las prácticas que sustentan esta actividad. Participan en esa red 55 ayuntamientos de más de 10.000 habitantes. Los Círculos de Comparación de Servicios Sociales desarrollan la técnica de la comparación y la mejora continua que persigue la búsqueda de la mejor práctica y los mejores resultados para mejorar la actuación de todos los participantes. En ese sentido, desde 2001 los ayuntamientos de la provincia de Barcelona trabajan conjuntamente para:

- Definir indicadores que reflejen la actividad que desarrollan.

- Medir los resultados obtenidos anualmente.

- Comparar los resultados y destacar los mejores.

- Buscar las mejores prácticas asociadas a los mejores resultados.

- Definir cuáles serían los resultados deseables.

El trabajo de estos círculos se traduce, entre otras cuestiones, en la publicación de un cuadro resumen de indicadores de servicios sociales municipales relativos a los servicios sociales básicos, la atención a domicilio y los centros abiertos, que recoge más de un centenar de indicadores, actualizados cada año, con relación a la financiación de los servicios, la satisfacción de las personas usuarias, la dotación de profesionales y sus condiciones de trabajo, la cobertura de los servicios o los procedimientos de acceso (listas de espera, tiempos medios de espera para la realización de entrevistas, etc.). En el marco de esta iniciativa, se publica un informe anual que recoge tanto la metodología seguida como los resultados agregados - no detallados por cada municipio- que se han obtenido, señalándose las áreas que requieren ser mejoradas.

Por otra parte, al margen del papel que la Diputación de Barcelona juega en este ámbito con los Círculos de Comparación Intermunicipal, existen numerosas iniciativas y mecanismos puestos en marcha por la Generalitat de Cataluña para la coordinación con los servicios sociales municipales y, particularmente, para la gestión del conocimiento en este ámbito. Se señalan de forma muy sucinta algunas de esas herramientas que, si bien generalmente están impulsadas por la Generalitat, implican de forma directa a los servicios sociales municipales y comarcales: 
- El Sistema de Información Social de Cataluña (Proyecto Hércules) es un sistema de información común, compartido, compartible y coordinado que garantiza la disponibilidad de la información relativa a las prestaciones de la Cartera de Servicios Sociales, la privacidad de los datos y la seguridad en el intercambio de información entre los agentes implicados, y la integración de los datos relativos a la atención del sector público y privado, con los objetivos de evitar duplicidades y mejorar la atención a los destinatarios de los servicios sociales. El sistema de información se articula en función de diversas herramientas, como el Cuadro de Seguimiento de la Cartera (QSCart) o el Registro Unificado de Datos de los Entes Locales (RUDEL).

- Mapa de Servicios Sociales. El Mapa de Servicios Sociales, que se actualiza anualmente, es el documento que contiene los datos básicos de la oferta del sistema catalán de servicios sociales ${ }^{26}$. Está estructurado en servicios sociales básicos y servicios sociales de atención especializada, proporciona datos exhaustivos y actualizados de los recursos disponibles en el sistema. Los datos se actualizan con carácter anual y se presentan separados por territorio. Esta información clave permite fundamentar las mejoras en los servicios, adecuar la participación y las actuaciones de todos los agentes que intervienen, ajustar las políticas sociales a la realidad cambiante y, en general, actuar de manera más eficiente frente a las necesidades sociales. Con relación a los servicios sociales básicos, el Mapa ofrece información - para cada zona básica de servicios socialessobre la dotación de profesionales (trabajadores o trabajadoras sociales y educadores o educadoras), las horas de SAD prestadas, las problemáticas atendidas, las personas y unidades familiares atendidas, las plazas disponibles en los servicios de estancia limitada, etc.

- Informe anual sobre la situación de los servicios sociales en Cataluña. De acuerdo con lo establecido en el artículo 50 de la Ley 12/2007, este informe recoge anualmente información tanto sobre las situaciones de necesidad social como sobre la acción del sistema catalán de servicios sociales. Se basa tanto en las fuentes estadísticas disponibles como en la que se deriva del Mapa de Servicios Sociales.

- El Centro de Documentación de Servicios Sociales DIXIT es una iniciativa del Departamento de Bienestar Social y Familia que se dirige a los y las profesionales de los servicios sociales para promover la gestión y la difusión del conocimiento en el ámbito del bienestar social, la promoción de la autonomía y la atención a la dependencia. DIXIT tiene los siguientes objetivos generales:

26 Mientras que el Mapa de Servicios Sociales de la Comunidad Autónoma de Euskadi tiene un carácter básicamente normativo, orientado a ordenar el despliegue territorial de los servicios sociales vascos y sus dotaciones mínimas, el Mapa de Servicios Sociales de Catalunya tiene un carácter básicamente descriptivo y analítico. a) potenciar la difusión, el intercambio y la generación de conocimiento en el ámbito de los servicios sociales y los derechos de la ciudadanía; b) liderar la transmisión de conocimiento y la igualdad de oportunidades en todo el territorio; c) promover la creación de una red de profesionales y favorecer canales de participación; d) preservar y explotar el conocimiento generado por el Departamento de Bienestar Social y Familia.

\subsection{Galicia}

En el plano organizativo, cabe destacar la existencia en la administración autonómica gallega de una unidad administrativa, el Servicio de Coordinación de Servicios Sociales Comunitarios, que tiene como función específica la coordinación de dichos servicios sociales, pues desde esta unidad se ofrece asesoramiento, orientación, información, formación y apoyo técnico a las y los profesionales de los servicios sociales comunitarios, básicos y específicos, para el desarrollo de programas y servicios en sus municipios.

Por otro lado, en lo que se refiere a las herramientas técnicas, el sistema gallego de servicios sociales también cuenta con programas informáticos que sirven de herramientas de coordinación, como la aplicación Sistema de Información de Usuarios de Servicios Sociales (SIUSS), que se utiliza en todos los ayuntamientos de Galicia y permite la recogida de los datos básicos de las personas usuarias de los servicios sociales comunitarios: toda la información relativa a las personas, a sus demandas, a las valoraciones profesionales y a los recursos idóneos y/o aplicados. El programa se configura a través de expedientes familiares y permite a las/los profesionales del trabajo social y demás técnicos que forman parte del equipo interdisciplinar, realizar la gestión integral de las situaciones en las cuales intervienen profesionalmente.

Otro programa informático en línea, denominado Servicios Sociales Comunitarios Municipales (SSCM), articula la gestión de las prestaciones básicas y complementarias de los servicios sociales comunitarios, permitiendo a las entidades locales titulares de servicios sociales comunitarios presentar su planificación anual y su correspondiente petición de financiación a la comunidad autónoma y, posteriormente, realizar la evaluación cuantitativa y cualitativa sobre los servicios efectivamente financiados y prestados.

Asimismo, el Manual de Trabajo, Información y Asesoramiento de Servicios Sociales (MATIASS), que es una web autonómica de referencia para la divulgación de información técnico-profesional en materia de servicios sociales en Galicia, constituye un instrumento de coordinación muy valioso, en la medida que proporciona apoyo técnico al profesional de los servicios sociales, favoreciendo su actualización y formación continua y facilitándole 
documentos técnicos de referencia, así como la descarga de modelos y formularios homologados editables para la gestión de servicios y prestaciones.

Por último, también tiene virtualidad de instrumento de coordinación el Registro Unificado de Entidades Prestadoras de Servicios Sociales (RUEPSS), que recoge la información referida a las entidades que desarrollan programas o son titulares o gestoras de centros o programas de servicios sociales en los siguientes ámbitos: personas mayores, discapacidad, igualdad, infancia, menores, familia, inclusión y servicios sociales comunitarios. Ello es así porque este registro facilita al público y a los y las profesionales de servicios sociales información y orientación útil para el acceso a los recursos sociales existentes en soporte electrónico, a través de la web.

En relación con la coordinación con otros sistemas de bienestar (educación, sanidad, vivienda...), en Galicia se han articulado las siguientes herramientas de coordinación:

- El Protocolo de Actuación para Profesionales de los Servicios Sociales para la Atención de Mujeres que Sufren Violencia de Género.

- Las guías de intervención ante distintas situaciones de vulnerabilidad, en las que intervienen, además de servicios sociales o de salud, el sistema judicial. Estas guías son:

- La guía sobre intervención en situaciones de maltrato infantil.

- La guía de actuación coordinada contra el maltrato de personas mayores o adultas con discapacidad.

- La guía informativa sobre protección jurídica y discapacidad.

- El Protocolo de Coordinación, Intervención y Derivación Interinstitucional en Atención Temprana, firmado por las consellerías de Política Social, Sanidad y Educación.

\subsection{Castilla y León}

Desde el punto de vista de las herramientas de coordinación, se vienen desarrollando en Castilla y León las siguientes iniciativas:

- Acceso unificado al sistema a través de los centros de acción social (CEAS). Implica que la primera atención se realice desde el sistema público y con una actuación profesional, lo que garantiza el acceso de los ciudadanos y ciudadanas en condiciones de igualdad.

Se prevé la homogenización de los instrumentos y herramientas de valoración e intervención entre los agentes para lograr una actuación coordinada y eficaz en la atención de los casos y un acceso y contenido unificado en las prestaciones.

- Sistema unificado de información. La plataforma SAUSS se convierte en el registro único de personas usuarias de los servicios sociales, registro compartido por los agentes y profesionales del sistema. Esta plataforma integra la denominada 'historia social única' de la persona y conecta con otras herramientas informáticas de gestión de servicios y prestaciones como los módulos informáticos de protección a la infancia, la valoración de la situación de dependencia y la renta garantizada de ciudadanía (RGC), la gestión y provisión del Servicio de Ayuda a Domicilio y la gestión de las prestaciones económicas para la atención de necesidades básicas de subsistencia en situaciones de urgencia social. En la actualidad, el acceso se puede realizar a través de las entidades locales y las gerencias de servicios sociales, y también a través de los profesionales responsables en la comunidad de la atención a las situaciones de violencia de género, los profesionales del Servicio Integral de Apoyo a las Familias en Situación de Desahucio y los Equipos de Promoción de la Autonomía Personal (EPAP).

- Decreto regulador de la historia social única. El borrador de este Decreto define la historia social única como "el instrumento documental en el que se registran los datos personales, familiares, de necesidades sociales, prestaciones y seguimientos y cualesquiera otros significativos de la situación sociofamiliar de un usuario, la demanda, el diagnóstico y subsiguiente intervención y la evaluación de la situación”. La historia social única será electrónica y estará integrada en SAUSS. El decreto regulará la información que contiene la historia, el tratamiento de las anotaciones subjetivas de los profesionales, la información contenida de terceros, la cesión de datos a terceros miembros del sistema y de otras administraciones públicas, el acceso de los agentes del sistema y el acceso de la persona titular de la historia social única, entre otros aspectos.

- Para la gestión de la actividad sociosanitaria, se ha articulado un sistema de información y conexión informática entre los centros de salud y los CEAS, que conforman los Equipos de Coordinación de Base (ECB), destinada a facilitar el trabajo conjunto entre los profesionales. Principalmente, se comparten las Guías de Gestión Compartida de Casos y las actas de las reuniones. Esta herramienta permite identificar y atender los casos que precisan gestión coordinada entre ambos sistemas, lo que resulta especialmente útil para la planificación en recursos sociosanitarios.

\subsection{Castilla-La Mancha}

En cuanto a herramientas de planificación, diagnóstico y control de calidad, puede decirse que nunca han existido como tales, más allá de las responsabilidades de asignación y control de ejecución presupuestaria de la propia Consejería. El 
único mecanismo que la Junta de Castilla-La Mancha ha utilizado (y sigue utilizando) son las reuniones periódicas entre los profesionales de referencia de las zonas (trabajadores o trabajadoras sociales) que mensualmente realizan reuniones de área para coordinar actuaciones o criterios de intervención. Dos veces al año las direcciones provinciales de servicios sociales básicos se reúnen con los profesionales de las zonas y áreas para transmitir líneas de actuación, prioridades, criterios de acción, informar sobre convocatorias y bases reguladoras de ayudas, etc.

Por otra parte, en las delegaciones provinciales ${ }^{27} \mathrm{de}$ Bienestar Social existe personal técnico responsable para todas y cada una de las prestaciones y servicios (jefatura de servicios básicos y jefaturas de los diversos servicios especializados), a través de los cuales se suben y bajan líneas de acción o se recogen sugerencias, y que son los responsables de tramitar las derivaciones y asignaciones de prestaciones especializadas en la provincia. Es decir, todo lo que no son servicios de atención primaria municipal se gestionan a través de las direcciones provinciales, de las que dependen los centros y recursos especializados (recursos ubicados generalmente en las capitales de provincia $)^{28}$.

En lo que se refiere a la coordinación de los profesionales, sólo existen dos vías de coordinación interna entre los diferentes niveles de prestación de los servicios municipales:

- Una coordinación técnica entre profesionales de zonas que pertenecen a un área (mediante reuniones semanales o quincenales de apoyo mutuo y puesta en común, aunque sin protocolo preestablecido) y otra coordinación técnica entre los profesionales responsables de las áreas y la jefatura de servicios básicos de cada delegación provincial (servicio periférico), realizada también a través de reuniones sin protocolizar (se realizan una o dos rondas de visitas a cada área durante el año).

- Una coordinación técnico-política entre las direcciones generales de la Consejería (ubicada en Toledo) y las diferentes direcciones provinciales de los servicios periféricos, que a su vez transmiten a los profesionales las directrices de la Consejería mediante las reuniones de áreas y jefaturas del servicio en cada provincia y mediante dos reuniones anuales que cada dirección provincial organiza para informar a todos los trabajadores y trabajadoras sociales de las zonas de las diversas convocatorias de ayudas y subvenciones de la consejería, normativas nuevas, regulación de órdenes, etc. que les pueden afectar y son de su competencia.

${ }^{27}$ Son delegaciones de las diferentes consejerías que actualmente se denominan Direcciones Provinciales de Servicios Periféricos.

${ }^{28}$ Muy pocos ayuntamientos de la región tienen algún certificado de calidad, que afecta en todo caso a la administración municipal en su conjunto, no específicamente a los servicios sociales.
Cabe subrayar, por último, que no existen protocolos de coordinación externa con servicios como educación o sanidad. Son los profesionales en cada zona los que se encargan de contactar con escuelas o centros de salud si en los casos de acompañamiento o intervención familiar que atienden lo consideran necesario ${ }^{29}$.

\section{Financiación}

\subsection{Comunidad Foral de Navarra}

En el ámbito de la atención primaria, el modelo de financiación de los servicios sociales de Navarra distingue entre la financiación de las infraestructuras y la de los servicios sociales de base. En lo que se refiere a las infraestructuras, su financiación corre a cargo de los presupuestos generales de Navarra (tanto las de carácter público como privado), siempre que estén establecidas como tales en el Plan Estratégico de Servicios Sociales.

Por su parte, los cuatro programas de atención primaria son cofinanciados por la administración autonómica y las entidades locales. La cantidad aportada por la administración foral se establece mediante convenios plurianuales, y nunca podrá ser inferior al $50 \%$ del coste de los cuatro programas de obligado desarrollo. La valoración económica del programa, aunque se establece mediante convenios plurianuales, es anual.

El procedimiento para determinar la aportación exacta se recoge en el Decreto Foral 32/2013, de 22 de mayo, por el que se aprueba el reglamento de desarrollo de la Ley Foral de Servicios Sociales en materia de programas y financiación de los servicios sociales de base. De acuerdo con esta norma, la financiación de las zonas básicas de servicios sociales (ayuntamientos y/o mancomunidades) para el desarrollo de los cuatro programas de atención primaria se define a partir de dos tramos: un tramo fijo en función del coste estimado de los programas y un tramo variable, determinado a partir de una serie de indicadores establecidos en el decreto: dispersión, envejecimiento, infancia, incorporación social, población atendida, inmigración y presupuesto destinado a la financiación de los programas (en este caso, el presupuesto se refiere a lo que aporta cada ayuntamiento, no cada zona básica). Estos datos se determinarán anualmente a partir de las estadísticas de Gobierno de Navarra y

29 El 21 de octubre de 2015 se firmó un acuerdo de colaboración entre la Consejería de Bienestar Social, la Consejería de Fomento, el Colegio de Abogados y el Colegio de Trabajo Social en virtud del cual se decide centralizar recursos de atención antes dispersos, en seis oficinas de intermediación hipotecaria: la atención social y la asistencia jurídica gratuita ya existentes se coordinarán desde estas oficinas que no representan la creación o dotación adicional de profesionales o recursos, sino que se crean para aumentar la facilidad y rapidez de acceso de las familias en proceso de desahucio a las ayudas sociales y a la asistencia jurídica gratuita. Es el único protocolo de coordinación externa existente, aunque no se puede valorar su implementación, ya que acaba de firmarse. 
de las memorias anuales entregadas por cada zona básica.

El porcentaje mínimo del $50 \%$ de financiación fija autonómica podrá ampliarse hasta el $80 \%$ (asumiendo el $20 \%$ restante para las entidades locales) en las denominadas zonas de especial actuación. Tiene esta consideración las zonas que, según Decreto Foral 33/2010, de 17 de mayo, por el que se establece la zonificación de servicios sociales de la Comunidad Foral de Navarra, tienen menos de 5.000 habitantes. Sin embargo, el Decreto Foral que establece la financiación señala que también podrán ser consideradas como zonas de especial actuación aquellas zonas básicas cuya población sea igual o superior a 5.000 habitantes e inferior a 5.100 habitantes (donde se financiará el $70 \%$ del coste estimado de los programas y el importe correspondiente al tramo variable), así como aquellas zonas básicas cuya población sea igual o superior a 5.100 habitantes e inferior a 5.200 habitantes (donde se financiará el $60 \%$ del coste fijo estimado además de lo previsto al tramo variable) ${ }^{30}$.

Como antes se ha señalado, el tramo fijo de financiación se determina a partir de los Equipos Mínimos Interprofesionales de Atención Primaria necesarios para el desarrollo de los cuatro programas obligatorios en cada territorio. Como contrapartida, las zonas básicas deberán justificar todo gasto y actuación recogida en el convenio a través de una memoria económica y técnica anual. Para la entrega de la memoria, se establece un plazo determinado, cuyo incumplimiento puede llevar a perder el derecho a la financiación (se establece un plazo de tres meses para subsanarlo, aunque la cuantía a financiar se va reduciendo progresivamente si la subsanación se demora). En lo que se refiere a los servicios sociales especializados, es financiada al $100 \%$ por la administración titular de los servicios, que en general es la administración autonómica, si bien, como se ha dicho, las administraciones municipales también pueden desarrollar, si lo desean, servicios especializados adicionales.

Además de la financiación del departamento competente de Gobierno de Navarra y de los ayuntamientos titulares de los servicios sociales de base, también existen otras vías de financiación vinculadas a proyectos e intervenciones concretas. A modo de ejemplo, dentro de las funciones de los programas de atención primaria se establece en desarrollo de acciones de prevención de drogodependencias. Para estas acciones el Instituto Navarro de Salud Pública cuenta con fondos a los que pueden suscribirse, con la presentación previa de un plan de acción, los servicios sociales de base. En estos casos una parte de la financiación corre a

${ }^{30}$ Por otro lado, en el caso de Pamplona, la zona básica se corresponderá con cada barrio (ya que en cada uno de ellos hay desarrollado una unidad básica de servicios sociales). Asimismo, las zonas de más de 30.000 habitantes tendrán consideración de dos zonas básicas. cargo del Departamento de Salud de Gobierno de Navarra y otra es asumida por las entidades locales. La financiación de funciones definidas en la Ley de Servicios Sociales por otros departamentos es un hecho controvertido $\mathrm{y}$, en ocasiones, complejo de gestionar, debido a que no existe ninguna coordinación con el departamento competente de la política social autonómica, asumiéndose ésta exclusivamente por el Departamento de Salud y las entidades locales. A esta dificultad se le añade que, según las experiencias relatadas, no existe un criterio único para la financiación de estas acciones, por lo que en la práctica es posible encontrar cómo en una zona se apoya económicamente la contratación de educadores y educadoras mientras que en otra la cuantía se destina al desarrollo de otras actividades vinculadas con el ámbito de actuación financiado.

Por último, cabe señalar que las prestaciones garantizadas por la legislación estatal en materia de dependencia que se incluyan dentro de los programas de atención primaria serán financiadas íntegramente por la administración foral y los servicios especializados y las prestaciones complementarias desarrolladas por los entes locales serán financiadas por éstos. Con relación a esta última cuestión cabe señalarse que, en la práctica, la creación y financiación de servicios adicionales por los entes locales depende de la capacidad económica, iniciativa, interés, trayectoria, etc. de las entidades locales ${ }^{31}$. Ello da lugar a que la homogeneidad territorial continúe siendo en Navarra una asignatura pendiente, debido a que, por ejemplo, además de las ayudas autonómicas los ayuntamientos pueden tener ayudas de emergencia propias (con condicionados diferentes en cada ayuntamiento), dando lugar a una situación de desigualdad en el acceso a recursos. Del mismo modo, esta diversidad se observa de manera muy intensa en el desarrollo de programas de prevención e intervención comunitaria como escuelas de familias, ludotecas o apoyos escolares, las cuales muestran un desarrollo muy desigual entre zonas básicas de servicios sociales o municipios.

\subsection{Catalunya}

La cuestión de la financiación de los servicios sociales municipales en el caso catalán se ha abordado ya al analizar la figura de los contratosprograma. Con relación a esta cuestión, la Ley 12/2007 regula de esta forma, en su artículo 62, la financiación de los servicios sociales básicos:

- Los ayuntamientos y la Generalitat comparten la financiación de los servicios sociales básicos,

${ }^{31}$ Algunos de estos programas en ocasiones pueden estar también financiados o cofinanciados por partidas autonómicas de otros departamentos, como es el caso del empleo social protegido, financiado por el Servicio Navarro de Empleo. Los ayuntamientos, a iniciativa propia, deben presentar un proyecto, en este caso de contratación de personas en procesos de incorporación social, para optar a la posible financiación. 
incluidos los equipos de servicios sociales, los programas y proyectos, el servicio de ayuda a domicilio y los demás servicios que se determinen como básicos ${ }^{32}$. Sin perjuicio de que los servicios sociales básicos deben tender a la universalidad y gratuidad, el usuario o usuaria puede tener que copagar la financiación de la teleasistencia y de los servicios de ayuda a domicilio.

- La aportación de la Generalitat a los servicios sociales básicos debe fijarse en sus presupuestos, de acuerdo con lo que establezcan el Plan Estratégico de Servicios Sociales y la Cartera de Servicios Sociales, y debe pagarse mediante un convenio cuatrienal con la corporación local titular del área básica de servicios sociales. Esta aportación no puede ser inferior, en ningún caso, al $66 \%$ del coste de los equipos de servicios sociales básicos, de los programas y proyectos, y de los servicios de ayuda a domicilio y de teleasistencia que el Plan y la Cartera establecen para el ámbito territorial de cada área básica de servicios sociales.

- La financiación de la infraestructura, de los locales, del material, del mantenimiento del sistema de información, del apoyo administrativo y de las prestaciones económicas de urgencia social corre a cuenta del ente local gestor del área básica de servicios sociales.

- Si al final del ejercicio anual la ratio de personal de los equipos o el volumen de la actividad de los diferentes servicios, programas y proyectos no alcanza el mínimo establecido por el convenio, el importe correspondiente debe deducirse del siguiente pago de la Generalidad y deben adoptarse las medidas necesarias para la prestación del servicio público. Asimismo, la Generalitat debe incluir unos suplementos en sus pagos si las ayudas económicas para emergencias sociales que otorga el ente local lo justifican. Lo establecido por el presente apartado debe cumplirse respetando los términos del convenio cuatrienal entre ambas administraciones.

- El ente local titular del área básica de servicios sociales puede decidir el sistema de provisión de servicios para la ayuda a domicilio y la teleasistencia, de acuerdo con las formas de prestación que se establezcan por reglamento.

Por lo que respecta al nivel de financiación de los servicios sociales básicos, se observa en los últimos años un mayor compromiso por parte de las administraciones supramunicipales. A pesar de la variabilidad a lo largo de los años (producto de las dificultades en la imputación de ingresos por parte de los entes locales), se observa una tendencia ascendente. Entre 2012 y 2014 el gasto por habitante destinado a los servicios sociales básicos ha oscilado

32 Como en el caso de las demás comunidades de régimen común, la Generalitat recibe con carácter finalista por parte de la Administración central una financiación específica para el sostenimiento de los servicios sociales locales mediante el Plan Concertado de Servicios Sociales. entre los 45 y los 49 euros anuales - esta cantidad incluye, además de las prestaciones garantizadas de cartera de los servicios sociales básicos, los gastos en estructura (dirección, personal administrativo y de apoyo, infraestructuras, etc.) y de programas propios que no está financiada por el contrato-programa-. En torno al $50 \%$ de este gasto es directamente financiado por las administraciones locales, lo que supone un porcentaje superior al $33 \%$ establecido por la Ley $12 / 2007$.

\subsection{Galicia}

Los servicios sociales comunitarios municipales se sustentan sobre las siguientes fuentes de financiación:

- Las aportaciones municipales, procedentes de los créditos consignados en los presupuestos municipales por los propios ayuntamientos titulares de los servicios con cargo a sus recursos propios.

- Otras aportaciones locales, fundamentalmente las subvenciones de las diputaciones provinciales a los ayuntamientos de menos de 20.000 habitantes, prioritariamente destinadas a la financiación del SAD básico y a la contratación de personal técnico con perfil profesional diferente y complementario al del trabajador o trabajadora social de referencia.

- Las aportaciones autonómicas, procedentes de los presupuestos de la comunidad autónoma y de la cofinanciación de la Administración del Estado, a través del Plan Concertado de Prestaciones Básicas de Servicios Sociales de Corporaciones Locales y de una parte los fondos del Imserso para la atención a la dependencia (la que cofinancia el SAD-dependencia).

- Los recursos financieros generados por los ingresos que, en concepto de copago, realicen las personas usuarias de estos servicios. Con todo, estos recursos se integran dentro de las aportaciones municipales, ya que son los ayuntamientos quienes los recaudan.

La financiación municipal con cargo de los recursos propios está en función de lo que cada corporación aprueba en sus presupuestos anuales.

La financiación de las diputaciones provinciales se determina cada año en sus convocatorias de subvenciones y, en los últimos años, se aprecia un esfuerzo por mantener una financiación continua y estable para apoyar estos servicios.

La financiación autonómica de los servicios sociales municipales se regula en el capítulo VIII del Decreto 99/2012, que articula un cambio de modelo de financiación, sustituyendo la tradicional convocatoria anual de subvenciones por transferencias finalistas de ciclo anual, establecidas por una norma con vigencia indefinida, 
lo que ha venido a aportar calidad, continuidad y estabilidad a la prestación de los servicios sociales comunitarios. De acuerdo con el Decreto, podrán ser beneficiarias de dichas transferencias finalistas las corporaciones locales de Galicia titulares de los servicios sociales comunitarios, diferenciándose entre transferencias corrientes y transferencias de capital. Las transferencias de capital tienen como finalidad nuevas inversiones en centros de servicios sociales, su equipamiento o la adaptación y mejora de la accesibilidad de las instalaciones, mientras que las transferencias corrientes financian los gastos de funcionamiento de los servicios sociales comunitarios: gastos de personal, de prestación del SAD-básico y SAD-dependencia, sostenimiento de otros programas de actuación comunitaria...

En lo que se refiere a las transferencias finalistas corrientes, se regula un procedimiento general mediante el que se gestiona la financiación de los servicios sociales comunitarios municipales con cargo a los presupuestos de la comunidad autónoma y a la cofinanciación que aporta el fondo ministerial para el desarrollo de las prestaciones básicas de servicios sociales de corporaciones locales (el denominado Plan Concertado). Esta financiación se articula mediante el proyecto anual de servicios sociales comunitarios municipales que presenta anualmente cada corporación local, con el objetivo prioritario de garantizar la continuidad y estabilidad de estos servicios, en particular mediante la renovación anual de la 'financiación básica' (trabajadores y trabajadoras sociales de referencia en todos los ayuntamientos $y$, en ayuntamientos de 20.000 o más habitantes, equipos técnicos multidisciplinares y SAD-básico), tomando como referencia, para cada anualidad, los servicios sociales comunitarios financiados, efectivamente prestados y correctamente justificados en el ejercicio inmediatamente anterior.

Además, también se regula otro procedimiento específico de transferencias finalistas destinadas a la financiación del SAD, que se financia con cargo a los presupuestos de la comunidad autónoma y a la cofinanciación del Imserso, y cuya cuantía se determina en función de las horas de atención efectivamente prestadas y registradas por cada corporación local en un sistema de información compartido entre la comunidad autónoma y las corporaciones locales titulares de los servicios.

Finalmente, cabe señalar con relación a la financiación de los servicios sociales municipales que la participación económica de las personas usuarias está regulada a nivel autonómico, siendo relativamente pequeño el margen de maniobra que al respecto tienen las autoridades locales. En ese sentido, el Decreto 99/2012 regula un copago obligatorio para el SAD, con un régimen diferente según se trate de SAD-dependencia (en este caso, a los ayuntamientos no se les deja ningún margen regulatorio) o SAD-básico (en este caso, los ayuntamientos tienen que cumplir unos mínimos, pero tienen mayor flexibilidad para concretar el régimen de copago). No obstante, en ambos casos se establece una regulación progresiva de la participación económica de la persona usuaria en el coste del servicio a través del copago en función de su capacidad económica. Este decreto deja también abierta la posibilidad de establecer un copago para otros servicios, pero siempre sujeto a las siguientes reglas:

- Los servicios se prestarán de forma gratuita para todas las personas usuarias cuya capacidad económica, calculada en términos de renta per cápita familiar, sea igual o inferior al $80 \%$ del indicador público de renta de efectos múltiples (IPREM).

- La regulación municipal del copago tendrá en todo caso carácter progresivo, en función de la capacidad económica.

- El límite máximo a la participación económica de las personas usuarias en el coste de los servicios será el $40 \%$ de su capacidad económica.

- Se declaran expresamente exentos de copago los siguientes servicios sociales comunitarios (“en ningún caso se les aplicará el copago"):

- Programa de valoración, orientación e información.

- Servicio de educación y apoyo familiar.

- Programa básico de inserción social.

- Servicios sociales específicos de apoyo psicosocial y familiar vinculado a la atención temprana.

\subsection{Castilla y León}

La Ley de Servicios Sociales de Castilla y León regula, mediante el artículo 110, las bases para la financiación del sistema de servicios sociales, estableciendo los servicios que deben ser cofinanciados por la administración de la comunidad autónoma y los municipios, al tiempo que establece los porcentajes que cada institución debe aportar a su financiación. La Ley señala que la comunidad autónoma debe cofinanciar aquellos servicios de titularidad municipal que hayan sido calificados como esenciales dentro del sistema de servicios sociales. La Tabla 1 muestra cuáles son estos servicios e indica los porcentajes de participación de cada Administración en su financiación.

Además, la Ley señala que es la Junta de Castilla y León quien debe fijar el coste estimado para cada servicio, estableciendo un módulo-tipo de coste para cada prestación, siempre tomando como base un informe emitido por el Consejo de Coordinación Interadministrativa del Sistema de Servicios Sociales y el Comité Consultivo de Atención a la Dependencia. La fijación de dicha cuantía sirve, a su vez, para establecer el límite máximo que la Junta puede destinar a la financiación de cada uno de los servicios. No obstante, también se permite que las 
Tabla 1. Castilla y León. Cofinanciación de los servicios esenciales de competencia municipal según el artículo 110 de la Ley $16 / 2010$

\begin{tabular}{|c|c|c|c|}
\hline \multirow{2}{*}{\multicolumn{2}{|c|}{ Servicio }} & \multicolumn{2}{|c|}{ Financiación } \\
\hline & & Junta de Castilla y León & Municipios \\
\hline \multirow[b]{2}{*}{ Centros de acción social } & Personal técnico & $100 \%$ & - \\
\hline & $\begin{array}{l}\text { Personal administrativo } \\
\text { y auxiliar }\end{array}$ & - & $100 \%$ \\
\hline $\begin{array}{l}\text { Equipos Multidisciplinares Específicos de las áreas de } \\
\text { servicios sociales }\end{array}$ & Personal técnico & $100 \%$ & - \\
\hline Ayudas a Domicilio & & $90 \%$ & $10 \%$ \\
\hline Apoyo a la Convivencia y a la Participación & & $90 \%$ & $10 \%$ \\
\hline $\begin{array}{l}\text { Prestaciones de sensibilización y promoción de la } \\
\text { solidaridad y el apoyo informal }\end{array}$ & & $65 \%$ & $35 \%$ \\
\hline Prevención & & $65 \%$ & $35 \%$ \\
\hline Ayudas económicas de emergencia social & & $65 \%$ & $35 \%$ \\
\hline Acogimiento de Urgencia para Personas sin Alojamiento & & $65 \%$ & $35 \%$ \\
\hline Teleasistencia & & $65 \%$ & $35 \%$ \\
\hline
\end{tabular}

Fuente: Ley 16/2010 de Servicios Sociales de Castilla y León.

administraciones locales puedan recurrir a formas de financiación complementaria para mejorar las prestaciones cuya financiación está expresamente regulada por la Ley de Servicios Sociales.

\subsection{Castilla-La Mancha}

La participación de las diferentes administraciones en la financiación de los servicios sociales de atención primaria depende del tipo de zona (es decir, del volumen de habitantes de cada municipio):

- En las zonas PRAS, la financiación es prácticamente en su totalidad autonómica ${ }^{33}$.

- En las zonas Plan Concertado, todo el personal de servicios sociales es municipal (ya sea funcionario o contratado), pero la financiación es compartida entre el ayuntamiento y la Junta de CastillaLa Mancha. La financiación es $80 \%$ regional y $20 \%$ municipal si se trata de municipios medianos, o $60 \%$ regional y $40 \%$ municipal si se trata de municipios grandes ${ }^{34}$.

Excepto los servicios de información, orientación, valoración y acompañamiento, el resto de las prestaciones están sujetas a copago, ya sea de manera expresa o encubierta.

${ }^{33}$ En estas áreas, la financiación y la contratación del personal y el kilometraje de sus desplazamientos corresponde a la administración autonómica. Podríamos decir que el $98 \%$ del coste corriente total de los servicios sociales en este tipo de zonas lo sostiene y gestiona de forma directa la administración autonómica, si bien las infraestructuras y equipamientos corresponden a los propios municipios. El personal de ayuda a domicilio es contratado por los ayuntamientos, que financian en todo caso este gasto mediante un convenio específico, en el que se regulan los precios públicos para este servicio, entre la Junta de Castilla-La Mancha y el ayuntamiento en cuestión.

34 Es importante señalar a este respecto que, como antes se ha indicado, la administración autonómica recibe, mediante el Plan Concertado, financiación finalista por parte de la administración central.

\section{Conclusiones: similitudes, diferencias, retos comunes y posibles aprendizajes}

\subsection{Dificultades y retos de los servicios sociales municipales en Navarra, Galicia, Catalunya, Castilla-La Mancha, y Castilla y León ${ }^{35}$}

Los expertos y expertas que han colaborado en la elaboración de este artículo, describiendo el modelo de servicios sociales de atención primaria que existe en cada comunidad, han reflexionado también sobre las dificultades y los retos que tienen planteados los servicios sociales municipales de sus respectivas comunidades. Si bien en algunos casos se trata de retos o problemas muy específicos, que afectan a territorios muy concretos, en la mayoría de los casos se trata de problemas comunes y relativamente generalizados, que en buena parte afectan también a los servicios sociales municipales de la Comunidad Autónoma de Euskadi.

Los problemas más habitualmente señalados se recogen seguidamente.

\subsubsection{La indefinición del encargo institucional y del objeto de los servicios sociales}

El primero de los problemas se refiere, sin duda, a la diferencia entre el encargo que se hace a las administraciones municipales para la gestión de los servicios sociales de atención primaria y los medios que se le atribuyen para su desarrollo ${ }^{36}$, así como a la

35 La mayor parte de los contenidos de este epígrafe recogen fragmentos literales de los informes realizados con relación a cada una de las comunidades autónomas analizadas.

${ }^{36}$ En el informe del Ararteko sobre la situación de los servicios sociales de base (SIIS Centro de Documento y Estudios, 2010), también se hacía referencia al desajuste entre el mandato que se establece en las leyes vascas - tanto en la de servicios sociales como en la de garantía de ingresos e inclusión socia los medios que se asignan a los ayuntamientos para cumplir ese mandato y el encargo concreto 
a menudo deficiente definición de ese encargo, que se relacionan, a su vez, con la deficiente definición del objeto del conjunto de los servicios sociales.

Se señala así en relación con Catalunya -aunque la reflexión seguramente es válida para todas las comunidades autónomas analizadas-que los municipios no pueden desarrollar con plenas garantías la función que tienen encomendada dentro del sistema de servicios sociales: son el nivel más próximo al ciudadano y la puerta de entrada al sistema, pero no consiguen tener la autoridad de prescripción necesaria para conseguirlo. Han de garantizar el bienestar de los ciudadanos de su territorio, pero no tienen ni la dimensión, ni el volumen, ni la Cartera de Prestaciones necesaria para conseguirlo: las funciones y tareas que se les adscriben son inabarcables, con mucho, para las capacidades de gestión y de generación de recursos de los ayuntamientos.

El obstáculo principal con el que han de enfrentarse los municipios es intentar gestionar un servicio público con un objeto de actuación que se mueve entre lo inconcreto y lo indefinido. Todo ello bajo la apariencia de la simplicidad de un nivel básico de atención que oculta una alta complejidad técnica y de gestión. Para superar ese déficit, los servicios sociales de base han de realizar una inversión potente en recursos y conocimiento que les permita desarrollar y aceptar nuevas competencias en aquellos aspectos que les son propios y pueden obtener impactos significativos: la promoción de la autonomía personal y la atención a la dependencia, la prevención y el abordaje de la exclusión social, la atención a la desprotección y, en definitiva, la promoción de la interrelación social de la ciudadanía. En ese sentido, tras el cambio derivado de la aprobación de las leyes de segunda y tercera generación, los servicios sociales municipales han de dar un segundo salto cuantitativo y cualitativo: el contexto actual dibuja un escenario donde los servicios de cuidado, protección e interrelación social serán más generalizados, de necesidades más complejas y de mayor intensidad. El número de profesionales necesarios, el tipo y acceso a prestaciones que aporten valor a la calidad de vida de los ciudadanos y su intensidad hacen necesaria una mayor inversión. También parece necesario

que hacen a los servicios sociales de base tanto sus responsable políticos como la propia ciudadanía. De acuerdo con aquel informe, el problema no se limita a la descompensación que existe entre las funciones asignadas y los recursos disponibles: existe también un margen de incoherencia importante entre el encargo institucional que la normativa establece - una intervención social próxima y de calidad, el abordaje integral de las necesidades de personas y familias- y el encargo concreto que los responsables institucionales trasladan, en cada ayuntamiento, a los servicios sociales de base: una atención rápida, si es necesario superficial, que permita una gestión eficaz de las prestaciones y servicios y que impida la extensión de las listas de espera. En ese sentido, la inmensa mayoría de las personas consultadas para la redacción de aquel informe pusieron de manifiesto la enorme distancia existente entre las funciones que se encomiendan a los servicios sociales de base, y el papel esencial que en teoría se les atribuye, $y$ las funciones que en la realidad se les exigen y los medios que se les asignan. avanzar - como se ha hecho en algunas comunidades autónomas, entre ellas la Comunidad Autónoma de Euskadi- en una cierta especialización de la atención primaria37.

La definición del encargo de los servicios sociales municipales pasa también por reflexionar sobre el papel que éstos deben jugar en el ámbito de la garantía de rentas. Si bien en ese ámbito la Comunidad Autónoma de Euskadi ha dado ya pasos que parecen irreversibles y que en gran medida establecen un terreno de juego más coherente, persisten incluso en la Comunidad Autónoma de Euskadi problemas con relación a esta cuestión que requieren un esfuerzo de reflexión y coordinación por parte de todos los agentes involucrados ${ }^{38}$.

\subsubsection{El reto de la ordenación territorial}

También hemos visto que -al menos en algunas de las comunidades autónomas analizadas- la organización territorial de los servicios sociales tiene un efecto perverso en lo que se refiere a aspectos tan fundamentales como la equidad del sistema y su eficiencia. Múltiples administraciones competentes, de diferente tamaño y nivel, y una provisionalidad de las normas básicas son algunos de los aspectos que hacen que no podamos hablar, en ninguna de las comunidades autónomas analizadas, de un sistema homologable $u$ homogéneo para todo el territorio autonómico.

La existencia de diferencias interterritoriales en el acceso a los servicios sociales es una realidad en todas las comunidades autónomas analizadas, independientemente del modelo de ordenación territorial adoptado en el ámbito de los servicios sociales. El muy reducido tamaño de buena parte de los municipios españoles -incluyendo los de la Comunidad Autónoma de Euskadi- apunta

${ }^{37}$ Tal y como explica Aguilar Hendrickson (2014), “el generalismo de los servicios primarios y de la mayoría de sus profesionales, unido a la sobreespecialización de buena parte del nivel especializado, crean además dificultades importantes para mejorar la eficacia y gestionar adecuadamente el conocimiento en los servicios sociales. La existencia de un punto de acceso único e inespecífico puede ser muy conveniente. No todas las demandas están claras desde el principio y un primer mecanismo de selección y encauzamiento, en especial en campos como el social, pueden evitar numerosos problemas. Sin embargo, más allá de esta función de triage, cuando comienzan procesos de atención más intensos es difícil que un profesional pueda ser al mismo tiempo un buen organizador de cuidados de personas dependientes, un buen acompañante de procesos de incorporación social y un buen interventor en conflictos familiares que afecten a menores al mismo tiempo y además pasando de un rol al otro varias veces al día todos los días. Por lo tanto, parece razonable sostener que, en la parte que va más allá de ser puerta de entrada, la atención "primaria' necesita de una cierta especialización".

${ }^{38}$ En el marco estatal, la propuesta de limitar el objeto de los servicios sociales de base no los exime de gestionar las prestaciones y ayudas relacionadas con la garantía de rentas que ahora le son propias. Pero no pueden continuar haciéndolo como lo hacen, dentro del proceso común de atención social: la presión sobre las organizaciones municipales y sus profesionales es una amenaza para su futuro. Hay que pensar nuevas formas de gestión más eficientes y equitativas, que permitan la transferencia de las prestaciones económicas que ahora se realizan desde los municipios. 
la necesidad de una reestructuración territorial que acometa la reducción drástica del número de municipios y cree espacios administrativos más homogéneos en cuanto a población, que permitan una más justa y equitativa provisión de servicios. En ese sentido, un elemento de mejora pasa por repensar y redefinir el concepto de municipio o ayuntamiento en clave de garantizar su viabilidad como centro de gestión de los servicios: habría que definir cuál debe de ser la dimensión mínima que debe de tener un ayuntamiento para poder funcionar correctamente como gestor de los servicios a la comunidad y establecer un nuevo mapa municipal de acuerdo con esa nueva definición, tal como han hecho muchos otros países de nuestro entorno.

\subsubsection{Los problemas derivados de una compleja gobernanza}

Si bien cabe pensar que en la Comunidad Autónoma de Euskadi el problema es mayor debido a la implicación en el sistema de tres niveles competenciales distintos, los problemas derivados de la compleja arquitectura institucional que rige los servicios sociales están más o menos presentes en todas las comunidades autónomas analizadas ${ }^{39}$. En efecto, la dimensión de las organizaciones locales y la distribución competencial y de toma de decisiones suponen un obstáculo importante para realizar el salto necesario en los servicios sociales municipales.

La gestión de prestaciones y servicios de por sí complejos resultan aún más difíciles en organizaciones de tamaño tan diferente, que carecen en muchas ocasiones de la masa crítica suficiente. No es posible conseguir economías de escala 0 curvas de aprendizaje eficientes con el mapa de servicios sociales básicos existente en la mayor parte de las comunidades autónomas analizadas y con su actual distribución territorial. Al contrario, la confusión que implica la falta de correspondencia entre las administraciones que prestan, planifican, regulan y financian los servicios acaba provocando una fuga constante de energía en la relación interadministrativa y de responsabilidad pública.

Una de las vías de avance que se plantea para dar respuesta a estos problemas de gobernanza es -en la línea de la 'Gizakidetza' propuesta para la Comunidad Autónoma de Euskadi por parte de algunas personas entrevistadas para el informe del

39 Tal y como indica Aguilar Hendrickson (2014), en España hay varios cientos de instituciones políticamente autónomas en materia de servicios sociales. Además de la administración general del Estado y las 17 comunidades autónomas, hay que contar 54 diputaciones provinciales o consejos y cabildos insulares, 70 comarcas y 388 mancomunidades de municipios, 399 municipios mayores de 20.000

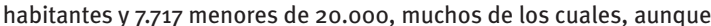
no obligados, son responsables de servicios sociales. Esta multiplicidad de actores políticamente autónomos, que pueden decidir sobre la amplitud o no de los servicios y sus precios públicos, por ejemplo, crea importantes necesidades de coordinación del sector y dificulta los procesos de reorientación del conjunto del sistema que pueden ser vetados por muchos de los actores de los niveles inferiores.
Ararteko que deriva este artículo (SIIS Centro de documentación y Estudios, 2016: 92 ss.)-

la de ampliar el ámbito competencial autonómico y desarrollar un nivel de atención mínimo garantizado más amplio, que contribuya a reducir las desigualdades entre zonas. En esa vía, un posible modelo podría ser el existente para la provisión autonómica en el ámbito sanitario. Sin duda, la potencialidad de la gestión municipal de los servicios sociales es la cercanía al territorio, lo cual posibilita la adecuación de las actuaciones a las necesidades reales y la participación de la comunidad en su gestión, evitando el diseño de acciones alejadas de la realidad comunitaria. Sin embargo, el aumento de las competencias autonómicas, al menos en las comunidades autónomas pequeñas ${ }^{40}$, no debería ser causa de una ruptura con el medio, más bien al contrario. Parece apropiado mantener un nivel autonómico de amplia responsabilidad con una adecuada interlocución y amplia participación comunitaria a través de la coordinación entre ambos entes y la colaboración en la gestión y diseño de acciones para la intervención. Este modelo podría compatibilizar el avance hacia una mayor cohesión territorial con un sistema de servicios sociales participativo y comunitario.

\subsubsection{Los recortes presupuestarios y la falta de desarrollo normativo lastran el desarrollo de los servicios}

Al igual que la Ley vasca de Servicios Sociales, la mayor parte de las leyes que regulan los servicios sociales municipales se aprobaron antes, o al inicio, de la actual crisis económica. Desde su puesta en marcha, se señala para el caso de Navarra, se identificaron disfunciones en la gestión, indefinición de algunas de las funciones de los diferentes programas y una falta de directrices autonómicas para hacerles frente. Estas dificultades, comprensibles en un primer momento de implantación de un modelo sustancialmente diferente al anterior, no fueron subsanadas ni abordadas, por lo que la crisis alcanzó a los servicios sociales y profesionales en un momento de definición y reubicación ${ }^{41}$. En Navarra $-\mathrm{y}$, cabe pensar, también en las demás comunidades autónomas analizadas- a este escenario de trasformación y falta de directriz se le sumó un cambio en el día a día de los servicios. Las consecuencias de la crisis en los servicios sociales no sólo llegaban determinadas por la implantación de medidas de austeridad que

\footnotetext{
$4^{\circ}$ En este caso, la propuesta se refiere específicamente a Navarra. ${ }^{41}$ En el caso de Castilla-La Mancha, la reducción progresiva de dotación presupuestaria, en todos los ejercicios de la última legislatura, ha supuesto la eliminación completa de programas, la reducción hasta la insignificancia de otras actuaciones y, en todos los casos, una fragilización general del sistema público. Las únicas partidas de gasto que no han sufrido reducciones, o que incluso han sido aumentadas, corresponden a prestaciones y servicios privatizados. Si a ello sumamos que una buena parte de los profesionales vinculados al sistema lo hacían a través de proyectos y programas subvencionados a los ayuntamientos, el impacto que tales recortes han tenido en el empleo vinculado al sector ha sido muy importante.
} 
se materializaban en menores recursos económicos y técnicos para intervenir (equipos profesionales no reforzados, reducción de partidas para algunos programas o implementación de cambios normativos que amplían los requisitos de acceso a algunas prestaciones garantizadas), sino que a las estrategias de austeridad pública se le sumaban un aumento de necesidades en los hogares (más hogares y con necesidades más intensas). En este escenario la carga de trabajo se multiplica debido, tanto al incremento de la demanda, como a la diversificación de perfiles a atender y a la reducción del tiempo disponible para intervenir de manera integral con las personas usuarias bajo los principios que establecen las nuevas normas ${ }^{42}$

A los recortes presupuestarios se suma -aunque más bien cabría decir que deriva de ellos- un notable retraso en el desarrollo normativo de las leyes de servicios sociales: figuras esenciales para la definición de los servicios sociales municipales, como los Mapas de Servicios Sociales, los Planes Estratégicos y las Carteras de Servicios o bien no se desarrollan o bien -como en la Comunidad Autónoma de Euskadi- lo hacen con extrema dificultad.

Como consecuencia de todo ello, los servicios sociales se encuentran actualmente en un momento complicado y con cierta falta de horizonte. Entre los factores que motivan este escenario, destacan algunas de las decisiones tomadas en los últimos años (nuevamente hay que señalar que la descripción se refiere a Navarra, si bien podría probablemente ser extensible a la mayor parte de las comunidades autónomas analizadas):

- La reforma unilateral de algunas prestaciones, sin atender a la valoración de los propios profesionales, contradiciendo el principio de la Ley que aboga por una adecuación de las respuestas institucionales a las necesidades sociales.

- El diseño sin criterio de prestaciones de emergencia para dar una respuesta rápida, pero no planificada, a las necesidades sociales.

- El debilitamiento de lo público al incorporar prestaciones materiales financiadas por entidades privadas, $\mathrm{y}$ un cambio de rumbo hacia

${ }^{42}$ En todo caso, es importante también señalar que los problemas de la atención primaria en los servicios sociales españoles van más allá de la dotación de recursos humanos. En ese sentido, Aguilar Hendrickson (2014: 14) señala que no parece que, al menos hasta 2011, se hubiera producido un colapso de los servicios por la combinación de una demanda desbordada y unos medios reducidos:

No sabemos con certeza qué ha sucedido después. En todo caso, estos datos parecen apuntar a que las tensiones que han vivido y viven los servicios sociales deben explicarse, en parte, por dificultades para desarrollar eficazmente su acción que tienen que ver con su configuración o con el tipo de medios de que disponen, más que con la cantidad de los mismos. Es posible que éstos sean insuficientes, pero al menos en términos cuantitativos brutos, no parece que sean más insuficientes que en 2007 y probablemente menos insuficientes que en 2003 una mayor presencia de entidades privadas en la gestión y promoción de las funciones de los servicios sociales.

- Un giro hacia la gestión indirecta a través del tercer sector en las áreas más especializadas.

- Una falta de criterio en las decisiones tomadas, que ha dado lugar a una contradicción de mandatos y directrices, desprestigiando la imagen de los servicios y la satisfacción de los personas usuarias.

- El escaso respaldo institucional a los profesionales ante el cambio constante de información y normativas.

- La falta de coherencia en la hoja de ruta del sistema, que ha dado pie a planteamientos incoherentes entre alcaldes, presidentes de mancomunidades, jefes de servicio, políticos autonómicos, etc.

- El colapso de los servicios y una mayor complejidad en la tramitación de prestaciones que no deja tiempo para el acompañamiento social, la planificación conjunta de métodos de trabajo, ni el trabajo social comunitario. El día a día se consume, según los profesionales, en la gestión de ayudas y en las respuestas rápidas, inmediatas. Esta falta de tiempo y medios para establecer una relación de ayuda con las personas usuarias que dé lugar a un proceso de acompañamiento y trabajo conjunto es uno de los primeros síntomas de un sistema que camina hacia el asistencialismo.

- La reducción del tiempo para iniciar procesos de coordinación y metodologías de colaboración en red.

- El malestar, estrés y frustración de los profesionales por encontrar obstáculos que les permitan hacer trabajo social, y por enfrentarse al malestar de las personas usuarias ante las necesidades y expectativas no cubiertas.

\subsubsection{La necesidad de reforzar la intervención individual y familiar, y el cuidado del capital humano de los servicios sociales municipales}

Al analizar los retos de los modelos de servicios sociales municipales establecidos en las cinco comunidades autónomas que se han analizado, también se ha insistido en la necesidad de garantizar una atención más eficiente y personalizada, basada en la intervención social y no sólo en la gestión de prestaciones. Para ello, sería fundamental repensar las funciones de los programas de atención primaria a fin de reforzar sus acciones y evitar duplicidades en la gestión, reducir el tiempo invertido en la gestión de ayudas y apostar por hacer trabajo social, desde la gestión de casos de carácter individual hasta el orientado a la comunidad, pero siempre desde la intervención adaptada y acompañada que realmente posibilite el desarrollo de itinerarios de emancipación. 
También se apunta como un eje clave del sistema el cuidado del capital humano. El personal técnico de los servicios sociales es una de sus fortalezas. En su inmensa mayoría son profesionales excelentes, con un alto grado de motivación y compromiso, pero llevan mucho tiempo viéndose superados y superadas por el incremento de la demanda, lo que puede llegar a afectarles y a erosionar la calidad de la atención. Por eso es imprescindible adoptar medidas que contribuyan a apoyar a los equipos profesionales, a fortalecerlos y a mantener su motivación de manera continuada.

\subsubsection{La necesidad de reforzar las herramientas de gestión}

Del análisis realizado se deriva también que, si bien la dimensión de gestión pública de los servicios sociales ha avanzado en los últimos años, todavía necesita otro impulso en ámbitos como la planificación y la evaluación. Capítulo aparte es la necesidad de que los servicios sociales dispongan de sistemas de información que garanticen la transparencia y la rendición de cuentas por parte de las instituciones competentes. Actualmente, en la mayor parte de las comunidades autónomas los sistemas de registro de datos y gestión no generan una información suficientemente consistente y de valor, de la misma forma que, pese a sus mejoras, los sistemas estatales de información no generan información agregada de suficiente calidad ${ }^{43}$. Si bien es cierto que la construcción de un buen sistema de información de servicios sociales requiere antes dar respuesta a los problemas relativos a la definición del encargo y el objeto de aquéllos, es obvio también que se pueden dar en paralelo - de hecho se están dando- pasos que permitan trabajar a partir de indicadores de proceso y de impacto, que permitan a su vez valorar la eficacia y la eficiencia de estos servicios.

Junto con el desarrollo de los sistemas de información, resulta también urgente desarrollar y afianzar herramientas útiles de valoración y diagnóstico, que permitan objetivar las necesidades de las personas atendidas y planificar adecuadamente la intervención requerida.

\subsubsection{La ausencia de un corpus teórico y el débil empoderamiento profesional}

Como se ha señalado en el apartado cualitativo, el análisis de los modelos establecidos en las demás comunidades autónomas también apunta a que otro gran reto de los servicios sociales, en especial en el nivel básico, es mejorar el corpus teórico

${ }^{43}$ Los datos del SIUSS y de otros sistemas parecidos relativos a los grupos de población atendidos y los problemas planteados son prácticamente inutilizables y muchos responsables de la Administración lo reconocen en privado. El problema no radica tanto en los sistemas de registro en sí, sin duda mejorables, sino en la conceptualización débil de estos aspectos (Aguilar Hendrickson, 2014). y la capacitación científico-técnica de los y las profesionales. Aspectos básicos de la intervención social, como la capacidad diagnóstica, el diseño de actuaciones y prestaciones significativas en la calidad de vida de la ciudadanía, y poder medir y evaluar el impacto de aquéllas constituyen, en estos momentos, líneas de mejora que tendrían que ser prioritarias en las administraciones, instituciones académicas y organizaciones profesionales ${ }^{44}$.

\subsection{Los servicios sociales municipales de la Comunidad Autónoma de Euskadi en el contexto estatal: diferencias, similitudes y posibles aprendizajes}

Más allá de las reflexiones sobre las dificultades y los retos comunes de los servicios sociales municipales en las comunidades autónomas analizadas, el interés del análisis realizado es el de identificar las diferencias y similitudes que existen con relación al caso vasco y, en la medida de lo posible, extraer aprendizajes que puedan contribuir a mejorar la organización de los servicios sociales municipales de la Comunidad Autónoma de Euskadi. Se recogen a continuación los que se han considerado más significativos.

\subsubsection{Dos niveles similares de atención, pero con funciones diferentes...}

La primera similitud, la más básica, se refiere a la articulación de todos los sistemas analizados en torno a dos niveles de atención: un nivel primario y otro secundario. Efectivamente, ya se ha señalado que un rasgo típico de la organización de los servicios sociales en España desde los años ochenta ha sido la estructuración del sector en dos niveles. Un primer nivel denominado 'de atención primaria', 'comunitario', 'general' o ‘básico’ y un segundo nivel llamado 'especializado'. El primer nivel está formado por servicios de tipo casi siempre inespecífico o generalista, descentralizados en el territorio, que prestan una atención de tipo ‘ambulatorio' (sobre todo, aunque no sólo, en forma de consulta en despacho), domiciliario y, con menos intensidad, en el espacio público. Son de titularidad local, en la mayor parte de los casos municipal, y en otros, de diputaciones, comarcas o mancomunidades de municipios, y coinciden a grandes rasgos con el ámbito del Plan Concertado (Aguilar Hendrickson, 2014).

No son tan similares, sin embargo, ni los cometidos que se asignan a la atención primaria, ni su

$44 \mathrm{El}$ informe del Ararteko sobre los servicios sociales de base (SIIS Centro de Documento y Estudios, 2010) ya ponía de manifiesto la ausencia de un modelo de intervención común, la carencia de una estructuración suficiente que dote de herramientas, equipos, procedimientos, instrumentos y prácticas profesionales comunes a los servicios sociales de base. Se echa en falta en ese sentido, señalaba el informe, la existencia de corpus procedimental que oriente y delimite la práctica profesional, no sólo del trabajo social y de la intervención socioeducativa, sino del conjunto de los servicios sociales de base. 
grado de definición, ni su consideración como derecho subjetivo, ni su ubicación en el entramado institucional:

- En lo que se refiere a las funciones de los servicios sociales municipales y/o de atención primaria, la Comunidad Autónoma de Euskadi se distingue de los otros modelos por atribuirles una serie de servicios de alojamiento, atención diurna y acogida nocturna que van más allá del catálogo de servicios o funciones que se establece en las demás comunidades autónomas. Si en ellas los servicios o prestaciones que se atribuyen a los servicios sociales se centran básicamente en los que en la Comunidad Autónoma de Euskadi se atribuyen a los servicios sociales de base ${ }^{45}$, en la Comunidad Autónoma de Euskadi se les encomienda también la gestión - con carácter de derecho subjetivo- de servicios de atención diurna para personas mayores y en situación de exclusión, los centros de acogida nocturna para las personas en situación de exclusión, y diferentes modalidades de alojamiento (apartamento tutelado y vivienda comunitaria, para diversos colectivos).

Ciertamente, la atribución de servicios de este tipo a las administraciones locales no se da sólo en la Comunidad Autónoma de Euskadi -en Catalunya, es posible delegar determinados servicios correspondientes a la atención especializada a los ayuntamientos de mayor tamaño; en Navarra, los ayuntamientos pueden prestar también servicios especializados en su término municipal si así lo consideran conveniente; y en Galicia, se prevé la figura de los servicios comunitarios específico, pero es la Comunidad Autónoma de Euskadi la comunidad que con más claridad rompe la equiparación entre servicios sociales municipales y servicios sociales básicos, ‘especializando’ en cierto modo la atención primaria ${ }^{46}$.

- Otra de las diferencias entre la Comunidad Autónoma de Euskadi y el resto de las comunidades autónomas es que estos servicios de alojamiento, acogida nocturna y atención

45 Es decir, información, diagnóstico, valoración y orientación (1.1), atención domiciliaria (1.2), intervención socioeducativa y psicosocial (1.3) y servicio de apoyo a personas cuidadoras (1.4). La Comunidad Autónoma de Euskadi presenta la particularidad de haber encomendado la teleasistencia al gobierno autonómico, lo que no ocurre en las demás comunidades autónomas.

${ }^{46}$ Esta idea coincide con la propuesta que en las Propuesta para la configuración de un modelo actualizado de servicios sociales municipales hace la Federación Española de Municipios y Provincias (2009) en el sentido de articular los equipos municipales de intervención en dos niveles diferenciados: una Intervención social básica, o de primer nivel, responsable de las prestaciones de atención primaria en servicios sociales y de la coordinación de intervinientes en el proceso de global de prestación de servicios, cuyo soporte es el plan de intervención individual y/o de la unidad de convivencia; y una intervención social de segundo nivel, o específica, que asegure y refuerce la calidad de las prestaciones básicas de servicios sociales, especialmente en situaciones complejas, con prestaciones técnicas y materiales. Tales prestaciones estarían dirigidas a un área de necesidad o un colectivo específico, con un proceso de intervención singular identificado, que incluye otros apoyos diferenciados y/o complementarios. diurna tienen en la Comunidad Autónoma de Euskadi carácter de derecho subjetivo -no discrecional- están recogidas en el Mapa de Servicios Sociales y, por tanto, están sujetas a unas normas específicas en cuanto a su despliegue territorial - por laxas que éstas seany tienen una función relativamente específica con relación a la atención secundaria, que se centra en la prestación de servicios de baja intensidad y/o de carácter preventivo, para colectivos en riesgo o con problemáticas más leves. En las demás comunidades autónomas, estos servicios de atención primaria 'especializada' tienen un carácter más discrecional y/o una definición más débil que los de secundaria.

- En lo que se refiere al cometido de los servicios sociales municipales, es también importante señalar que en las demás comunidades autónomas mantienen - a diferencia de lo que ocurre hoy en la Comunidad Autónoma de Euskadi- la gestión de las prestaciones de garantía de ingresos, lo que añade complejidad y carga de trabajo adicional a estos servicios.

\subsection{2. ... y con arquitecturas competenciales muy diferentes}

La principal diferencia entre el modelo vasco y el establecido en las demás comunidades autónomas se refiere, en todo caso, a la arquitectura institucional: si bien es cierto que, en general, la atención primaria se atribuye en (casi) todos los casos a los ayuntamientos, la atención especializada o secundaria es, en general, competencia de la administración autonómica en Navarra, Galicia, Catalunya, Castilla-La Mancha y Castilla y León. En la Comunidad Autónoma de Euskadi, por el contrario, la administración autonómica mantiene, como en las demás comunidades autónomas, competencias de planificación y regulación, pero la responsabilidad respecto a la gestión de las prestaciones y servicios de atención secundaria corresponde a las tres diputaciones forales. La consecuencia es que, mientras que en las demás comunidades autónomas nos encontramos con un sistema doble, en el que la administración autonómica planifica, regula y presta los servicios especializados -ejerciendo en ese sentido un liderazgo claro y poco discutido-, en la Comunidad Autónoma de Euskadi la participación directa de los tres niveles institucionales obliga a una coordinación interinstitucional que no siempre resulta fluida.

En todo caso, más allá de esa diferencia - por lo demás, obvia - interesa destacar cuál es el papel que en las demás comunidades autónomas asumen las diputaciones provinciales:

- El modelo de Castilla y León es, en cierto modo, el más parecido al que existe en Álava, ya que en esa Comunidad las diputaciones asumen la prestación de los servicios sociales básicos en los municipios de menos de 20.000 habitantes (véase el apartado 2.4). 
- En Galicia, las diputaciones asumen un papel más testimonial, pero tienen en todo caso una función importante en lo que se refiere a la financiación del SAD, al asesoramiento técnico y a la prestación de los servicios sociales básicos en los municipios de menos de 20.000 habitantes.

- En Cataluña, más concretamente en Barcelona, la Diputación provincial juega un papel especialmente activo tanto en lo que se refiere a la financiación de los servicios sociales básicos como en lo que se refiere a la prestación de determinados servicios de atención directa y, muy particularmente, al asesoramiento técnico a los profesionales municipales. Como se ha señalado, la singularidad de la Diputación de Barcelona en el campo de los servicios sociales es tanto por el volumen de recursos destinados (casi 25 millones de euros, sin contar el capítulo I y 430 profesionales) como, sobre todo, por la orientación a los municipios desde la óptica de la innovación y la economía de escala.

En lo que se refiere a la gobernanza del sistema, también resulta muy particular la existencia en Euskadi de un Órgano Interinstitucional de Servicios Sociales, del que forman parte los ayuntamientos, y la capacidad de veto que se otorga a los ayuntamientos, así como a las diputaciones, a la hora de aprobar el contenido del Decreto de Cartera, es decir, las características básicas de los servicios y los requisitos de acceso.

\subsubsection{Cofinanciación generalizada frente a responsabilidad financiera municipal en la Comunidad Autónoma de Euskadi}

La segunda diferencia esencial se refiere al modelo de financiación de los servicios sociales municipales establecido en la Comunidad Autónoma de Euskadi y en las otras cinco comunidades autónomas analizadas: en todas ellas, las instituciones supramunicipales contribuyen a la financiación de los servicios sociales municipales mediante transferencias finalistas, condicionadas a un uso determinado: en Navarra, el Gobierno Foral financia entre el $50 \%$ y el $80 \%$ del coste de los programas obligatorios de los servicios sociales básicos; en Catalunya, al menos el $66 \%$; en Castilla-La Mancha, entre el $80 \%$ y el $100 \%$; en Castilla y León, entre el $65 \%$ y el $100 \%$, dependiendo del servicio.

En cambio, pese a la mayor envergadura del 'encargo' que se hace a los ayuntamientos vascos en lo que se refiere a la provisión de servicios sociales, en el modelo que la Ley de Servicios Sociales establece teóricamente para la Comunidad Autónoma de Euskadi, las administraciones locales deberían financiar con sus propios fondos la totalidad de los servicios de su competencia. Si bien es cierto que con el fondo económico establecido en el Decreto de Cartera se ha generado en la Comunidad Autónoma de Euskadi un mecanismo de cofinanciación de algunos de los servicios municipales, las diferencias siguen siendo a este respecto muy importantes.

En cualquier caso, con relación a esta cuestión es necesario hacer dos matizaciones:

- En las comunidades autónomas de régimen común analizadas -es decir, todas salvo Navarra- los gobiernos autonómicos perciben una financiación finalista por parte del Gobierno central, en el marco del Plan Concertado de Prestaciones de Servicios Sociales en Corporaciones Locales, para financiar precisamente los servicios de atención primaria ${ }^{47}$. No puede decirse, en cualquier caso, que la financiación del Gobierno central resulte decisiva para la cobertura del gasto que estos servicios representan.

- El nivel de financiación general -no finalistaque reciben los ayuntamientos vascos es muy superior al que reciben los ayuntamientos de las comunidades autónomas de régimen común y, si bien la diferencia es menor, también superior al que reciben los ayuntamientos navarros ${ }^{48}$.

\subsubsection{La definición de las ratios de atención}

Otra de las diferencias que existen entre la Comunidad Autónoma de Euskadi y algunas de las comunidades autónomas analizadas se refiere al establecimiento - fundamentalmente en Galicia y Navarra, aunque también, en menor medida, en Catalunya- de ratios de personal en los servicios sociales de base, lo que, en parte, se relaciona con la participación de las entidades supramunicipales en la financiación de esos servicios.

En ese sentido, Navarra regula con detalle el perfil de las personas profesionales que deben prestar sus servicios en cada uno de los programas (profesionales del trabajo social, la educación social, la educación familiar y personal administrativo), así como su dotación mínima, diferenciando las

47 El Plan Concertado financia la red de centros de servicios so ciales de las comunidades autónomas adheridas a él - todas salvo la Comunidad Autónoma de Euskadi y Navarra-, con un gasto total en 2011 de 1.551 millones de euros. De ellos, 86 (el 5,5\%) fueron financiados por el Ministerio; 784 (el 50\%) por las comunidades autónomas; y 677 (el $43 \%$ ), por las corporaciones locales.

${ }^{48}$ En ese sentido, es preciso señalar que los municipios vascos son los que tienen una menor capacidad de recaudación propia de todo el Estado, cuando se mide con relación al PIB (1,1\% del PIB, frente al 1,9\% del Estado y el 2,5\% de Andalucía). En términos de euros per cápita, la recaudación municipal asciende en la Comunidad Autónoma de Euskadi a 313 euros al año, frente a 422 en el conjunto del Estado. Con datos de 2005, Zubiri et al. (2009) explicaban que esa menor capacidad de recaudación no se traduce en una menor capacidad de gasto, debido al mayor volumen de las transferencias que los ayuntamientos vascos reciben de las instituciones comunes. De hecho, según ese autor, las transferencias recibidas por los ayuntamientos de la Comunidad Autónoma de Euskadi son, en euros por habitante, un $95 \%$ superiores a los que reciben los municipios de territorio común. Suponen, además, un porcentaje muy superior de sus ingresos: el $55 \%$, frente al $37 \%$ de los municipios del territorio común y el $38 \%$ de los de la Comunidad Foral de Navarra. 
dotaciones correspondientes a los municipios en función de su tamaño. Galicia ha adoptado una política similar, estableciendo una dotación mínima de profesionales del trabajo social, la educación social, la sociología, la psicología y otras titulaciones superiores, así como personal administrativo, que se diferencia tanto en función del tamaño del municipio como del modelo de unidad social establecido (unidades de trabajo social, unidades de trabajo y educación social, y unidades interdisciplinares de intervención social). Cataluña, por su parte, se ha limitado de momento a establecer las ratios mínimas del servicio básico de atención social (tres trabajadores o trabajadoras sociales y dos educadores o educadoras por cada 15.000 habitantes) y el servicio de centro abierto.

\subsubsection{Una ordenación territorial más laxa}

La ordenación territorial de los servicios sociales municipales es, probablemente, el aspecto en el que las diferencias entre las comunidades autónomas analizadas son mayores:

- En Navarra, se establecen 44 zonas básicas -que pueden incluir uno o más municipios, 0 mancomunidades - y áreas - que incluyen entre cinco y doce zonas básica-.

- En Cataluña, se parte del área básica de servicios sociales (con una población de 20.000 habitantes) y se tiene en cuenta el diferente tamaño municipal, al atribuir las competencias respecto a los servicios sociales básicos a los ayuntamientos de más de 20.000 habitantes, mientras que en los municipios de menor población la responsabilidad se atribuye a los consejos comarcales. En todo caso, la diversidad de opciones y formas de gestión es notable.

- Galicia también establece el área como elemento básico de la ordenación territorial en el ámbito de los servicios sociales, diferenciando entre diferentes tipos de áreas (urbanas, metropolitanas, rurales, etc.), lo que, como hemos visto, implica diferencias en las ratios profesionales de los servicios sociales de base. Con todo, es preciso recordar que la ordenación territorial de los servicios sociales viene a coincidir en Galicia casi en su totalidad con la ordenación municipal, pues, salvo en los casos de agrupaciones o mancomunidades, que son minoritarias y voluntarias, cada ayuntamiento presta los servicios sociales en su término municipal, careciendo de referencias comunes o de similitudes con la organización territorial del sistema educativo o sanitario.

- En el caso de Castilla y León, se diferencian las zonas de acción social y sus agrupaciones, las áreas de acción social.

- Finalmente, en el caso de Castilla-La Mancha, pese a que se reconoce al municipio como unidad territorial básica para la prestación de servicios sociales, en ausencia del preceptivo mapa de servicios sociales, los municipios tienden a agruparse en las zonas y área establecidas por el Gobierno autonómico en 2004.

De este panorama, desde la perspectiva de la Comunidad Autónoma de Euskadi, cabe destacar algunos elementos de interés:

- En la mayor parte de los casos, es patente la preeminencia del municipio -como ente administrativo- en lo que se refiere a la determinación de las áreas y zonas, y su autonomía a la hora de agruparse con otros municipios para la prestación de servicios.

- Cabe destacar también la diferenciación que se realiza en Galicia entre diferentes tipos de unidades de actuación, en función de la realidad demográfica y socioeconómica local, que se traduce en requerimientos de personal diferentes.

- Pese a su escaso desarrollo, también cabe tener en cuenta la figura de los centros de servicios sociales establecida en Navarra, que, como se ha dicho, tienen funciones de apoyo a los servicios sociales de base.

En todo, la Comunidad Autónoma de Euskadi se diferencia de la mayor parte de los esquemas de ordenación territorial analizados en dos cuestiones básicas:

- La Comunidad Autónoma de Euskadi es la única que atribuye a los diferentes equipamientos de atención primaria -al margen de las unidades de servicios sociales de base - un grado determinado de proximidad y la recomendación de alcanzar, aunque sea a nivel del conjunto del territorio, unas dotaciones y coberturas mínimas, que contribuyan a garantizar una cierta armonización interterritorial y un cierto nivel de proximidad en el despliegue de los recursos.

- La delimitación geográfica concreta de los diversos niveles establecidos en el Mapa de Servicios Sociales - sectores, comarcas y áreas - queda al albur de las administraciones forales y locales, a las que únicamente se dan unas pautas generales. En la mayor parte de las comunidades autónomas analizadas, por el contrario, la delimitación geográfica de los ámbitos territoriales supramunicipales es, por lo general, más estricta.

- Mientras que la mayor parte de las comunidades autónomas analizadas tienen muy en cuenta el tamaño de los municipios a la hora de asignarles competencias concretas, en la línea de lo establecido en la normativa estatal, la Comunidad Autónoma de Euskadi no diferencia prácticamente en ningún aspecto a los ayuntamientos grandes, medianos o pequeños, más allá de las pautas que se recomiendan para la definición de los ámbitos territoriales correspondientes a los diferentes 
centros o de los indicadores sintéticos que se establecen para la definición de determinadas coberturas.

\subsubsection{El desarrollo de fórmulas de colaboración interadministrativa}

El análisis realizado en las páginas precedentes pone de manifiesto que, al margen de las mancomunidades, en algunas comunidades autónomas se ha tendido al desarrollo de fórmulas de colaboración interadministrativa que parecen haber cosechado resultados positivos. En ese sentido, cabe hacer referencia a dos modelos distintos, que dan respuesta a necesidades también muy diferentes: el Consorcio de Bienestar e Igualdad de Galicia y al Consorcio de Servicios Sociales de Barcelona:

- Como se ha señalado previamente, el Consorcio Gallego de Servicios de Igualdad y Bienestar -integrado por la Xunta de Galicia y por 272 de los 314 ayuntamientos gallegos, así como por cuatro mancomunidades ha sido fundamental para mejorar el equilibrio territorial en la oferta de servicios sociales públicos, permitiendo garantizar la prestación de servicios de calidad con niveles suficientes de cobertura y facilitar el acceso a escuelas infantiles y puntos de atención a la infancia, centros de atención a personas mayores y a la dependencia (centros de día, viviendas comunitarias, hogares residenciales y minirresidencias), equipos comarcales de inclusión social, centros de información y asesoramiento a la juventud u otros servicios de proximidad, como la comida a domicilio. Todo ello se basa en una fórmula de colaboración interadministrativa y de adhesión voluntaria, a través de la cual los ayuntamientos ceden sus equipamientos para que sean gestionados por dicho consorcio, comprometiéndose a aportar el $30 \%$ de la financiación, mientras que el consorcio asume el $70 \%$ restante con cargo a las transferencias de financiación que recibe de la administración autonómica y a los ingresos procedentes del copago de las personas usuarias.

- El Consorcio de Servicios Sociales de Barcelona, formado por el Ayuntamiento de Barcelona y la Generalitat de Catalunya, es una iniciativa pionera para evitar la actuación de diferentes niveles de la Administración en un mismo territorio desde la óptica de la cooperación y la codecisión. El objetivo ha sido evitar duplicidades, detectar y atender las necesidades de las personas atendidas y favorecer sus itinerarios, especialmente entre la atención básica y la especializada. Pese a su escaso y contradictorio desarrollo, el Consorcio supone un avance en el desarrollo de estructuras capaces de superar los efectos negativos de la actual división de los servicios sociales por niveles, y sus problemas de gobernanza y coordinación.

\subsubsection{El desarrollo de las herramientas de coordinación, mejora de la gobernanza y gestión del conocimiento}

Finalmente, cabe destacar algunas de las experiencias concretas de coordinación, mejora de la gobernanza y gestión del conocimiento que se vienen desarrollando en las comunidades autónomas analizadas. Resultan desde ese punto de vista particularmente interesantes las siguientes:

- Pese a su todavía escaso desarrollo, la Comisión de Coordinación de Atención Primaria de los Servicios Sociales de Base de la Comunidad Foral de Navarra -formada por seis representantes del Departamento responsable de los servicios sociales (actualmente, la Vicepresidencia de Derechos Sociales) y siete representantes de las áreas de los servicios sociales de base-supone un avance importante en lo que se refiere a la generación de mecanismos que -más allá de la regulación- permitan un liderazgo compartido en la gestión de los servicios de atención primaria.

- En el mismo sentido, cabe hacer referencia en Galicia al Servicio de Coordinación de Servicios Sociales Comunitarios, que tiene como función específica la coordinación de dichos servicios sociales. Desde esta unidad, se ofrece asesoramiento, orientación, información, formación y apoyo técnico a las y los profesionales de los servicios sociales comunitarios, básicos y específicos, para el desarrollo de programas y servicios en sus municipios.

- La figura de los contratos-programa de Cataluña, si bien estrechamente ligada a la financiación de los servicios sociales básicos, supone también un avance en la clarificación de las funciones y cometidos de cada parte.

- Particular interés tiene igualmente, en lo que se refiere a la gestión del conocimiento, las actuaciones de supervisión y formación de equipos y evaluación de servicios que se realizan mediante los Círculos de Comparación Intermunicipal en Servicios Sociales. Impulsados por la Diputación de Barcelona, los Círculos de Comparación Intermunicipal de Servicios Sociales son grupos estables de municipios que trabajan por la mejora de los servicios sociales a partir de la comparación de indicadores que reflejan su actuación y del intercambio y contraste de las prácticas que sustentan esta actividad. Como se ha señalado antes, el trabajo de estos Círculos se traduce, entre otros aspectos, en la publicación de un cuadro resumen de indicadores de servicios sociales municipales, relativos a los servicios sociales básicos, la atención a domicilio y los centros abiertos, que recoge más de un centenar de indicadores, actualizados cada año, con relación a la financiación de los servicios, la satisfacción de las personas usuarias, la dotación de profesionales y sus condiciones de trabajo, la cobertura de los servicios o los procedimientos 
de acceso (listas de espera, tiempos medios de espera para la realización de entrevistas, etc.). En el marco de esta iniciativa, se publica un informe anual que recoge tanto la metodología seguida como los resultados agregados -no detallados por cada municipio- que se han obtenido, señalándose las áreas que requieren ser mejoradas.

- También en Cataluña debe hacerse referencia al desarrollo del Sistema de Información de Servicios Sociales Hércules -que incluye entre sus herramientas un Registro Unificado de Datos de los Entes Locales (RUDEL) - y el carácter del Mapa de Servicios Sociales de Cataluña, orientado no tanto a la planificación del despliegue territorial de los recursos, sino a la descripción pormenorizada de las dotaciones, ratios de personal e intervenciones realizadas en cada municipio. Con relación a los servicios sociales básicos, el Mapa ofrece información - para cada zona básica de servicios socialessobre la dotación de profesionales (trabajadores o trabajadoras sociales y educadores o educadoras), las horas de SAD prestadas, las problemáticas atendidas, las personas y unidades familiares atendidas, las plazas disponibles en los servicios de estancia limitada, etc., lo que supone una mejora importante desde el punto de vista de la transparencia y la rendición de cuentas por parte de las administraciones locales.

- Finalmente, también tiene gran interés el Modelo de servicios sociales básicos de Cataluña (2015) publicado por la Generalitat, con el que se pretende fijar unos mínimos que permitan a las administraciones locales comparar y analizar su situación respecto a unos estándares amplios y flexibles, pero al mismo tiempo, concretos. Aunque se plantea como un modelo abierto, sujeto a revisión, el texto plantea que, una vez aprobado, debería constituir la base de un posterior proceso de regulación, con relación a criterios de prestación y acceso a los servicios, organización de los equipos de trabajo, requerimientos de los equipamientos y requisitos del sistema de información. 


\section{Bibliografía}

AGUILAR HENDRICKSON, M. (2014): Apuntes para un replanteamiento de los servicios sociales en España. VII Informe sobre exclusión y desarrollo social en España, serie Documento de Trabajo, Madrid, Fundación Foessa, Cáritas Española Editores [<http://www.foessa2014. es/informe/uploaded/documentos trabajo/04112014034343_2219.pdf〉].

- (2010): "La huella de la beneficencia en los servicios sociales”, Zerbitzuan, no 48 , págs. 9-16 [〈http://www.zerbitzuan.net/documentos/ zerbitzuan/La huella de la beneficencia.pdf`].

DEPARTAMENT DE BENESTAR SOCIAL I FAMÍLIA (2015): Model de serveis socials bàsics de Catalunya, Barcelona, Generalitat de Catalunya [«http:// www.siis.net/documentos/ficha/506965.pdfs].

DEPARTAMENTO DE BIENESTAR SOCIAL, DEPORTE Y JUVENTUD (2003): Manual de intervención en situaciones de desprotección infantil en la Comunidad Foral de Navarra, Pamplona, Gobierno de Navarra.

- (2000): Documento base para un plan de atención comunitaria de servicios sociales, Gobierno de Navarra [/https://www.navarra.es/home_es/ Temas/Asuntos+sociales/Publicaciones/ AtencionPrimaria/>].

FEDERACIÓN ESPAÑOLA DE MUNICIPIOS Y PROVINCIAS (2009): Propuesta para la configuración de un modelo actualizado de servicios sociales municipales, Federación Española de Municipios y Provincias [<http://femp.femp. es/files/566-894-archivo/nuevos_servicios_ sociales._libro.pdf〉].

SIIS CENTRO DE DOCUMENTACIÓN Y ESTUDIOS (2016): La situación de los servicios sociales municipales en la Comunidad Autónoma de Euskadi. Situación actual y propuestas de mejora / Udal gizarte zerbitzuen egoera Euskal Autonomia Erkidegoan. Egungo egoera eta hobetzeko proposamenak, serie Informes Extraordinarios de la Institución del Ararteko al Parlamento Vasco, Vitoria-Gasteiz, Ararteko [<http:// biblioteca.ararteko.net/Record/20987>].

- (2010): La situación de los servicios sociales de base en la Comunidad Autónoma del País Vasco / Euskal Autonomia Erkidegoko oinarrizko gizarte zerbitzuen egoera, serie Informes Extraordinarios de la Institución del Ararteko al Parlamento Vasco, Vitoria-Gasteiz, Ararteko [khttp://www.ararteko.net/RecursosWeb/ DOCUMENTOS/1/1_1941_3.pdf>].

VILÀ, A. (2009): Tendencias de la nueva legislación de los servicios sociales, Madrid, EAPN España [rhttp://www.tercersector.cat/sites/www. tercersector.cat/files/eapn_legislacio_serveis_ socials.pdf $\rangle]$.

ZUBIRI, I. et al. (2009): “El impacto económico del gasto en política social de la Diputación Foral de Gipuzkoa”, en ETXANIZ, M. et al., Ponencias del proceso de reflexión / Hausnarketa prozesuaren txostenak. Donostia-San Sebastián, Diputación Foral de Gipuzkoa, págs. 351-452 [<http://www. siis.net/documentos/ficha/180760.pdf〉]. 